\title{
SUBTASK 1.8 - INVESTIGATION OF IMPROVED CONDUCTIVITY AND PROPPANT APPLICATIONS IN THE BAKKEN FORMATION
}

Final Report

(for the period of May 1, 2011, through July 31, 2012)

Prepared for:

AAD Document Control

National Energy Technology Laboratory

U.S. Department of Energy

PO Box 10940, MS 921-107

Pittsburgh, PA 15236-0940

Cooperative Agreement: DE-FC26-08NT43291

Technical Monitor: John Terneus

Prepared by:

Bethany A. Kurz Darren D. Schmidt

Steven A. Smith Christopher J. Beddoe Corey D. Lindeman Blaise A.F. Mibeck

Energy \& Environmental Research Center University of North Dakota 15 North 23rd Street, Stop 9018 Grand Forks, ND 58202-9018 


\section{EERC DISCLAIMER}

LEGAL NOTICE This research report was prepared by the Energy \& Environmental Research Center (EERC), an agency of the University of North Dakota, as an account of work sponsored by the U.S. Department of Energy National Energy Technology Laboratory. Because of the research nature of the work performed, neither the EERC nor any of its employees makes any warranty, express or implied, or assumes any legal liability or responsibility for the accuracy, completeness, or usefulness of any information, apparatus, product, or process disclosed or represents that its use would not infringe privately owned rights. Reference herein to any specific commercial product, process, or service by trade name, trademark, manufacturer, or otherwise does not necessarily constitute or imply its endorsement or recommendation by the EERC.

\section{DISCLAIMER}

This report was prepared as an account of work sponsored by an agency of the United States Government. Neither the United States Government, nor any agency thereof, nor any of their employees, makes any warranty, express or implied, or assumes any legal liability or responsibility for the accuracy, completeness, or usefulness of any information, apparatus, product, or process disclosed, or represents that its use would not infringe privately owned rights. Reference herein to any specific commercial product, process, or service by trade name, trademark, manufacturer, or otherwise does not necessarily constitute or imply its endorsement, recommendation, or favoring by the United States Government or any agency thereof. The views and opinions of authors expressed herein do not necessarily state or reflect those of the United States Government or any agency thereof.

\section{ACKNOWLEDGMENT}

This material is based upon work supported by the U.S. Department of Energy National Energy Technology Laboratory under Award Number DE-FC26-08NT43291. The EERC would like to sincerely thank Mr. Robert Duenckel of CARBO Ceramics and Mr. Mike Vincent of Insight Consulting for the input that they provided on this report.

The EERC team would like to acknowledge Darren Schmidt for his efforts on behalf of this report. As of the publication date of this report, Darren Schmidt, was the original principal investigator of this project, had changed employment from the EERC to Weatherford. 


\title{
SUBTASK 1.8 - INVESTIGATION OF IMPROVED CONDUCTIVITY AND PROPPANT APPLICATIONS IN THE BAKKEN FORMATION
}

\begin{abstract}
Given the importance of hydraulic fracturing and proppant performance for development of the Bakken and Three Forks Formations within the Williston Basin, a study was conducted to evaluate the key factors that may result in conductivity loss within the reservoirs. Various proppants and reservoir rock cores were exposed to several different fracturing and formation fluids at reservoir conditions. The hardness of the rock cores and the strength of the proppants were evaluated prior to and following fluid exposure. In addition, the conductivity of various proppants, as well as formation embedment and spalling, was evaluated at reservoir temperatures and pressures using actual reservoir rock cores. The results of this work suggest that certain fluids may affect both rock and proppant strength, and therefore, fluid exposure needs to be considered in the field. In addition, conductivity decreases within the Bakken Formation appear to be a function of a variety of factors, including proppant and rock strength, as well as formation embedment and spalling. The results of this study highlight the need for advanced conductivity testing, coupled with quantification of formation embedment and spalling. Given the importance of proppant performance on conductivity loss and, ultimately, oil recovery, better understanding the effects of these various factors on proppant and rock strength in the field is vital for more efficient production within unconventional oil and gas reservoirs.

This subtask was funded through the Energy \& Environmental Research Center-U.S. Department of Energy Joint Program on Research and Development for Fossil Energy-Related Resources Cooperative Agreement No. DE-FC26-08NT43291. Nonfederal support for this project was provided by the North Dakota Industrial Commission Oil and Gas Research Council and proppant manufacturer CARBO Ceramics. The North Dakota Geological Survey also supported this project by supplying the rock core used for testing.
\end{abstract}




\section{TABLE OF CONTENTS}

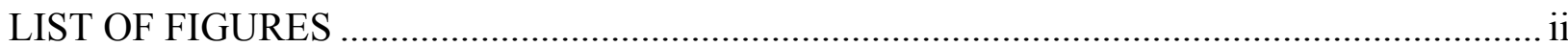

LIST OF TABLES ................................................................................................................. iv

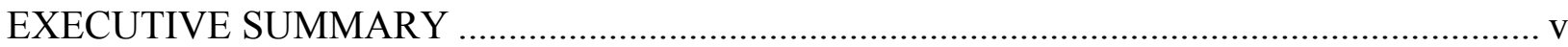

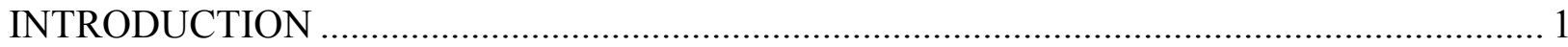

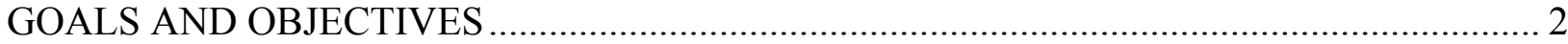

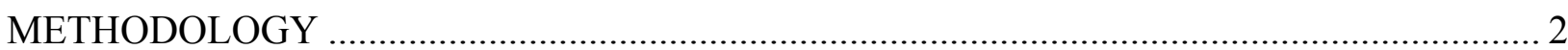

Activity 1 - Obtain Core Samples............................................................................... 3

Activity 2 - Embedment and Penetration Testing............................................................ 3

Activity 3 - Proppant Degradation Studies.................................................................... 7

Activity 4 - Conductivity Testing ............................................................................. 7

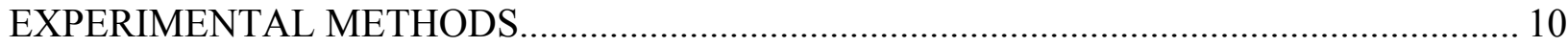

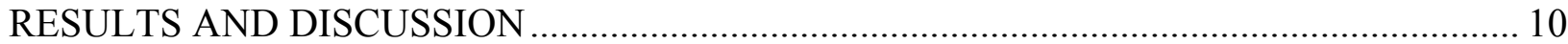

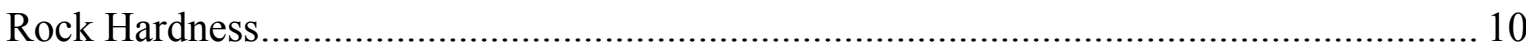

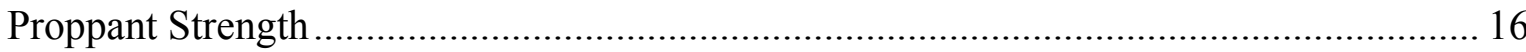

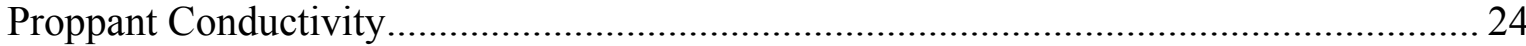

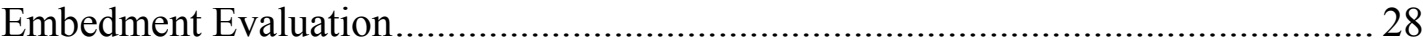

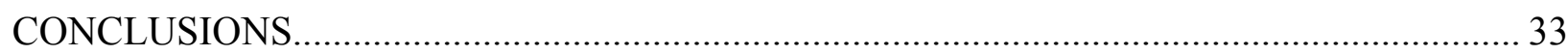

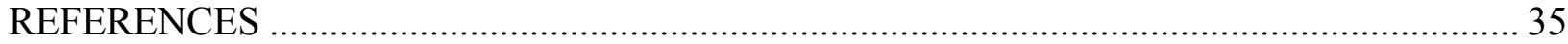

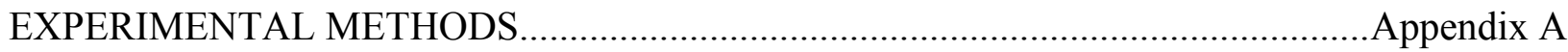

FORMATION FLUID ANALYSIS .......................................................................

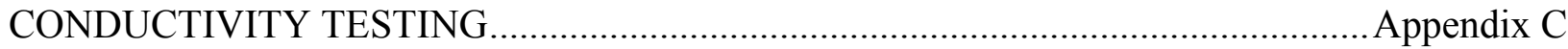

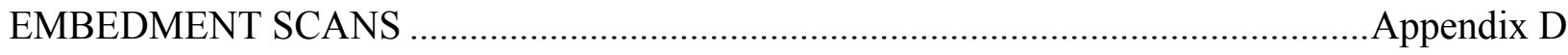




\section{LIST OF FIGURES}

1 Water jet cutting technique used to produce plugs, rectangular cubes, and slabs................ 4

2 Middle Bakken Formation, Lower Bakken shale, and Three Forks Formation samples...... 5

3 Fluids: slickwater, cross-linked gel, gelled diesel, Bakken crude, and

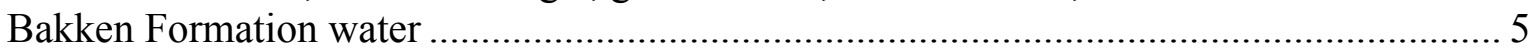

$4 \quad$ Brinell hardness test equipment and prepared sample specimen ...................................... 6

$5 \quad 20 / 40$ sand, resin-coated sand (RCS), and ceramic proppants prepared in vials with fluids prior to exposure at elevated temperature and pressure …………………………………. 7

$6 \quad$ Forney compression machine with a digital displacement indicator and load cell, which measures stress applied to the testing medium, and stainless steel consolidation ring apparatus utilized for proppant crush testing ........................................ 8

$7 \quad$ Disassembled Cooke conductivity cell based on API RP-61 ............................................. 9

$8 \quad$ Hoek cell apparatus for conductivity testing at reservoir conditions .................................... 9

9 Testing apparatus schematic and sample description for conductivity testing method ...... 10

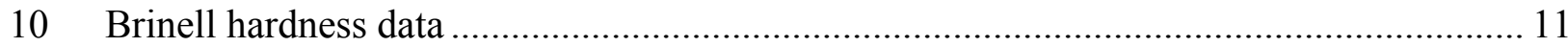

11 Pyrite vein and scattered pyrite throughout a Lower Bakken shale sample........................ 12

12 Brinell hardness for dry and saturated Middle Bakken Formation samples ....................... 13

13 Brinell hardness for dry and saturated Lower Bakken shale samples ................................. 13

14 Brinell hardness for dry and saturated Three Forks Formation samples............................ 14

15 Brinell hardness for Middle Bakken Formation samples relative to fluids.......................... 15

16 Brinell hardness for Lower Bakken shale samples relative to fluids ................................. 15

17 Brinell hardness for Three Forks Formation samples relative to fluids ............................ 16

18 Crush data at $6000 \mathrm{psi}$ and $2 \mathrm{lb} / \mathrm{ft}^{2}$ for sand, lightweight ceramic, and RCS proppant ....... 18

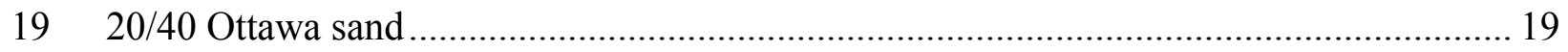

Continued... 


\section{LIST OF FIGURES (continued)}

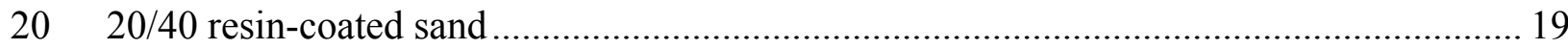

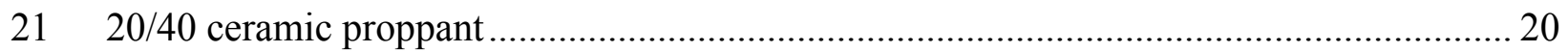

22 Stress-strain relationship of sand, RCS, and ceramic proppants ................................... 20

23 Stress-strain relationship for elastic and brittle materials...................................... 21

$24 \quad 20 / 40$ sand reacted proppant compared to unreacted proppant ...................................... 22

$2520 / 40$ RCS reacted proppant compared to unreacted proppant ................................... 22

$2620 / 40$ ceramic reacted proppant compared to unreacted proppant.................................. 23

27 Comparison of proppants reacted with Bakken Formation water relative to proppants that were not reacted with fluids.......................................................... 24

28 Crush results for various proppants exposed to Bakken Formation brine, Bakken Formation crude oil, gelled diesel, cross-linked gel, and slickwater ............................... 25

29 Graphical results of the conductivity tests using ISO Method 13503-5 ....................... 27

30 Cross sections taken from the top slab of the Lower Bakken rock that was run with Ottawa sand proppant. ........................................................................................ 29

31 Cross sections taken from the top slab of the Lower Bakken rock that was run with RCS proppant

32 Optical profiler image of the top Lower Bakken slab run with ECONOPROP

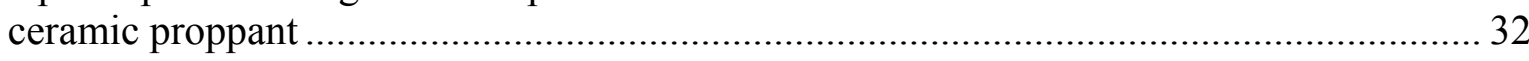

33 Cross sections taken from the top slab of the Lower Bakken rock run with ECONOPROP ceramic proppant 33

34 Optical profiler image of the bottom Lower Bakken slab run with ECONOPROP ceramic proppant

35 Cross sections taken from the bottom slab of the Lower Bakken rock run with ECONOPROP ceramic proppant 


\section{LIST OF TABLES}

1 CARBO Ceramics Test Conditions Used to Measure the Conductivity of the Three Proppants Within the Middle Bakken, Lower Bakken, and Three Forks

Rock Slabs

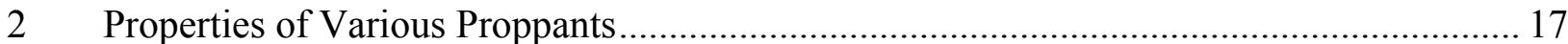

3 Results of the Conductivity Tests Using ISO Method 13503-5 ................................... 26

4 Decrease in Fracture Width at the Completion of the Conductivity Testing .................... 27

5 Total Loss in Fracture Width During Conductivity Testing ......................................... 32 


\section{SUBTASK 1.8 - INVESTIGATION OF IMPROVED CONDUCTIVITY AND PROPPANT APPLICATIONS IN THE BAKKEN FORMATION}

\section{EXECUTIVE SUMMARY}

The Bakken Formation in North Dakota is a significant portion of the largest contiguous oil reserve ever discovered in the lower 48 states. The U.S. Geological Survey's original study of the Bakken Formation found 4.3 billion barrels of recoverable oil in the Montana and North Dakota portion of the Williston Basin. According to federal testimony provided by the director of the North Dakota Department of Mineral Resources, "Hydraulic fracturing is a critical component of developing the Bakken Formation, indeed every shale play throughout the U.S. and Canada. Without hydraulic fracturing, under regulation of the states, this resource could not be produced." Hydraulic fracturing is the process of improving the ability of oil to flow through a rock formation by creating fractures. The process involves pumping into the fractures a mixture of water and additives that include various sizes of sand or ceramic particles called proppants that are designed to "prop" the fractures open, creating greater conductivity of fluids to the wellbore. However, within the Bakken Formation, field data suggest that operators are unable to sustain propped fractures spatially or temporally (Taylor, 2010, SPE Workshop August 5, 2010; Vincent, 2011, SPE 146376), resulting in decreased oil production. This research sought an improved understanding of proppant performance and the factors that contribute to hydraulic fracture conductivity loss in the Bakken Formation. As such, the key goals of this research included the evaluation of formation integrity relative to exposure to various fracturing and reservoir fluids and the evaluation of proppant performance following exposure to fracturing and formation fluids at reservoir conditions.

Laboratory tests were conducted to evaluate the sensitivity of Bakken and Three Forks Formation cores to various fluids; evaluate the strength of Ottawa sand, an unspecified premium precured resin-coated sand (RCS), and ECONOPROP ${ }^{\circledR}$ lightweight ceramic proppant to various fluids; and measure the relative laboratory conductivity performance of propped fractures using actual rock core. Fluids used in experiments to examine potential strength degradation for both rock and proppant included the following: slickwater - freshwater + polyacrylamide friction reducer; alkali borate cross-linked water-based gel; gelled diesel; Bakken Formation crude; and Bakken Formation brine.

The fluid exposure tests were conducted by immersing the rock and proppant samples in each of the above fluids within $250-\mathrm{mL}$ glass sample containers. The containers were inserted into closed reactors and maintained at $250^{\circ} \mathrm{F}$ and 3000 psi for 30 days. Following exposure, tests were completed to examine rock and proppant strength relative to fluid exposure. The exposure studies helped to isolate circumstances that may contribute to a decrease in material strength over time.

Brinell hardness testing of formation core samples after exposure to fluids revealed that slickwater consistently decreased the hardness of the formation face for Middle Bakken Formation, Lower Bakken shale, and Three Forks Formation samples. The Middle Bakken samples appeared more susceptible to strength loss when exposed to fluids than the other formation samples did. Rocks exposed to gelled diesel experienced very little change in rock hardness.

Proppants exposed to Bakken Formation water (brine) consistently experienced the greatest increase in strain relative to proppants that were not exposed. The strength of RCS appeared to be detrimentally affected by all fluids and/or the high temperature and pressure conditions of the reactor as compared to sand and ceramic. Fluids that had the greatest effect on RCS included cross- 
linked gel and Bakken oil and brine. Crush test results were consistent with elastic strength results of the various proppants and fluids, noting that resin-coated proppants do not normally produce a large quantity of crushed particles.

The results of this work demonstrated that the ceramic proppant was relatively unreactive and exhibited superior strength characteristics compared to the other proppant types following fluid exposures. RCS proppants are normally chosen to help prevent proppant flowback. However, these experiments suggest that fluid reactions and/or elevated temperatures and pressures with resin change the stress-strain relationship for RCS and that fluid considerations are important relative to the chosen resin.

The results of the conductivity testing demonstrated that at effective stress ranges from 6500 to $8000 \mathrm{psi}$, the ceramic proppant exhibited much higher conductivity than Ottawa sand (as much as 5 times greater) and moderately higher conductivity than the RCS (as much as 2.3 times greater). However, this was using a solution of $2 \mathrm{wt} \% \mathrm{KCl}$. Given that the fluid exposure tests suggest that the strength of the RCS may be affected by reservoir conditions and fluid exposure, and that slickwater and cross-linked gels have the potential to affect rock strength, advanced conductivity testing using the various fluids would be more representative of actual reservoir conditions.

Postmortem analysis of the rock slabs used for the conductivity testing enabled an evaluation of the mechanisms that may contribute to reduced conductivity, such as embedment or proppant crush. A Nanovea optical profiler was used to conduct a qualitative evaluation of embedment within the rock slabs. The results showed that between the different rock types, the Lower Bakken displayed the highest degree of embedment and spalling, followed by the Middle Bakken. The Three Forks slabs showed significantly less embedment than the Bakken rocks. Few patterns were apparent between proppant types, except that within the Lower and Middle Bakken, there appears to be a greater degree of ceramic proppant embedment than with the other two proppant types. This is likely because of the higher strength of the ceramic proppant. Within the Bakken rock samples, the top slab of each pair showed deeper and wider embedment craters than did the bottom slab. This likely indicates an even distribution of proppants within the simulated fracture.

Overall, the results of this study indicated that fluid exposure may affect both rock and proppant strength and should be considered in the field. In addition, conductivity decreases within the Lower and Middle Bakken appear to be a function of a variety of factors, including proppant and rock strength, as well as formation embedment and spalling. Formation embedment and spalling appear to be less significant within the Three Forks Formation. Ultimately, the results of this study highlight the need for conductivity testing using actual formation and/or fracturing fluids, coupled with quantification of formation embedment and spalling. Given the importance of proppant performance on conductivity loss and, ultimately, oil recovery, better understanding the effects of these various factors on proppant and rock strength in the field is vital for more efficient production within unconventional oil and gas reservoirs.

This subtask was funded through the Energy \& Environmental Research Center-U.S. Department of Energy Joint Program on Research and Development for Fossil Energy-Related Resources Cooperative Agreement No. DE-FC26-08NT43291. Nonfederal support for this project was provided by the North Dakota Industrial Commission Oil and Gas Research Council and proppant manufacturer CARBO Ceramics. The North Dakota Geological Survey also supported this project by supplying rock core used for testing. 


\section{SUBTASK 1.8 - INVESTIGATION OF IMPROVED CONDUCTIVITY AND PROPPANT APPLICATIONS IN THE BAKKEN FORMATION}

\section{INTRODUCTION}

The Bakken Formation in North Dakota is a significant portion of the largest contiguous oil reserve ever discovered in the lower 48 states (Donovan, 2010). The U.S. Geological Survey's (USGS's) original study of the Bakken Formation found 4.3 billion barrels of recoverable oil in the Montana and North Dakota portions of the Williston Basin. According to federal testimony provided by the director of the North Dakota Department of Mineral Resources (Helms, 2009), "Hydraulic fracturing is a critical component of developing the Bakken Formation, indeed every shale play throughout the U.S. and Canada. Without hydraulic fracturing under regulation of the states, this resource could not be produced." Hydraulic fracturing is the process of improving the ability of oil to flow through a rock formation by creating fractures. The process involves pumping a mixture of water and additives that include various sizes of sand or ceramic particles called proppants that are designed to "prop" the fractures open, creating greater conductivity of fluids to the wellbore. This research seeks an improved understanding of proppant performance in the Bakken Formation. Although it has been documented that propped fractures can be created to breach the lower Bakken shale, field evidence to date suggests that operators are typically unable to sustain a hydraulic connection through this barrier (Taylor, 2010). At the current time, this challenge requires operators to drill redundant wells completed in each of the Middle Bakken and Three Forks Reservoirs. Similarly, Bakken operators have fractured into offset wells that are spaced more than 2000 feet away (Vincent, 2011), demonstrating that very long propped fractures can be created. However, these fractures also lose hydraulic continuity over time. Although many factors contribute to conductivity loss, this research is targeted to identify what parameters are responsible for the collapse of propped fractures and the resulting loss of conductivity, namely:

- The evaluation of formation integrity relative to exposure to various fracturing fluids and native fluids.

- The evaluation of proppant performance under reservoir conditions and exposure to fracturing and formation fluids.

There is a need to examine proppant performance in the laboratory to ascertain the relative effects on conductivity of fluids in the reservoir. The choice between ceramic, sand, and blends of the two has an influence on economic performance. Prices of ceramic proppant and fracture sand in 2009 ranged from $\$ 0.40$ to $\$ 0.50 / \mathrm{lb}$ and $\$ 0.08$ to $\$ 0.10 / 1 \mathrm{~b}$, respectively (Roberts, 2009). Treatments in the Bakken Formation are using upward of 2 million $\mathrm{lb}$ of proppant (Sorensen and others, 2010) in 10,000-ft horizontal completions. Proppant quantity per well is expected to increase as some operators are having success with increasing the number of fracture stages from 10 to near 40 in a 10,000-ft lateral (Rankin and others, 2010). The cost differential between choosing ceramic over sand can be greater than $\$ 1$ million a well. In addition, competition for proppant can limit the ability to obtain higher-performing ceramics. This has led to strategies in the Bakken Formation that include using large amounts of fracture sand followed by ceramic 
proppant (Continental Resources, 2009; Newfield Exploration, 2010), which enables operators to obtain the strength and longevity benefits of ceramics near the wellbore while supporting the majority of the fracture farthest away from the wellbore with low-cost proppant and, hopefully, limiting flow back while maintaining conductivity. This research is intended to improve the understanding of proppants and formation rocks relative to fluids which may reveal alternative strategies for proppant applications.

\section{GOALS AND OBJECTIVES}

The goal of the project is to improve the lateral and vertical drainage of hydrocarbons from the Three Forks and Bakken Formations by identifying the factors that lead to the collapse of propped fractures. Field evidence suggests that fractures created to breach the lower Bakken shale from Middle Bakken and Three Forks horizontal completions typically are unable to sustain a hydraulic connection through this barrier. Even though many factors contribute to the collapse, the objective of this project focuses on laboratory testing to ascertain potential collapse of the formation face or collapse of proppant. Research is targeted to determine if conductivity can be remedied with a more appropriate selection of fluid types, proppant types, or proppant concentrations/fracture widths.

\section{METHODOLOGY}

Laboratory methods were devised to evaluate the sensitivity of Bakken and Three Forks core to various fluids, evaluate the strength of Ottawa sand, premium precured resin-coated sand (RCS), and light-weight ceramic proppants to various fluids, and measure the relative laboratory conductivity performance of propped fractures using actual core. Fluids used in experiments to examine potential strength degradation for both rock and proppant included the following:

- Slickwater - freshwater + polyacrylamide friction reducer

- Alkali borate cross-linked water-based gels

- Gelled diesel

- Bakken Formation crude

- Bakken Formation brine

The fluids above were selected based on the most common fluids expected to be encountered in the Bakken Formation. The most popular hydraulic fracture treatments in the Bakken Formation include water-based fluids. Treatments may be as basic as pumping a mix of water and sand, normally termed slickwater; a polyacrylamide-based friction reducer is commonly added in these types of treatments. More advanced treatments use chemicals to gel the water to increase viscosity and greatly improve the proppant transport and placement capability of the fluid. A common viscosifier is guar gum and is used to produce a "linear gel." The chemical properties of guar gum allow for the material to be cross-linked with alkali borate. Cross-linking a linear gel further increases the viscosity of the gel to a mucouslike substance which has superior proppant transport properties. 
For a period of time, it was common for operators to consider the use of hydrocarbonbased fracturing fluids for formations that may be sensitive to freshwater fluids. Freshwater, for example, can cause clays within the formation to swell, or minerals to precipitate, and reduce the ability to mobilize oil to the wellbore. Now most operators use potassium chloride or clay stabilizers in water-sensitive formations (Mike Vincent, personal communication, July 2012). Although freshwater fluids are used extensively in the Bakken Formation, operators have experimented with gelled-diesel fluids, but generally found inferior productivity (Mike Vincent, personal communication, July 2012).

The completion of a hydraulic fracture treatment concludes with flowing the fracture fluid back to the surface. During this time period, fluids used to stimulate the well return to the surface and are followed by formation fluids, which include oil, gas, and water. It is at this point that proppant is exposed to formation fluids, which include crude oil and formation water. Hydrogen sulfide is generally not present in the Bakken Formation, and carbon dioxide concentrations are typically low. Water associated with the formation, however, has a very high salinity of over $250,000 \mathrm{mg} / \mathrm{L}$ of sodium chloride which has potential for chemical interaction.

Experimental methodology included the exposure of formation core samples and proppant to the fluids listed above to ascertain the potential for loss of material strength. Brinell hardness testing was completed in Activity 2 and was used to index rock strength and measure hardness before and after exposure to fluids. Proppant strength relative to fluid exposure was evaluated in Activity 3, and conductivity tests using actual core were conducted in Activity 4. Discussion of these work activities follows.

\section{Activity 1 - Obtain Core Samples}

Support from the North Dakota Geological Survey (NDGS) was provided to obtain core for the project. Middle Bakken Formation, Lower Bakken shale, and Three Forks Formation samples were selected from North Dakota Industrial Commission (NDIC) Well \#16771 (NDIC \#16771) in Mountrail County. Samples obtained from the core included 1-in. $\times 2$-in. $\times 1$-in. cubes, 1.185-in.-diameter $\times$ 4-in.-long plugs, and 7-in. $\times 1.5$-in. $\times 0.375$-in. slabs. Figure 1 contains photos of the cutting tool and examples of plugs, cubes, and slabs. The cubes were used to examine strength measured by a Brinell hardness index test. The plugs were cut in half lengthwise and used in a modified conductivity apparatus to examine conductivity of a propped fracture between a halved formation plug mirrored with a mating steel plug. Slabs were prepared to geometrical specifications in accordance with ISO (International Organization for Standardization) Formation Samples 13503-5 "Procedures for Measuring the Long-Term Conductivity of Proppants."

\section{Activity 2 - Embedment and Penetration Testing}

Brinell hardness index testing includes the penetration of a metal ball into formation rock. This type of index testing was used to gauge the relative strength of Bakken and Three Forks samples before and after exposure to various fluids. Middle Bakken Formation, Lower Bakken shale, and Three Forks Formation samples (Figure 2) were indexed as received. Samples were 


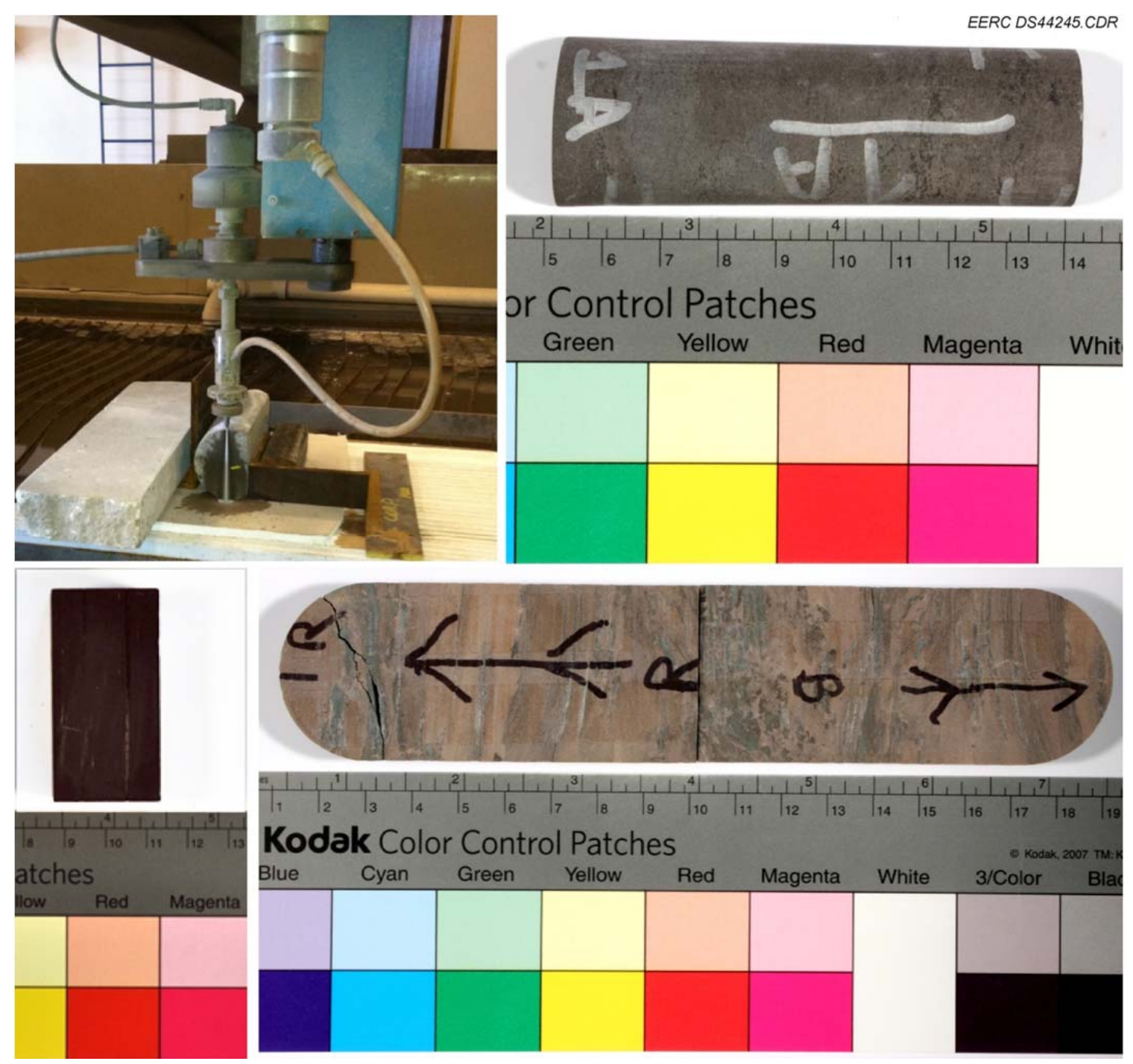

Figure 1. Water jet cutting technique (upper left) used to produce plugs (upper right, example from Middle Bakken Formation), rectangular cubes (lower left, example from Lower Bakken shale), and slabs (lower right, example from Three Forks Formation).

exposed to the fluids (Figure 3) by immersing rock samples in $250-\mathrm{mL}$ jars containing the fluid, which were inserted into reactors maintained at $250^{\circ} \mathrm{F}$ and 3000 psi for 30 days. The fluids included:

- Slickwater - mixture of polyacrylamide and freshwater.

- Cross-linked gel - guar polymer thickening agent, borate cross-linker, and freshwater.

- Gelled diesel - diesel fuel and phosphate ester.

- Bakken Formation crude - crude oil.

- Bakken Formation brine - highly concentrated saltwater. 


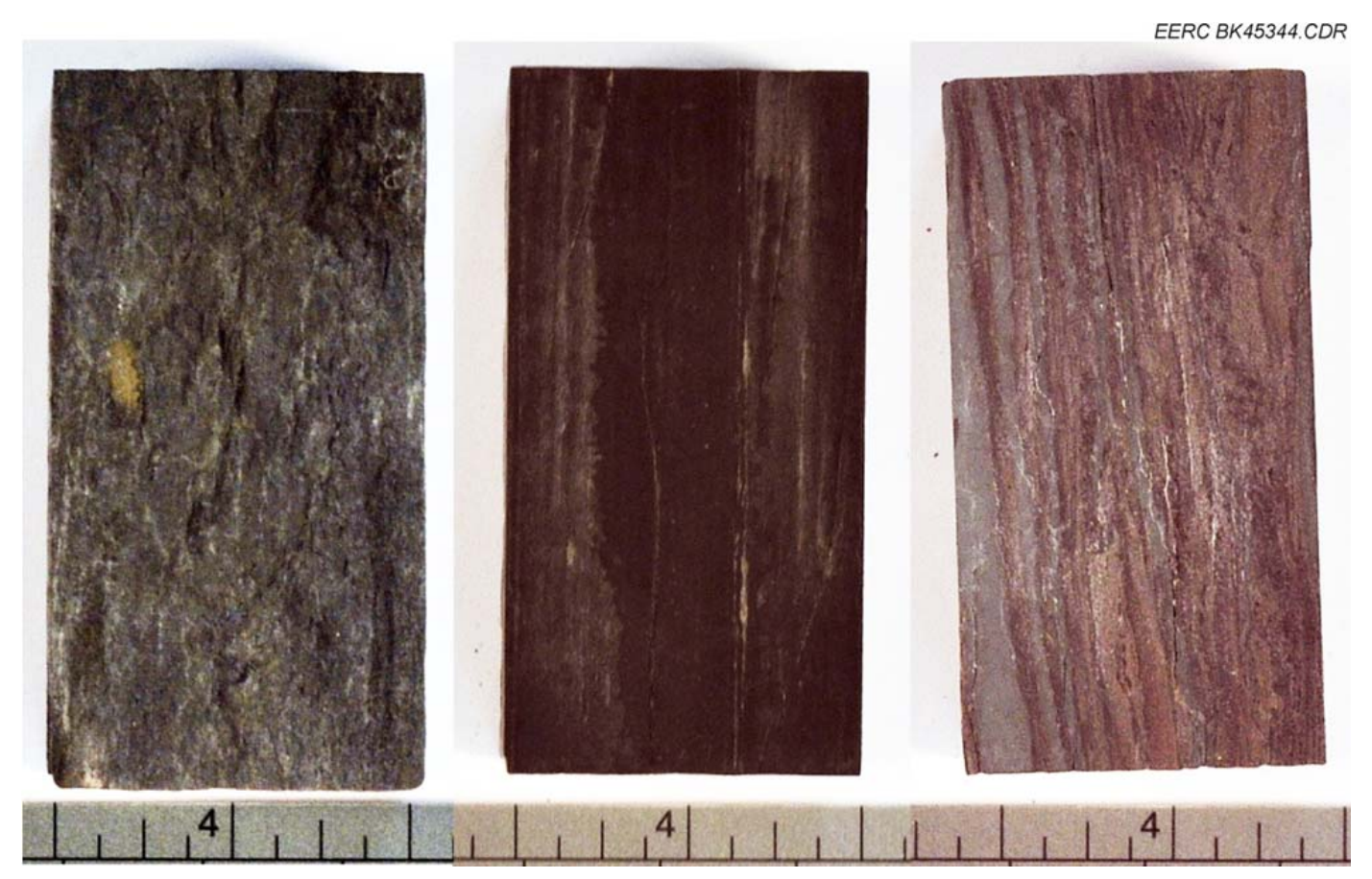

Figure 2. Middle Bakken Formation (left), Lower Bakken shale (middle), and Three Forks Formation (right) samples.

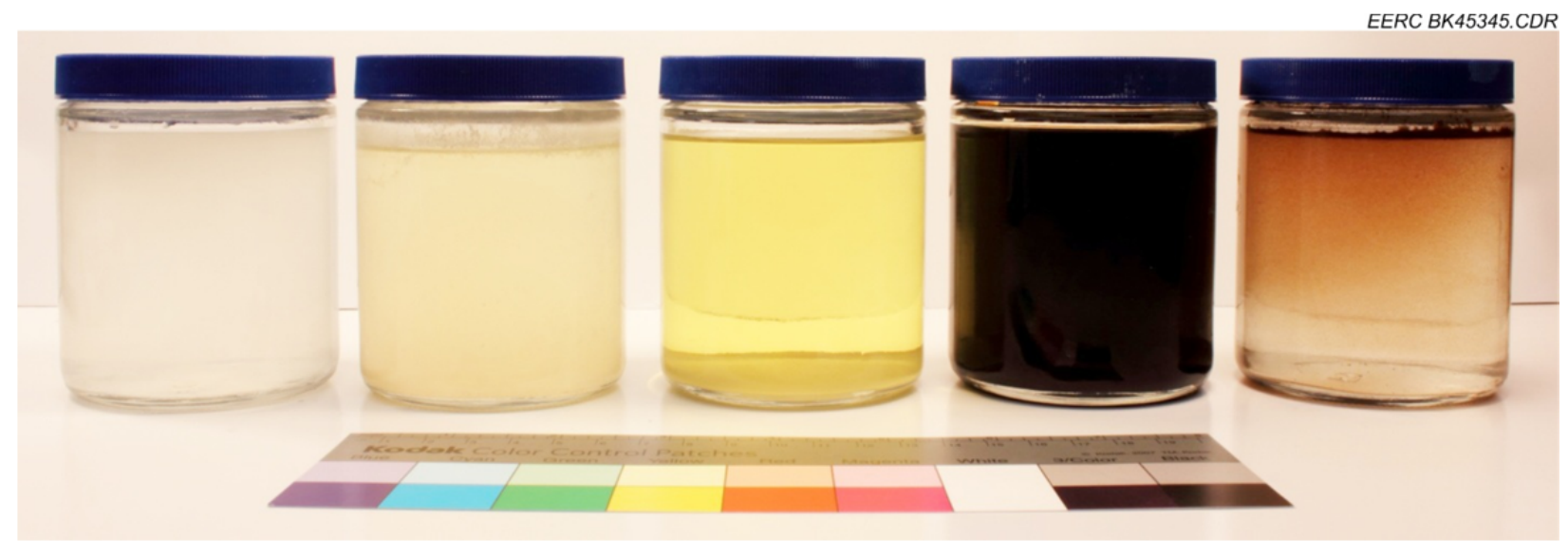

Figure 3. Fluids (from left to right): slickwater, cross-linked gel, gelled diesel, Bakken crude, and Bakken Formation water (brine). 
Index testing was conducted on each individual sample in both saturated and dry conditions to ascertain potential differences in hardness due to rock saturation. Samples that were not exposed to fluids were indexed on one side as received (dry) and subsequently saturated with water and indexed on the opposite side. Samples that were exposed to fluids were indexed in the same manner, although received wet and subsequently dried. Rock samples were encased in epoxy and steel to prevent premature fracturing during hardness testing. Figure 4 shows the test equipment and a prepared sample specimen.

The use of a handheld penetrometer to indicate rock strength from embedment and penetration was initially anticipated. Although adequate for relativistic measurement, hand operation of the penetrometer had the potential to yield inconsistencies. Therefore, other index methods were further investigated, including Brinell hardness, Rockwell hardness, microindentation, and Schmidt hammer. Primary consideration included standardization and the ability to control conditions. The Brinell hardness method was selected over other methods for the following reasons:

- Brinell hardness is commonly used by geomechanical laboratories and referenced by popular textbooks as a proxy to dynamic elastic modulus and yield strength for various rocks. Geertsma (1985) provides the following correlations:

- For dynamic Young's modulus: Edyn $=77.25 \mathrm{NBr}$ (Brinell hardness number)

- For yield strength: $\mathrm{NBr} \approx$ oyield

- Brinell hardness data are currently available for the Bakken Formation from various well files and can be compared to the laboratory results.

- $\mathrm{NBr}$ follows from the ratio of applied load $\mathrm{F}$ on a spherical indenter to the indentation depth $\mathrm{D}$, where $\mathrm{NBr}=\mathrm{F} / 2 \pi \mathrm{rD} \approx \mathrm{F} / \pi^{2}$ (Fjaer and others, 2008). Although Brinell and Rockwell hardness tests are similar, the Brinell test uses a larger-diameter sphere, which is better suited for larger-grain material such as rocks versus metals in which the hardness tests originated.
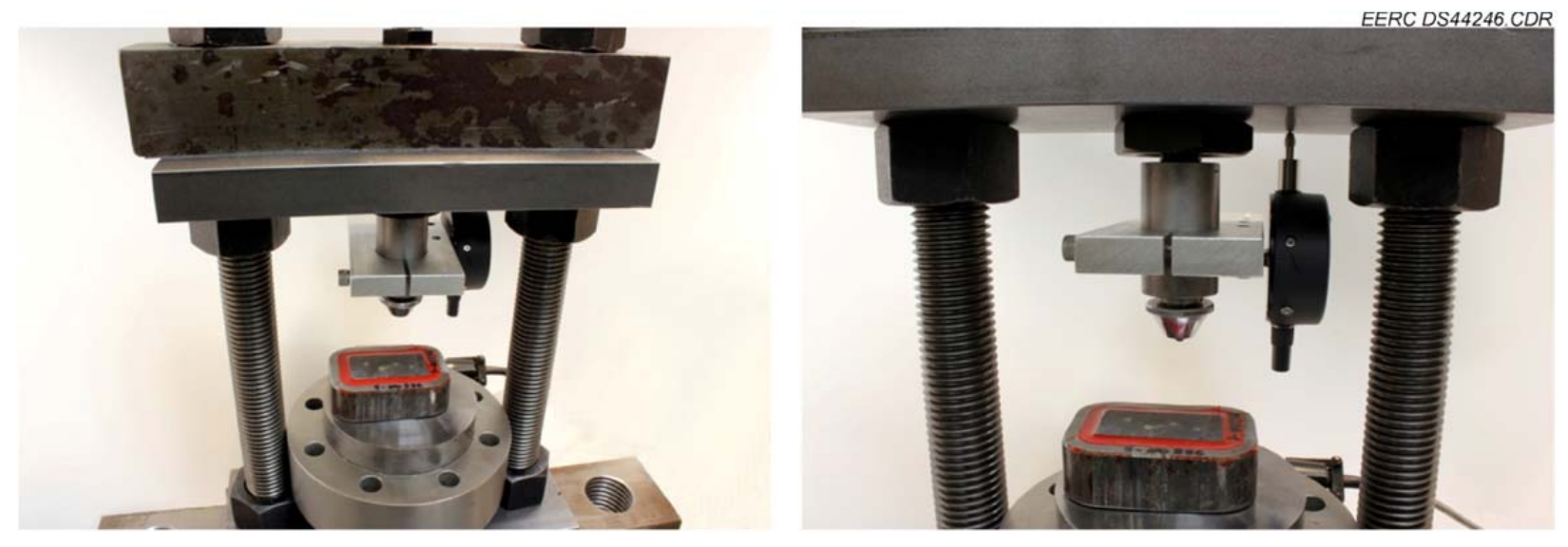

Figure 4. Brinell hardness test equipment and prepared sample specimen. 


\section{Activity 3 - Proppant Degradation Studies}

Activity 3 concentrated on the relationship between proppant pack strength and elastic parameters before and after exposure to hydraulic fracturing fluids at reservoir conditions. The fluids utilized in this activity were the same fluids used in Activity 2 (Figure 5). The three proppant types tested were a 20/40 Ottawa sand, a 20/40 premium precured RCS, and a 20/40 CARBO ECONOPROP ${ }^{\circledR}$ lightweight ceramic proppant. It should be noted that the RCS provided to the EERC was unspecified; however, it was not a CARBO product. Each proppant type was tested in an as-received state as well as after exposure to fluids for 30 days in highpressure/temperature $\left(\sim 250^{\circ} \mathrm{F}\right.$ and $\left.\sim 3000 \mathrm{psi}\right)$ reactor vessels. Proppant packs were tested by onedimensional consolidation using a Forney universal compression machine and a consolidation ring with hardened stainless steel platen (Figure 6). Measurements of stress (via load cell) and strain (by digital displacement indicator) were collected continuously throughout each test. The approach was based on previous work by Ferris (2000) in which a new method was developed to capture the elastic-plastic behavior of dilative sands.

\section{Activity 4 - Conductivity Testing}

Activity 4 included a series of flow-through fluid conductivity tests designed and conducted to gain a better understanding of how flow is affected in propped fractures under reservoir conditions with actual formation rocks. Tests included both customized and standard methods. The standard conductivity tests were conducted by CARBO Ceramics in accordance with American Petroleum Institute (API) Method API RP 61 "Recommended Practices for Evaluating Short Term Proppant Pack Conductivity" and ISO 13503-5. The API and ISO methods require the use of a conductivity cell (shown in Figure 7) that dictates core be cut in 7 -in. slabs with a thickness of $3 / 8$ in.

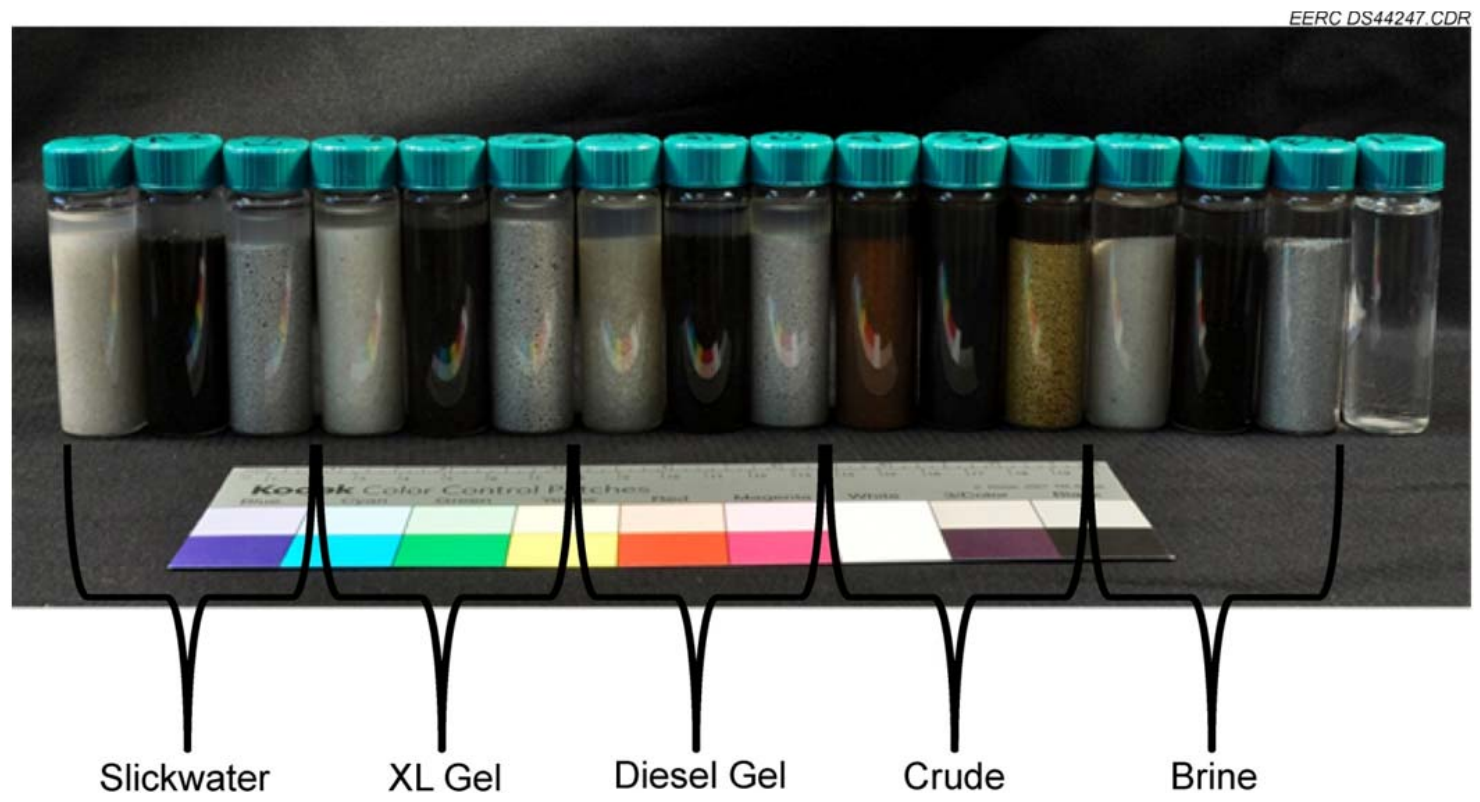

Figure 5. 20/40 sand, resin-coated sand (RCS), and ceramic proppants prepared in vials with fluids prior to exposure at elevated temperature and pressure. 

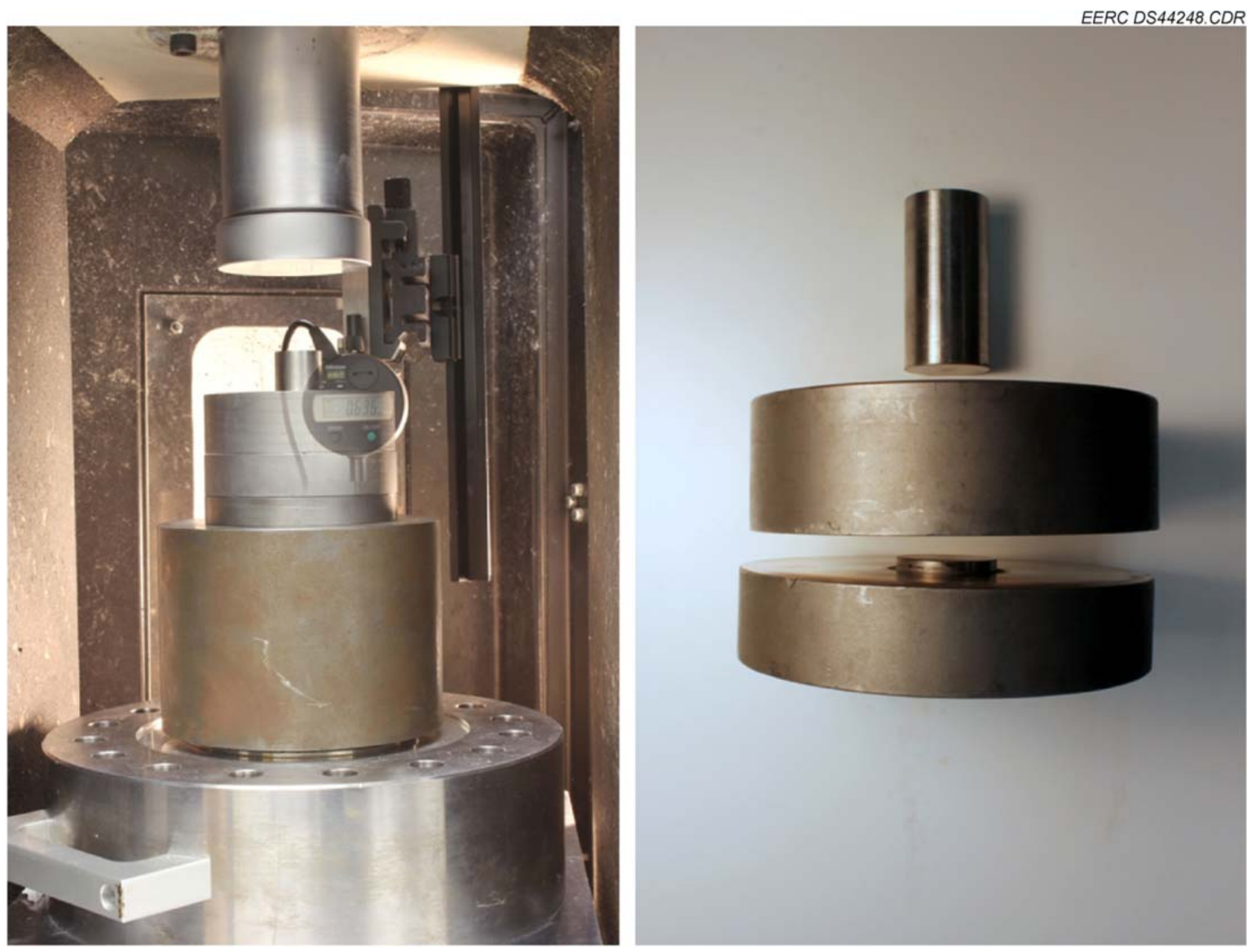

Figure 6. Forney compression machine with a digital displacement indicator and load cell (left), which measures stress applied to the testing medium, and stainless steel consolidation ring apparatus (right) utilized for proppant crush testing.

The standard conductivity tests were conducted using each of the three different rock types (Middle Bakken, Lower Bakken, and Three Forks) and each of the three proppant types (Ottawa sand, RCS, and ECONOPROP ceramic proppant). Each test was run at $6500 \mathrm{psi}$ closure pressure for 50 hours, followed by an increase to 8000 psi for 20 hours. The test conditions are summarized in Table 1. A full description of the testing can be found in Appendix C.

Given the time-consuming nature and difficulty of producing such shapes from formation cores, an alternative method was evaluated to utilize standard 1-in-diameter core plugs. The technique included placing core plug samples into a Hoek cell while flowing crude oil through a simulated fracture (Figures 8 and 9). This apparatus exposed rock samples to confining loads similar to those found in the reservoir while maintaining pore pressure and hydraulic flow across the sample. In particular, the experiment measured the pressure drop required to flow reservoir fluid through a simulated fracture over increasing loading and time. 


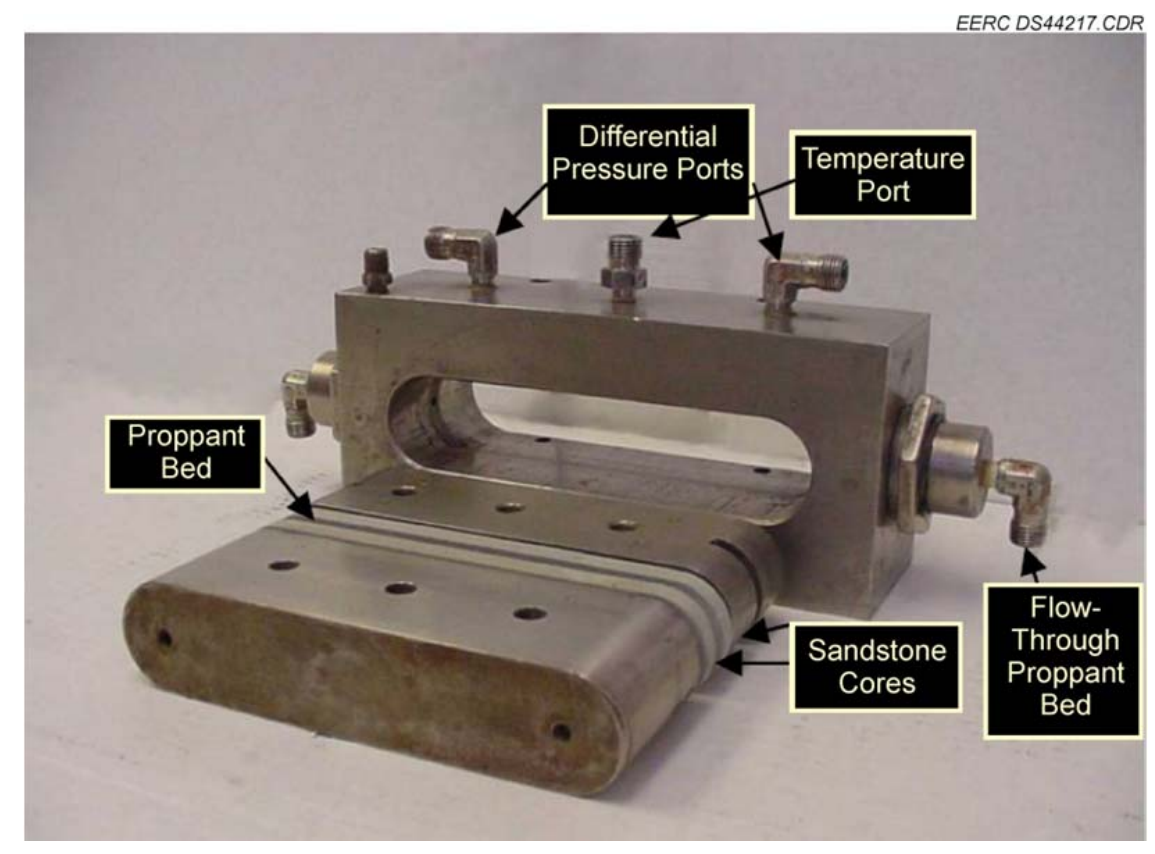

Figure 7. Disassembled Cooke conductivity cell based on API RP-61 (Palisch and others, 2007).

Table 1. CARBO Ceramics Test Conditions Used to Measure the Conductivity of the Three Proppants Within the Middle Bakken, Lower Bakken, and Three Forks Rock Slabs

\begin{tabular}{lc}
\hline Parameter & Testing Conditions \\
\hline Proppant Loading & $2 \mathrm{lb} / \mathrm{ft}^{2}$ \\
Applied Stress (net pressure) & 6500 and $8000 \mathrm{psi}$ \\
Fluid Type & $2 \% \mathrm{wt} \% \mathrm{KCl}$ \\
Temperature & $200^{\circ} \mathrm{F}$ \\
Backpressure (fluid pressure) & $500 \mathrm{psi}$ \\
Time (hours) at 6500 psi net pressure & $0,5,20,30,50$ \\
Time (hours) at 8000 psi net pressure & $0,5,20$ \\
\hline
\end{tabular}

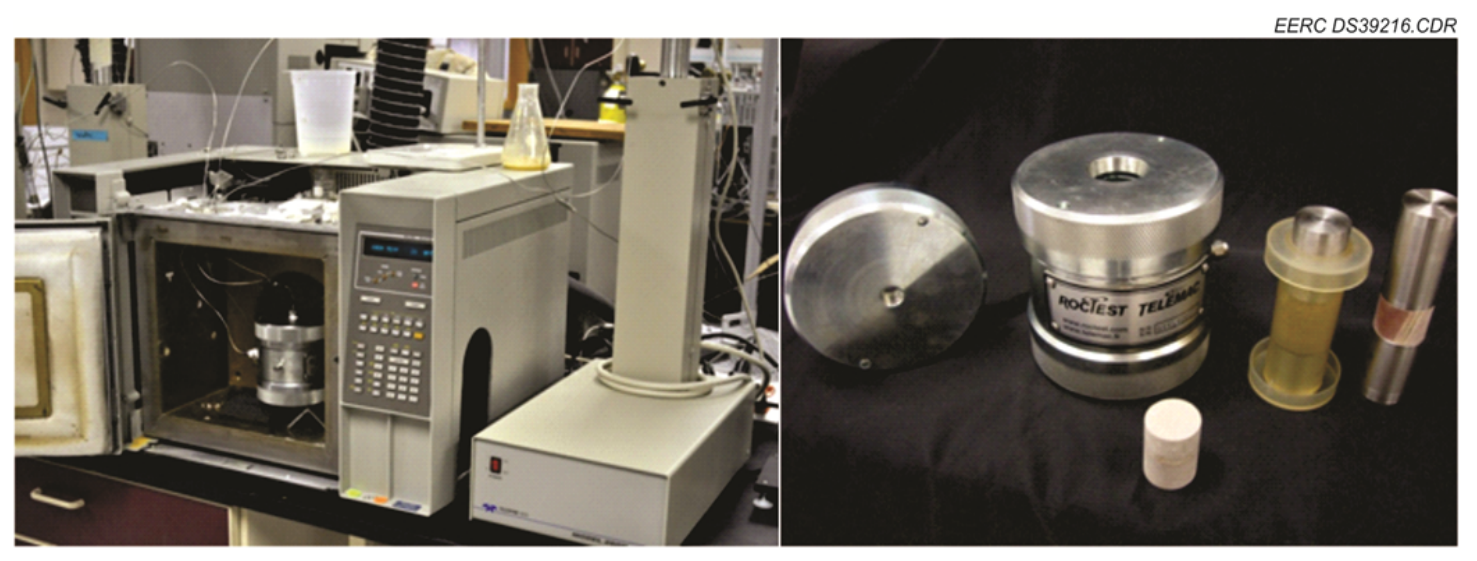

Figure 8. Hoek cell apparatus for conductivity testing at reservoir conditions. 

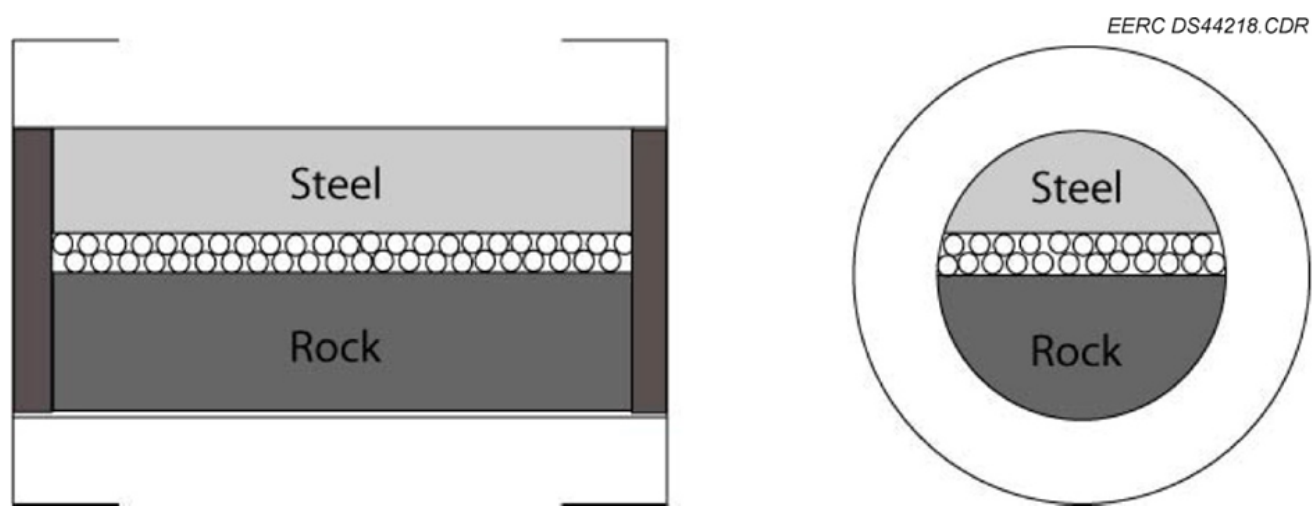

Figure 9. Testing apparatus schematic and sample description for conductivity testing method.

\section{EXPERIMENTAL METHODS}

A detailed description of the experimental methods is provided in Appendix A.

\section{RESULTS AND DISCUSSION}

\section{Rock Hardness}

Core for this project was obtained from the NDIC \#16771 located in the Manitou Field of Mountrail County. Two wells in proximity to this well had Brinell hardness data publically available from the well files:

- NDIC \#15986, Robinson Lake Field, Mountrail County, approximately 10 miles to the southeast.

- NDIC \#16083, Capa Field, Williams County, approximately 10 miles to the southwest.

Brinell hardness data are presented in Figure 10.

Brinell hardness for the Upper Bakken shale from the deeper well, NDIC \#15986, tended to be softer at the top of the formation $(<20)$ and harder approaching the Middle Bakken. Middle Bakken hardness ranged from 20 to 35. The more shallow well in Williams County provided hardness of $<20$, with Middle Bakken averaging near 20 and Three Forks ranging from 5 to 30, a significant variation. 

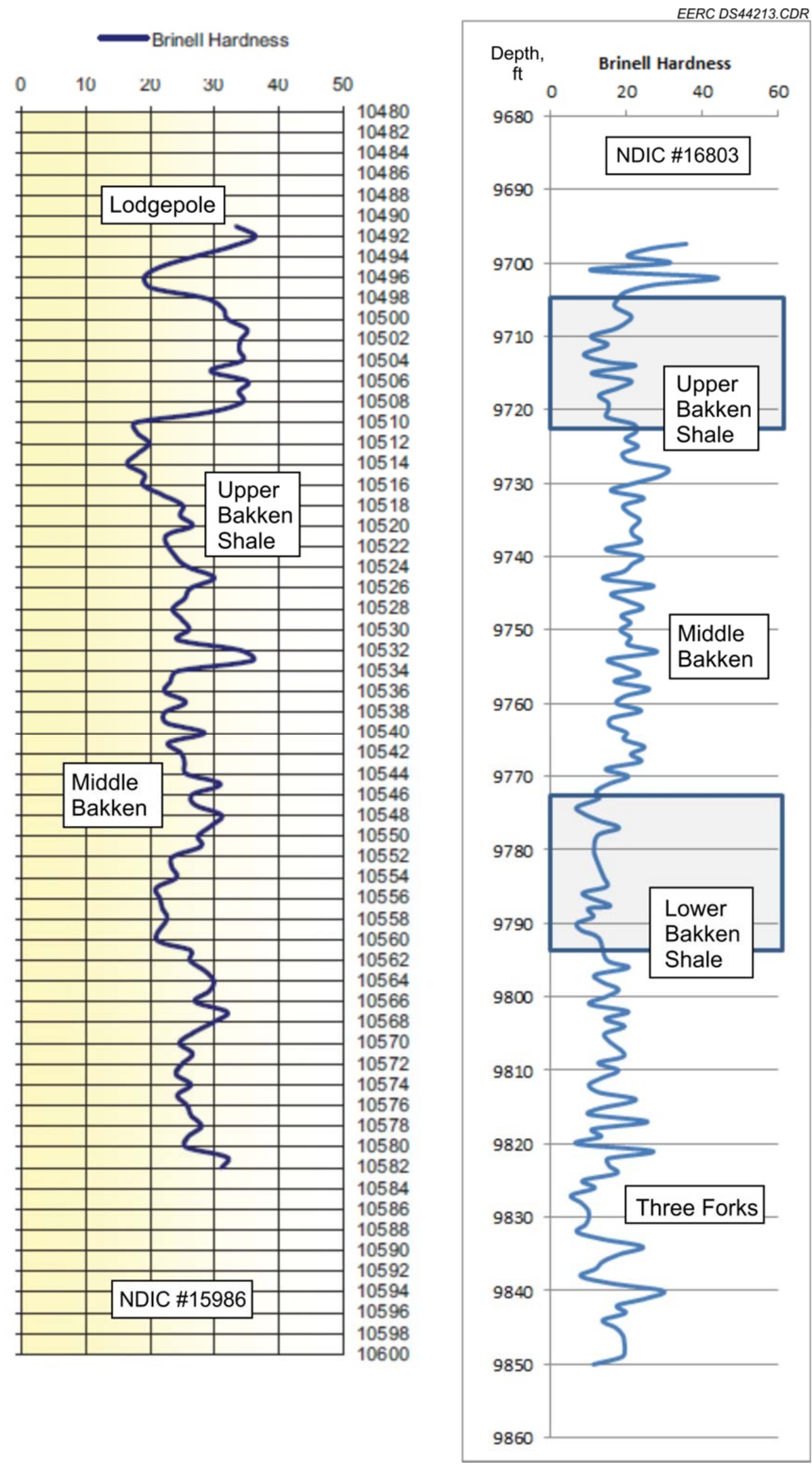

Figure 10. Brinell hardness data. 
Hardness testing for this activity included samples obtained from NDIC \#16771. The hardness results were higher in magnitude than the data provided from previous wells. However, the hardness results relative to the formation types were similar in that the Lower Bakken shale was soft, Middle Bakken samples were harder, and Three Forks samples were highly variable. Middle Bakken hardness ranged from 40 to 110, Lower Bakken 30-60, and Three Forks 40-140. The difference in magnitude between the well file data and the laboratory results is likely attribable to the constrained nature of the sample and the orientation. Penetrations were performed perpendicular to bedding planes, whereas the data from the well files were likely generated from penetrations performed parallel with the bedding planes on unconfined whole core. Bakken shale hardness results were generally half the hardness of the Middle Bakken Formation, and the Three Forks Formation hardness varied significantly. The variation was likely because of the interbedded green shales and sandstones within the Three Forks Formation.

Some samples of lower Bakken shale exhibited abnormally high hardness (80-120). The high values were a result of pyrite inclusions, shown in Figure 11. Hardness values relative to pyrite were not used in the analysis of the results.

As-received samples were tested to determine if a variation in hardness would be evident from testing conducted on a dry rock surface versus a wet rock surface. These tests were completed to determine if potential differences in hardness could be simply due to saturation of the rock versus degradation from 30-day fluid exposure. The results are provided in Figures 1214. Little difference in the average hardness was observed from dry versus saturated rock. The results were generated from eight indentations per sample on four Middle Bakken samples, four Lower Bakken samples, and three Three Forks samples.

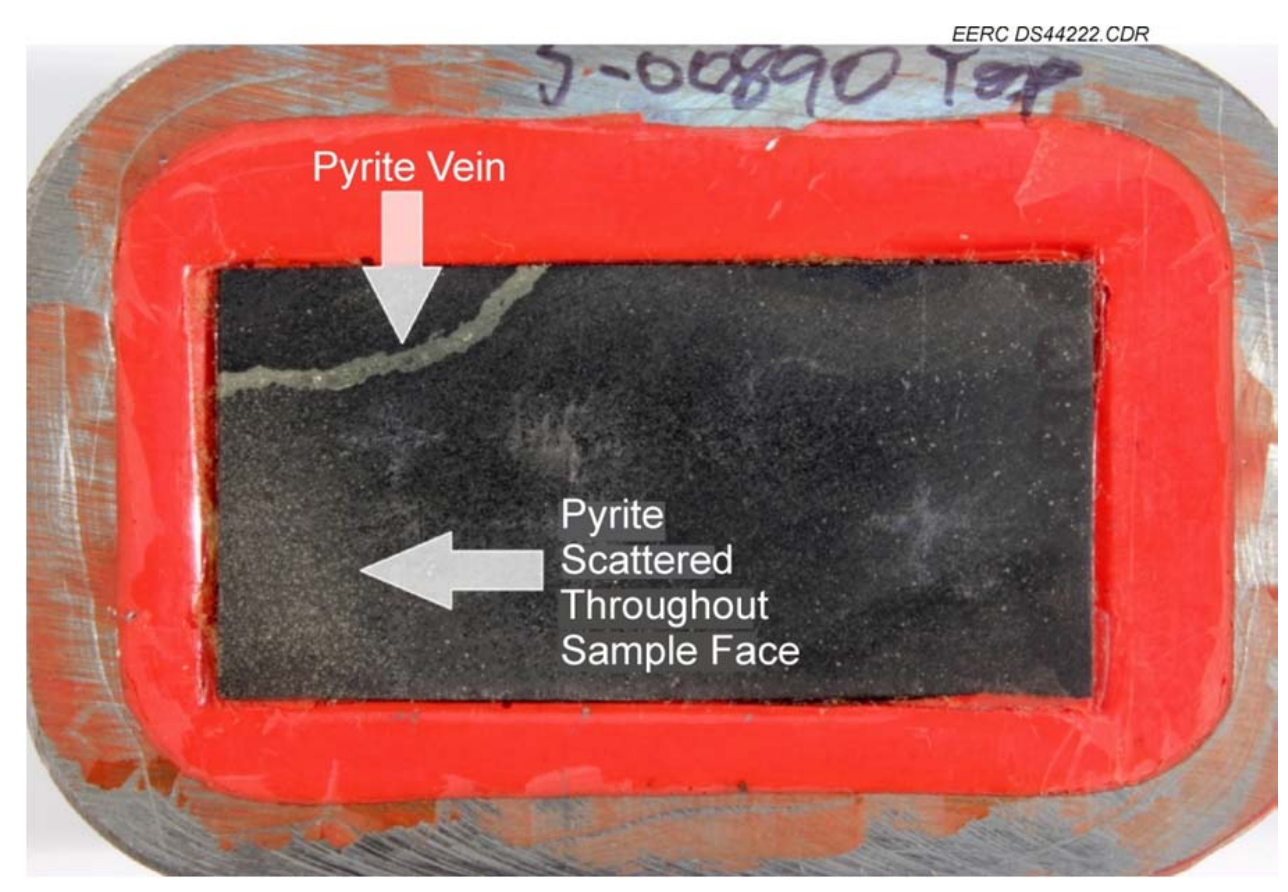

Figure 11. Pyrite vein and scattered pyrite throughout a Lower Bakken shale sample. 


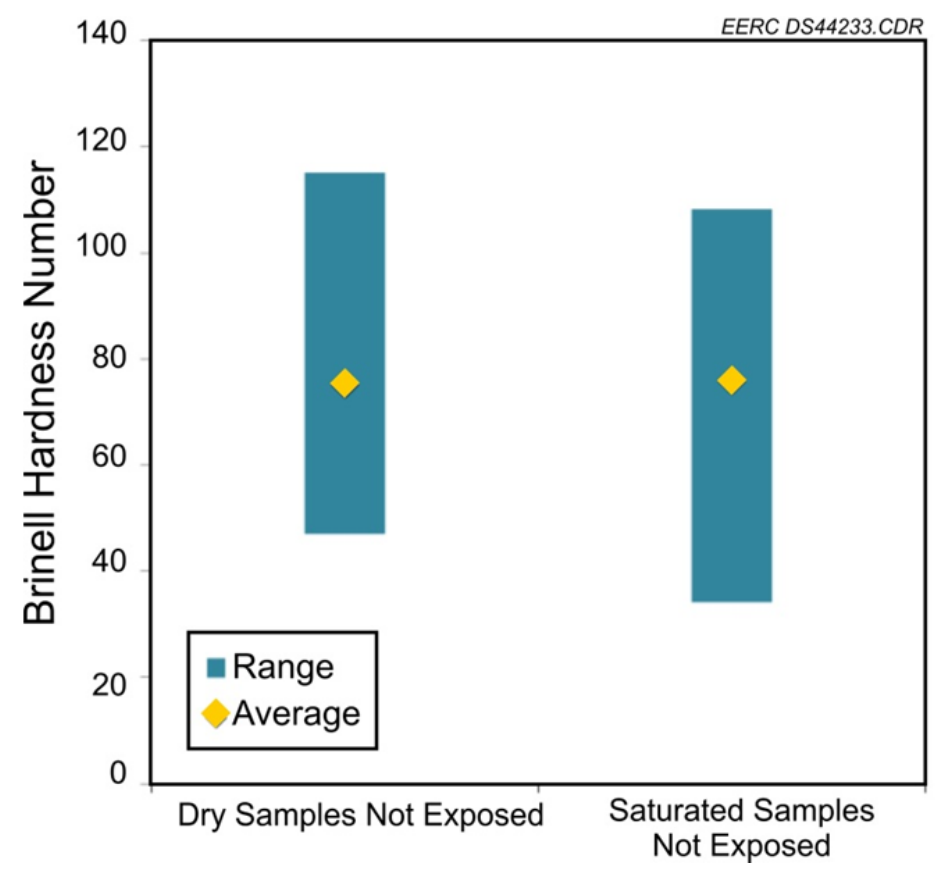

Figure 12. Brinell hardness for dry and saturated Middle Bakken Formation samples.

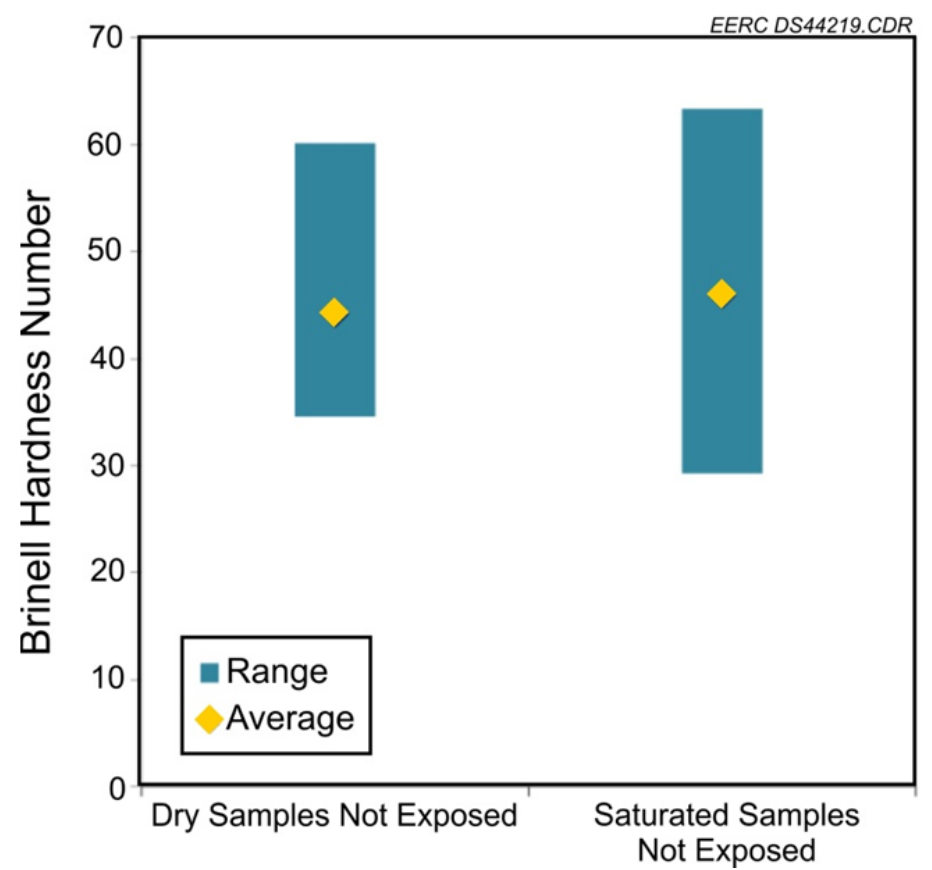

Figure 13. Brinell hardness for dry and saturated Lower Bakken shale samples. 


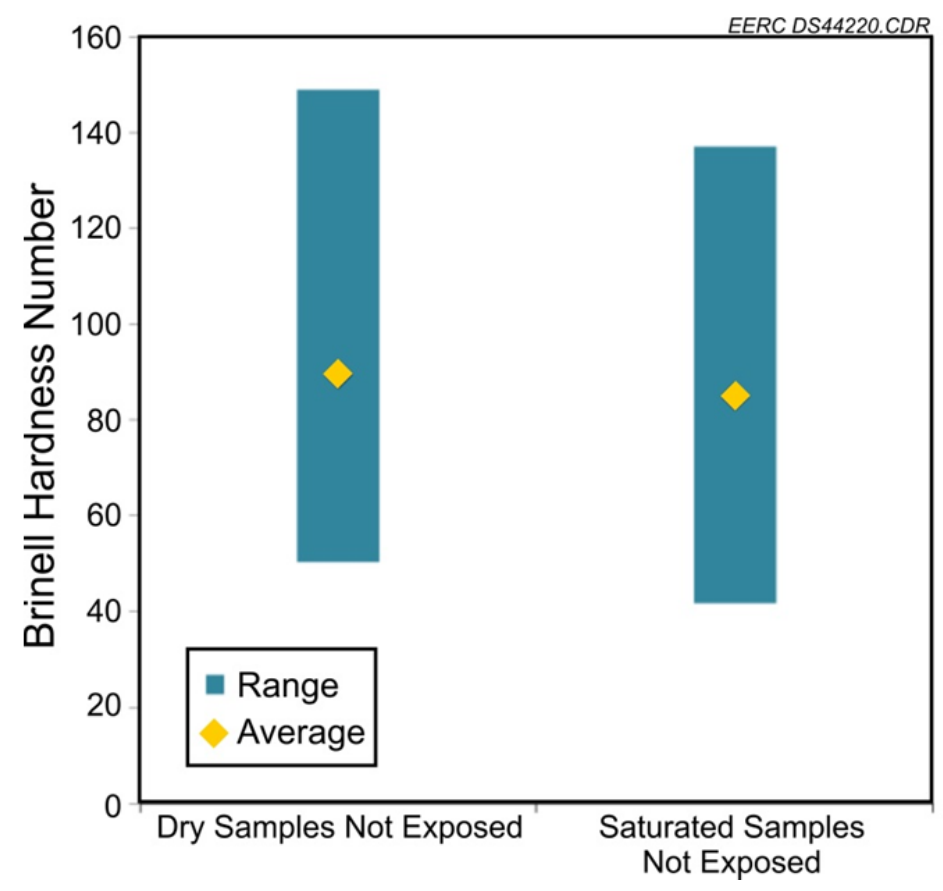

Figure 14. Brinell hardness for dry and saturated Three Forks Formation samples.

Middle Bakken Formation, Lower Bakken shale, and Three Forks Formation samples after 30-day exposure to fluids at $250^{\circ} \mathrm{F}$ and $3000 \mathrm{psi}$ were tested for Brinell hardness. The results are compared to saturated samples that were not exposed to fluids in Figures 15-17. While there appears to be a general decrease in the formation within the Middle and Lower Bakken, following exposure to slickwater, crosslinked gel, and formation water, the only statistically significant hardness reduction occurred with slickwater exposure. The variability of the Three Forks Formation introduces data scatter and difficulty in making a statistically valid conclusion; however, slickwater appeared to produce a notable decrease in rock strength for Three Forks samples. In contrast, results from gelled diesel exposure notably produced average values that were higher than the baseline average, although within limits of measurement variability.

The results of exposing the three rock formation samples to the various fluids and respective hardness testing suggested that the slickwater formulation decreased the strength of the formation face. The corresponding average decrease in Brinell hardness was as follows: $56 \%$ for Middle Bakken, $34.1 \%$ for Lower Bakken, and $84.3 \%$ for Three Forks, suggesting that, on average, the formation face could lose half of its original hardness after exposure to slickwater. The slickwater formulation used in this experiment included:

- $0.75 \mathrm{gal} / \mathrm{Mgal}$ of friction reducer - polyacrylamide.

- $0.5 \mathrm{gal} / \mathrm{Mgal}$ of biocide - gluteraldahyde.

- $0.5 \mathrm{gal} / \mathrm{Mgal}$ of scale inhibitor - phosphonate. 


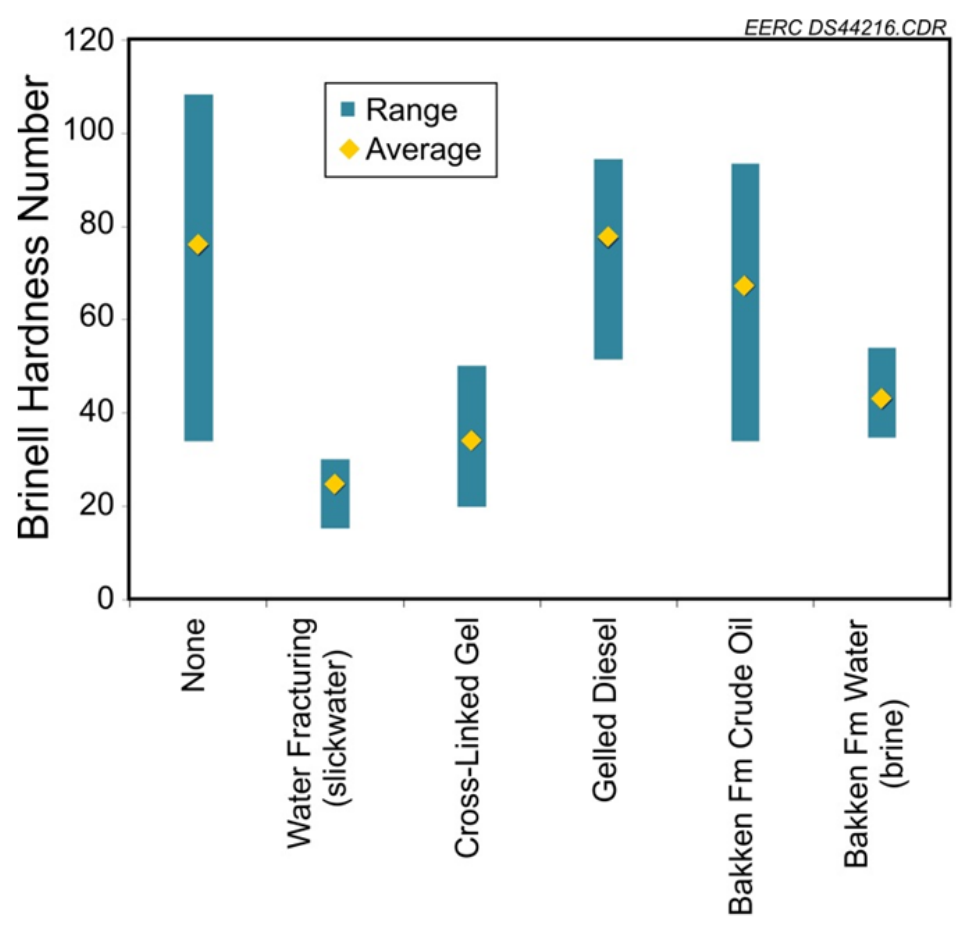

Figure 15. Brinell hardness for Middle Bakken Formation samples relative to fluids.

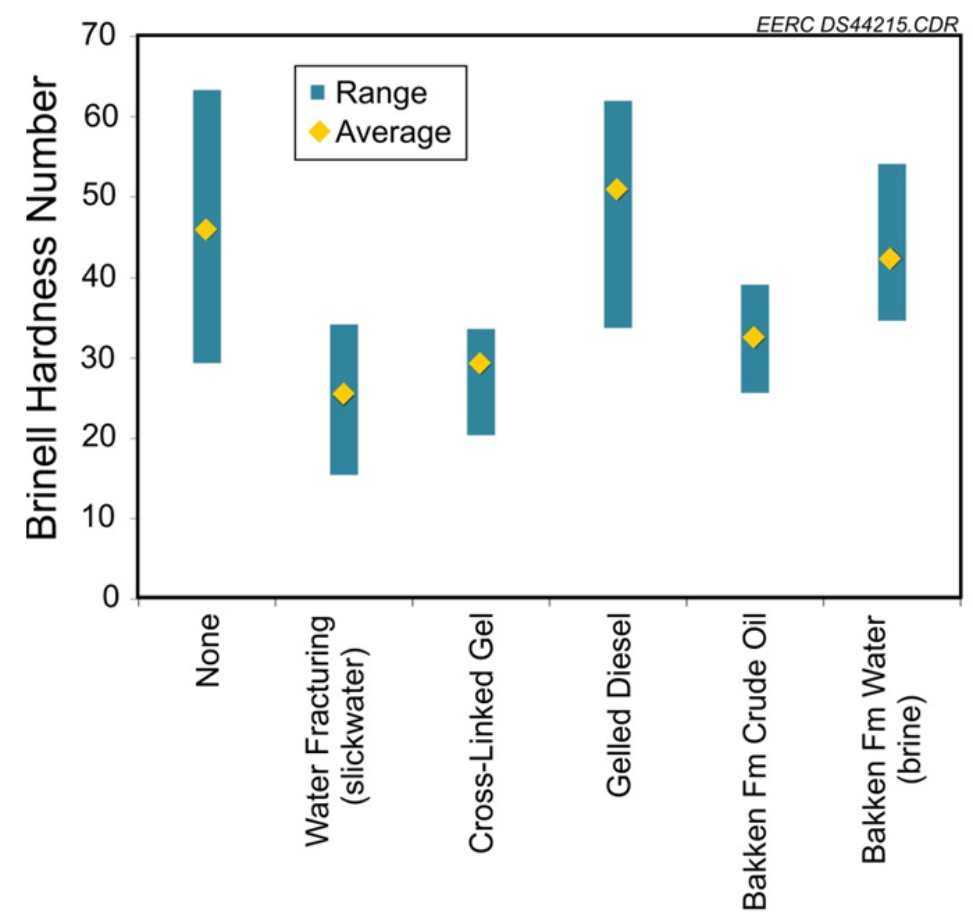

Figure 16. Brinell hardness for Lower Bakken shale samples relative to fluids. 


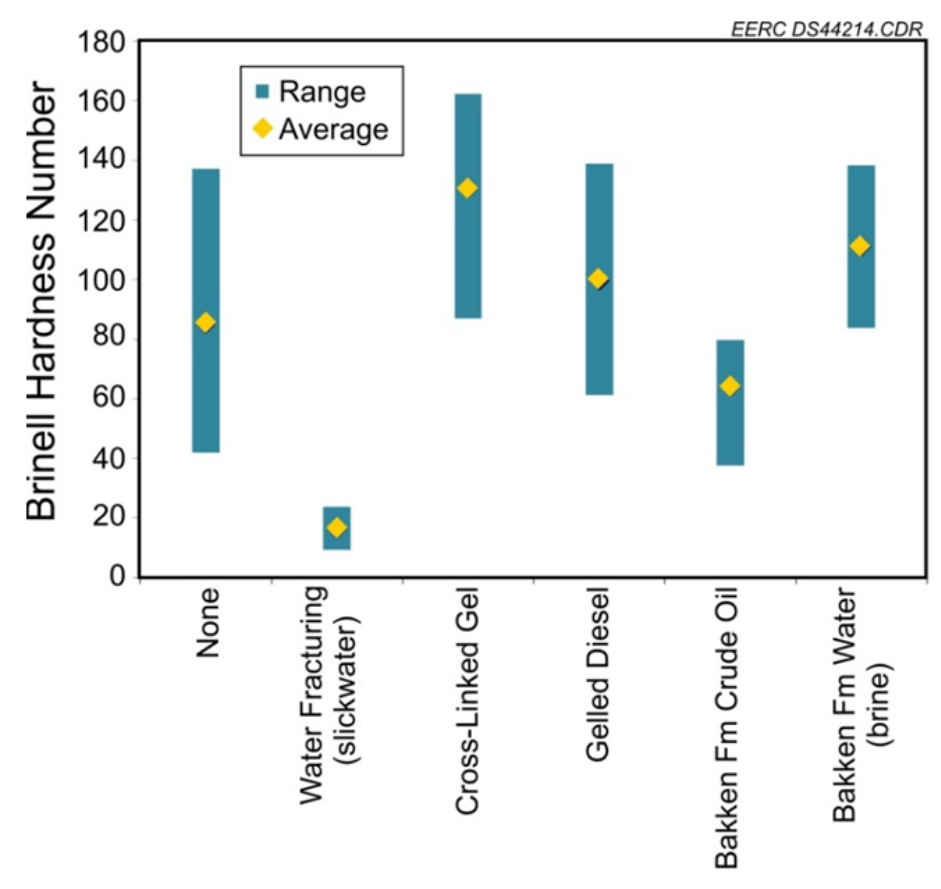

Figure 17. Brinell hardness for Three Forks Formation samples relative to fluids.

The cross-linked gel included $25.1 \mathrm{lb} / \mathrm{Mgal}$ guar, $0.65 \mathrm{gal} / \mathrm{Mgal}$ borate cross-link, $1.5 \mathrm{gal} /$ Mgal biocide, and $1.5 \mathrm{gal} / \mathrm{Mgal}$ of scale inhibitor in the formulation. The gel did not include friction reducer. Decreases in the strength of the formation face are important relative to longterm conductivity. Spalling of the formation face in the presence of proppant can produce fines that may contribute to reductions in conductivity. A softer formation face is also more likely to result in proppant embedment.

\section{Proppant Strength}

A number of factors are used to measure the characteristics of proppants. Table 2 provides some basic properties of the proppants used in this study. A typical measure of proppant strength is API RP-56, otherwise known as a crush test. The crush test is performed in a cell 2 in. in diameter, $3.5 \mathrm{in}$. in length, and loaded with proppant at $4 \mathrm{lb} / \mathrm{ft}^{2}$. Stress is increased at a rate of $2000 \mathrm{psi} / \mathrm{min}$ until the target stress is reached. The sample is then sieved, and any material smaller than the bottom size (40 mesh for $20 / 40$ proppant) is weighed and reported as \% fines generated. Inadequacies in using crush tests to evaluate proppants have been pointed out by Palisch and others (2009). The primary inadequacy is the inability of crush data to be used as a predictor for propped fracture conductivity. Crush data also provide the appearance that larger particles have lower particle strength when, in fact, the opposite is true. Therefore, in order to more precisely evaluate proppant strength, a method was devised based on Ferris (2000), in which the elastic properties of the proppant pack are measured. The elastic properties were measured by plotting the stress versus strain of a proppant pack in a cylinder that is $1 \mathrm{in}$. in diameter and $0.4 \mathrm{in}$. deep, loaded at approximately $4 \mathrm{lb} / \mathrm{ft}^{2}$. This loading density of 20/40 proppant includes eight to nine layers of proppant stacking. Although not representative of actual 
Table 2. Properties of Various Proppants

\begin{tabular}{lccc}
\hline Properties & $\begin{array}{c}20 / 40 \text { Ottawa } \\
\text { Sand }\end{array}$ & RCS & $\begin{array}{c}\text { ECONOPROP } \\
\text { Ceramic }\end{array}$ \\
\hline Roundness & 0.7 & 0.8 & 0.9 \\
\hline Sphericity & 0.7 & 0.8 & 0.9 \\
\hline Bulk Density, g/cm ${ }^{3}$ & 1.54 & 1.46 & 1.56 \\
\hline lb/cf & 96.1 & 96 & 96 \\
\hline Specific Gravity & 2.64 & 2.43 & 2.67 \\
\hline Particle-Size Distribution, wt\% retained & & & \\
\hline 16 & 0 & 0.5 & 0 \\
\hline 20 & 1.0 & 7.1 & 3.6 \\
\hline 25 & 7.3 & 32.3 & 22.0 \\
\hline 30 & 20.2 & 41.0 & 44.3 \\
\hline 35 & 39.6 & 11.6 & 29.7 \\
\hline 40 & 25.8 & 3.0 & 0.4 \\
\hline 50 & 5.8 & 2.2 & 0.0 \\
\hline Pan & 0.3 & 2.3 & 0.0 \\
\hline Mean Particle Diameter, mm & .555 & .681 & .660 \\
\hline Solubility in HCl/HF & 0.9 & 0.3 & 1.7 \\
\hline Crush, wt\% fines generated & 9.5 & 0.8 & 5.2 \\
at 7000 psi & & & \\
\hline
\end{tabular}

proppant loadings in the field of around $1 \mathrm{lb} / \mathrm{ft}^{2}$, the additional layers ensure the ability to capture the elastic movement of the proppant pack, which can be measured before crush occurs. The characteristics of proppant strain can be compared in both the elastic and plastic regions of the stress-strain curve and provide a description of the mechanics of the proppant pack as an elastic material.

The elastic properties of each of the three proppant types was also determined. Typically used in most Bakken Formation wells, 20/40 tends to be one of the larger-diameter proppants. It is highly desired to place larger 20/40 mesh proppant near the wellbore; therefore, 20/40 is commonly pumped last during a particular fracture stage treatment.

Tests were completed to evaluate strength data for dry, as-received proppant versus washed proppant. Washing of proppant was required to remove residues that remained from the 30-day fluid exposures. A test was required to determine how to compare the washed and exposed proppant to the baseline proppant, which could be tested either dry or washed.

Previous work (Palisch and others, 2009) was conducted on wet versus dry proppants (Figure 18). Although there was little variation in crush test results for proppant that was wetted with water while in the test apparatus, twice as much proppant was crushed when wetted 


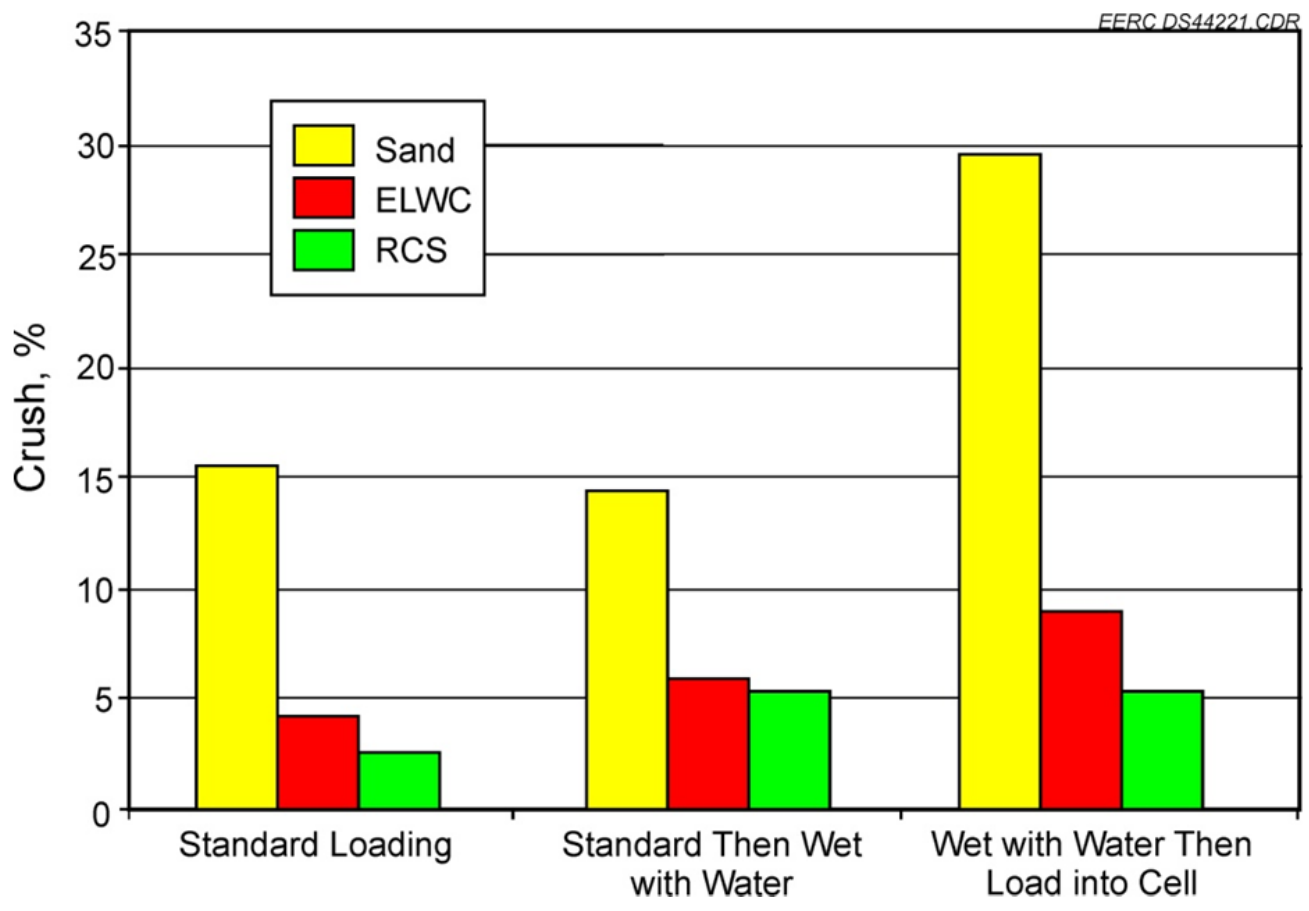

Figure 18. Crush data at $6000 \mathrm{psi}$ and $2 \mathrm{lb} / \mathrm{ft}^{2}$ for sand, lightweight ceramic (ELWC), and RCS proppant, dry versus wet, modified from Palisch and others (2009).

separately and subsequently loaded into a test apparatus. The previous work served to justify an investigation of elastic performance of proppants that were exposed to the washing fluids versus as-received dry proppant.

The procedure for washing of proppant included washing with distilled water, decanting, and submerging the sample in toluene for 30 seconds including agitation. After decanting a second time, the procedure was repeated, switching out the toluene for a $10 \% \mathrm{HCl}$ solution. The final step included drying at $125^{\circ} \mathrm{F}$.

The strength results for as-received versus washed proppants are provided for sand, RCS, and ceramic in Figures 19-21. The data in these figures include proppant that was unwashed, dry as-received proppant, and proppant that was washed with toluene and $10 \% \mathrm{HCl}$. A total of five tests were performed with each sample. The data were used to calculate and plot three standard deviations from the average. The average difference in the stress-strain relationship for asreceived (dry) versus washed proppant varies little for all proppant types.

The stress-strain relationship is compared for sand, RCS, and ceramic proppants in Figure 22. The data include the results from the washed proppants. Ceramic proppant indicates a high stiffness, with cleaving beginning to occur in the range of 9000-10,000 psi. Sand appears less stiff than ceramic but more stiff than RCS at less than 7000 psi. Greater strain is associated with the resin at less than 7000 psi than for noncoated sand; however, RCS exhibits good 


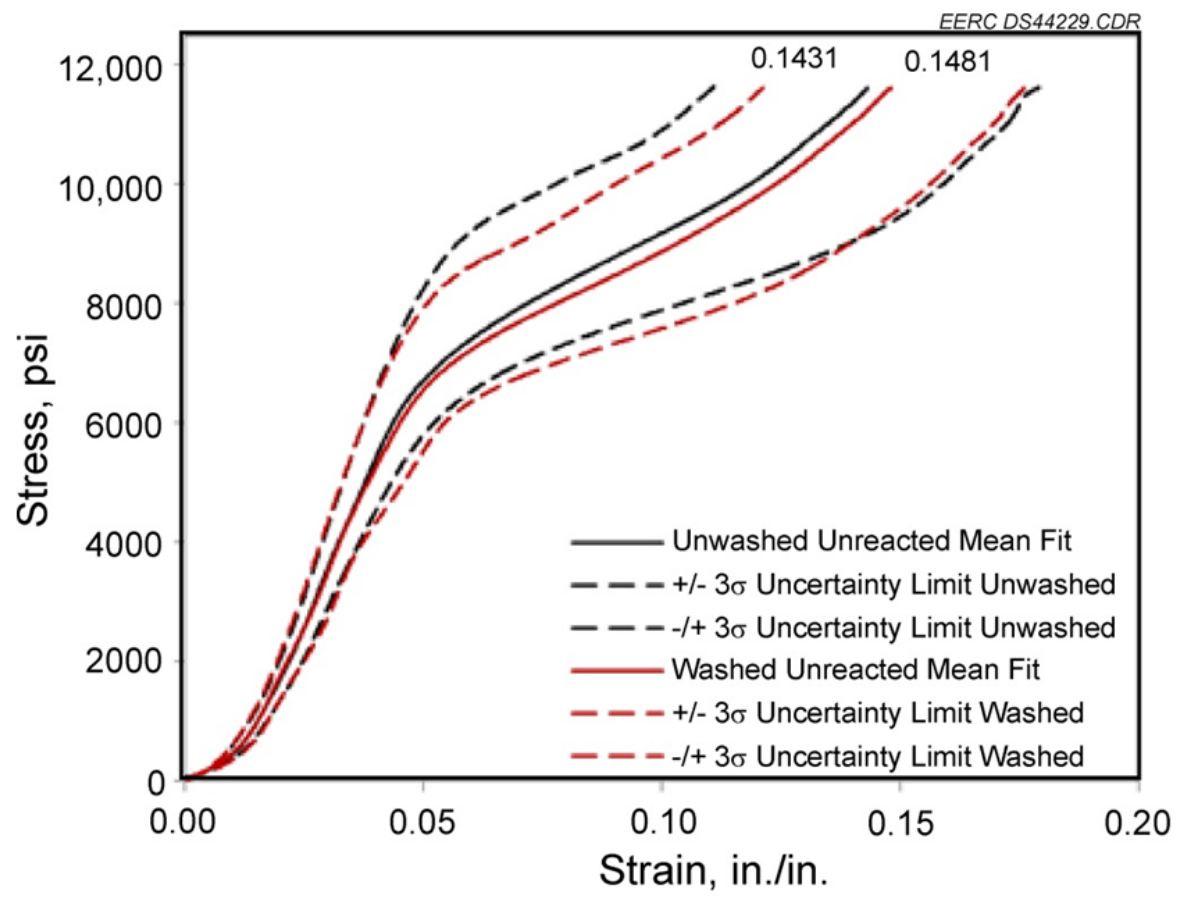

Figure 19. 20/40 Ottawa sand.

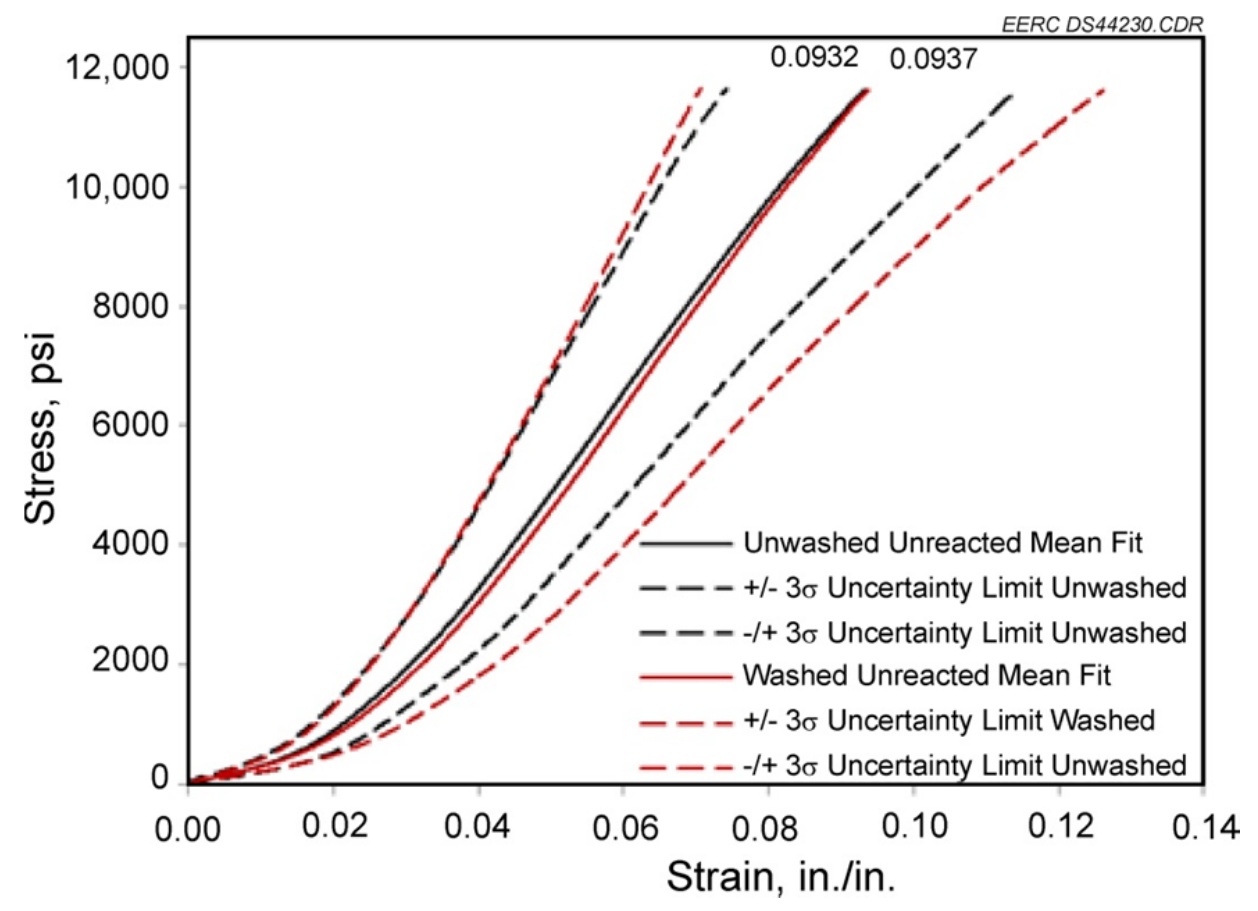

Figure 20. 20/40 resin-coated sand. 


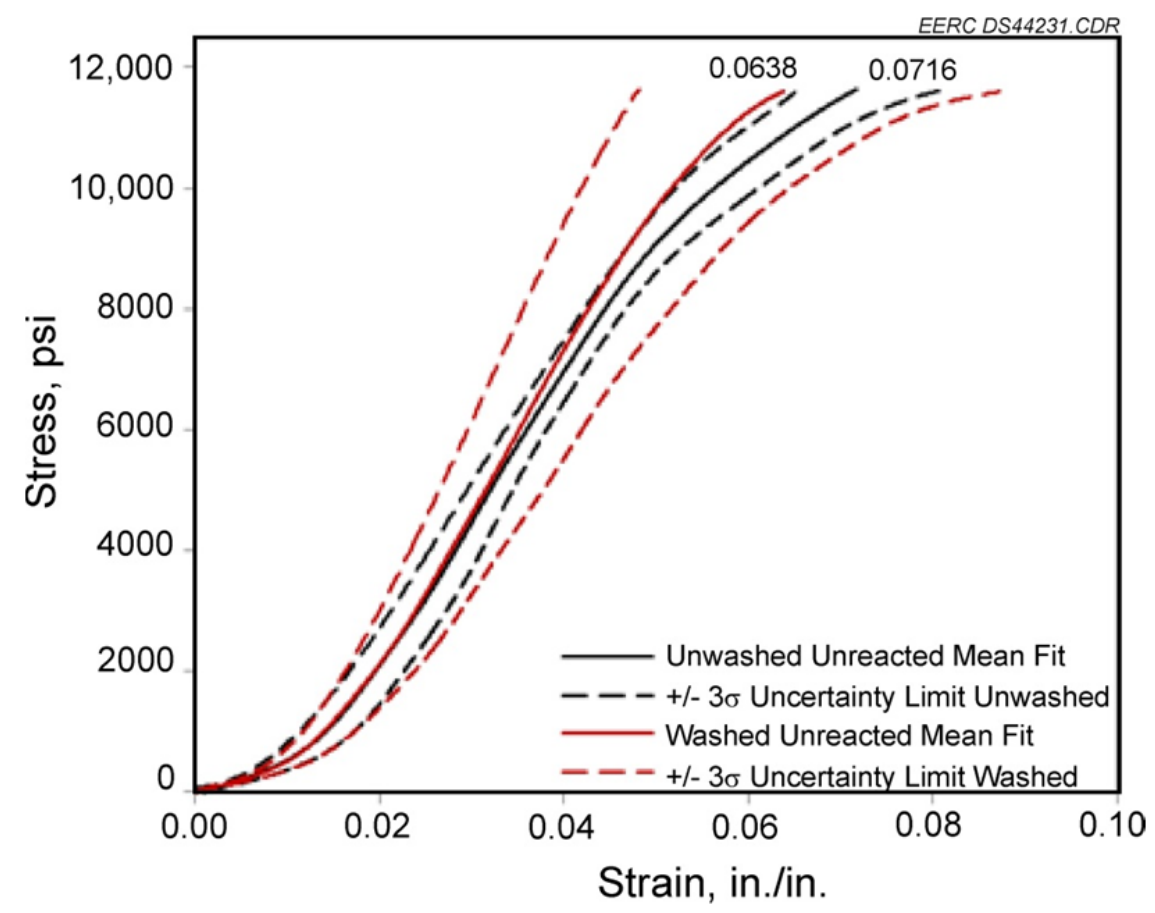

Figure 21. 20/40 ceramic proppant.

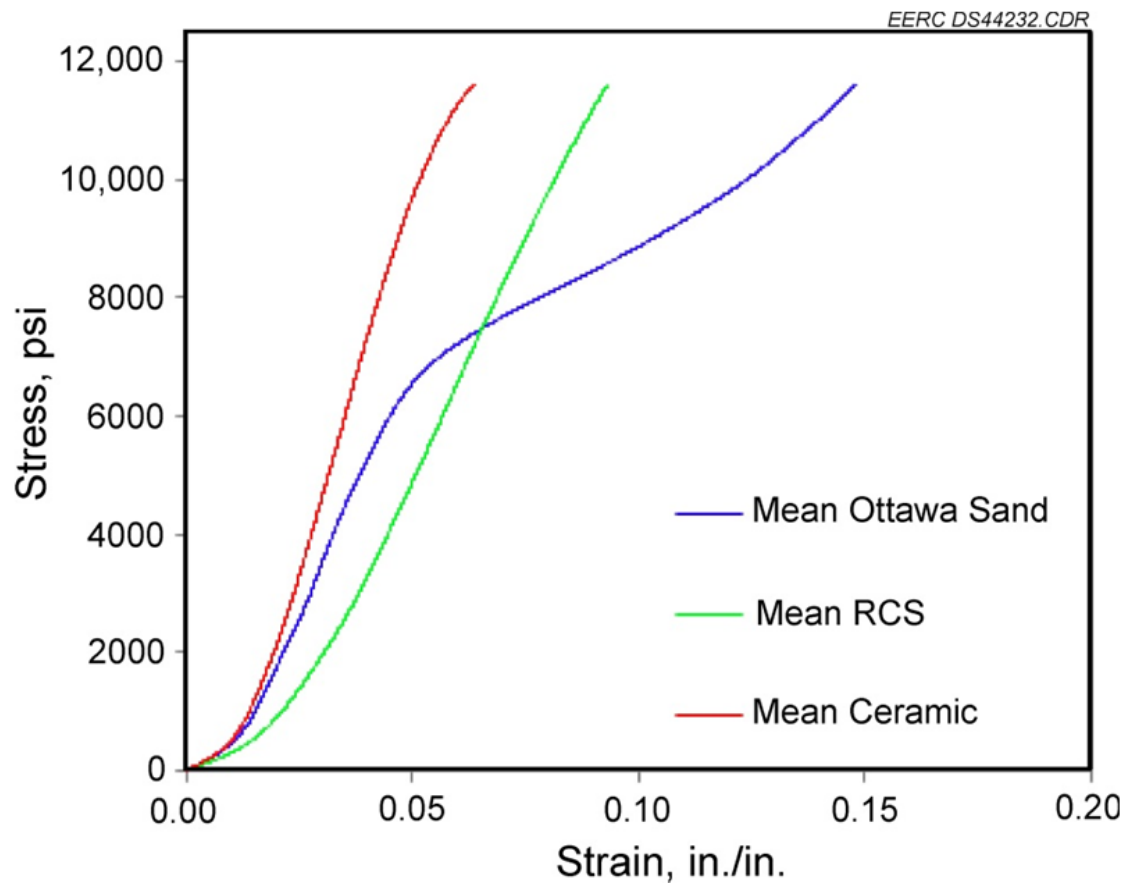

Figure 22. Stress-strain relationship of sand, RCS, and ceramic proppants. 
resistance to strain at stresses above 7000 psi. No noticeable immediate failure is evident with RCS as compared to ceramic proppant at stresses in the 9000-10,000-psi range. The relative increase in stiffness at the end of the curve for sand at 9000 psi is likely due to a consolidation of particles and accompanying reduction of porosity. An example of various stress-strain relationships for elastic and brittle materials is provided in Figure 23.

Proppants including 20/40 sand, RCS, and ceramic were exposed to fluids for 30 days at $3000 \mathrm{psi}$ and $250^{\circ} \mathrm{F}$. The fluids included slickwater, cross-linked gel, gelled diesel, Bakken Formation crude, and Bakken Formation water. Analysis for these fluids is provided in Appendix B. Figures 24-26 provide the elastic-plastic behavior of the proppants which were reacted with fluids compared to the average elastic-plastic behavior of the unreacted proppant and the respective standard deviations. The data for the unreacted proppant include five tests of washed proppant. The standard deviation is greater for the sand and RCS than for the ceramic; however, this is largely because one of the five tests deviated from the other four. Reacted proppant samples included enough material to run two elastic tests. The data in Figures 24-26 include the average of two tests.
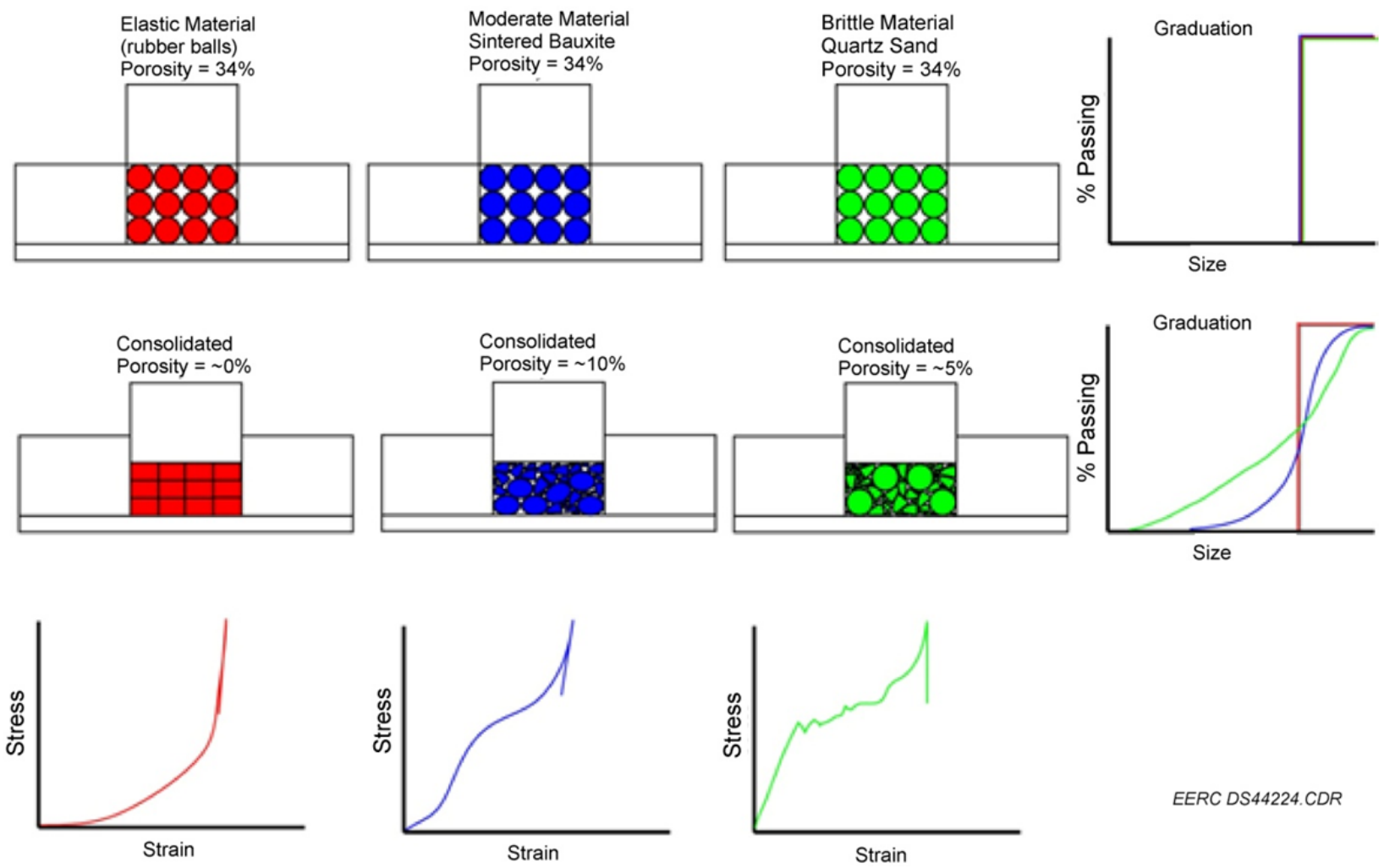

EERC DS44224.CDR

Figure 23. Stress--strain relationship for elastic and brittle materials. 


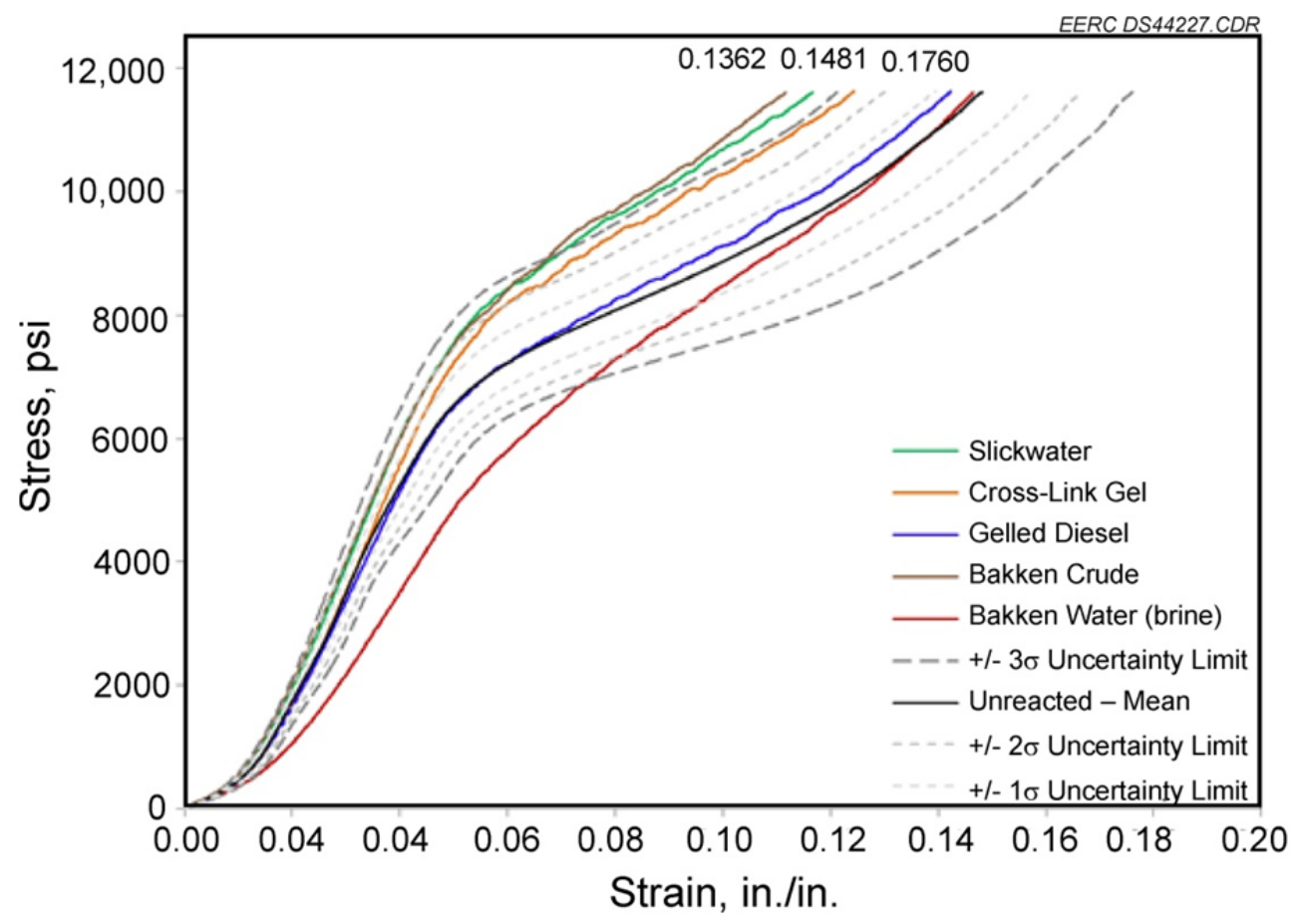

Figure 24. 20/40 sand reacted proppant compared to unreacted proppant.

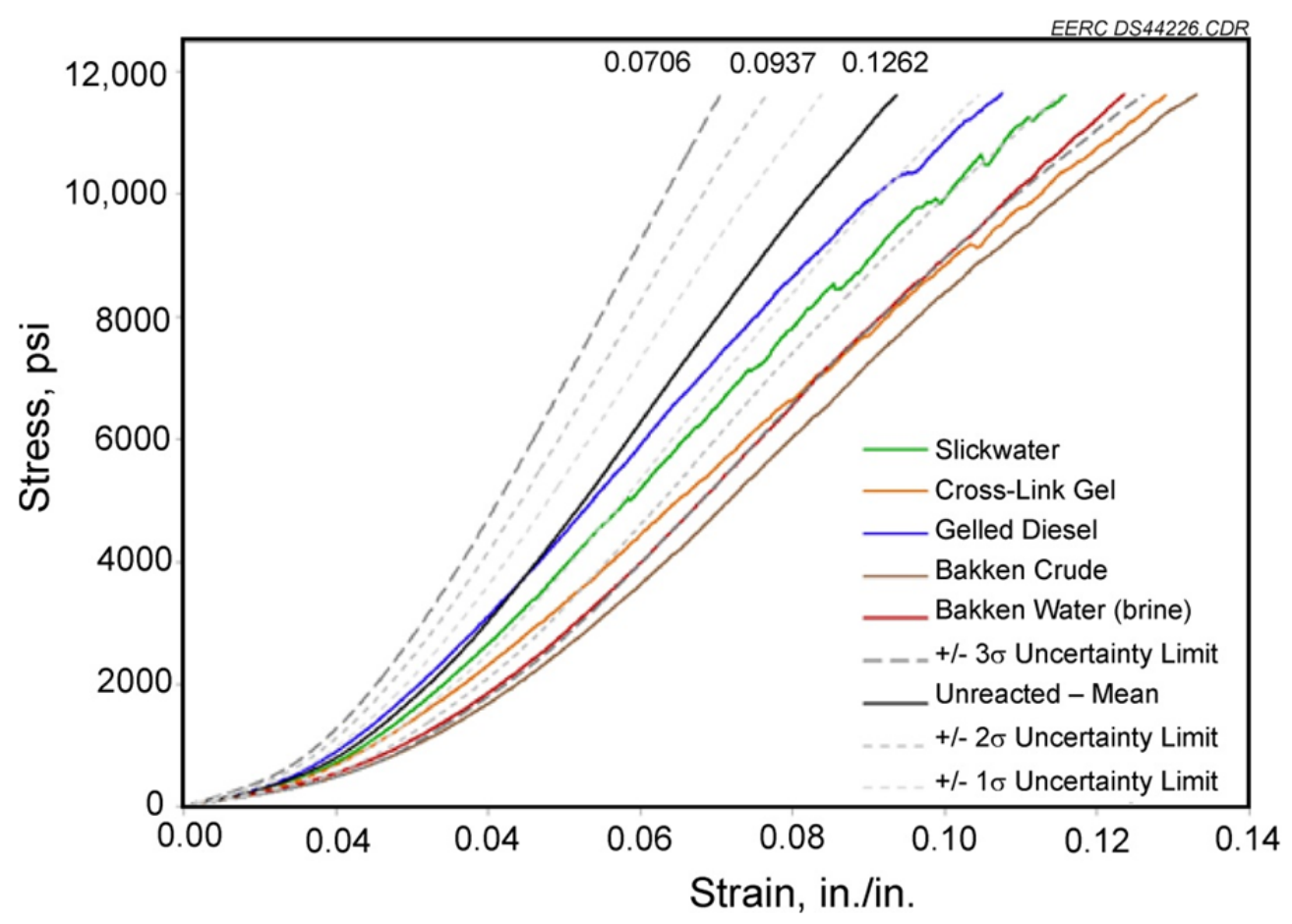

Figure 25. 20/40 RCS reacted proppant compared to unreacted proppant. 


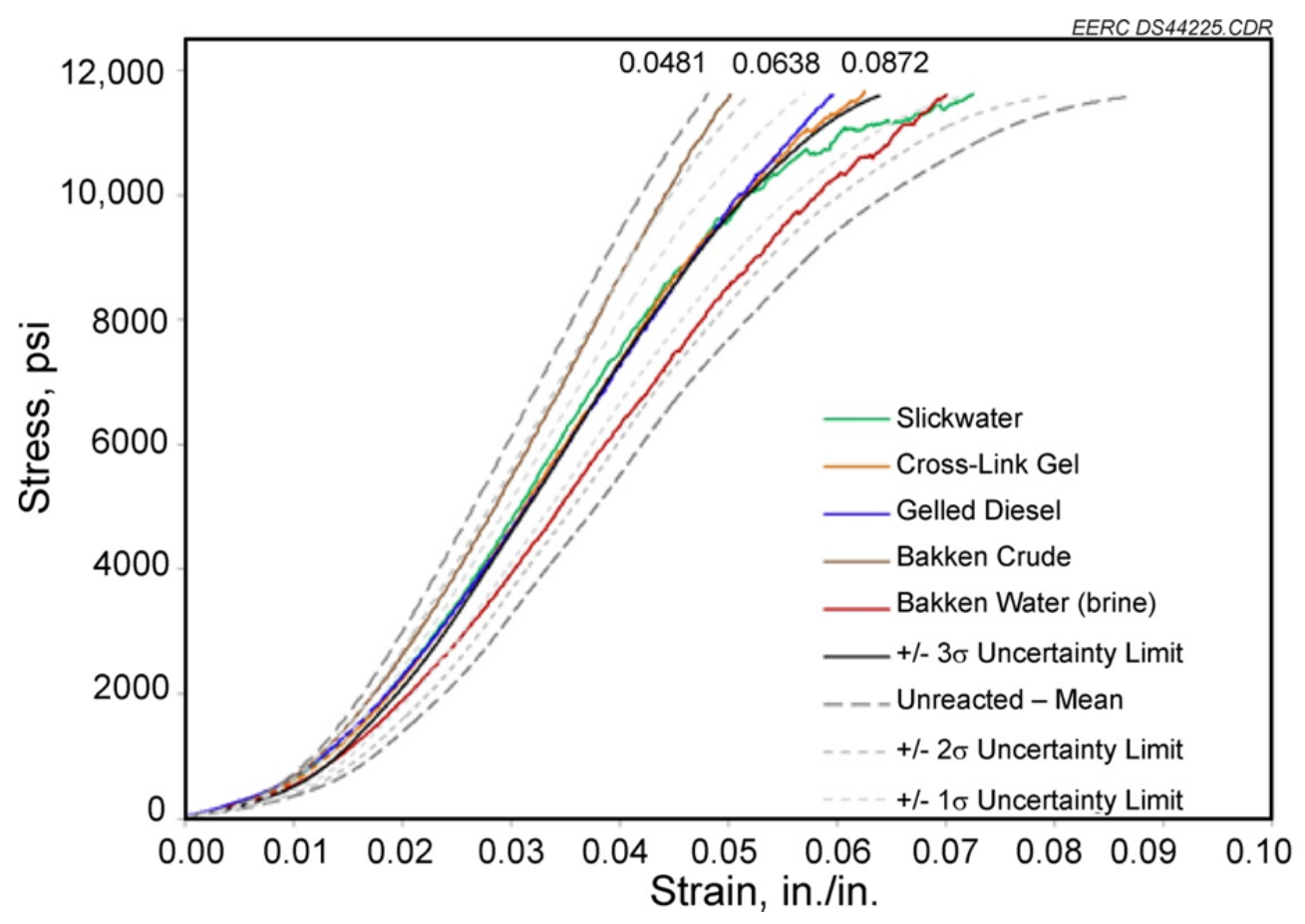

Figure 26. 20/40 ceramic reacted proppant compared to unreacted proppant.

Sand proppants (Figure 24) did not appear to exhibit a significant change in elastic behavior relative to the average baseline curve, with the exception of sand reacted in Bakken Formation water. The brine concentration of formation water is above $250,000 \mathrm{mg} / \mathrm{L}$. It is suspected that the salts are reacting to compromise material stiffness in the elastic range, or salt adhered to the surface is allowing more strain to occur at lower stress.

RCS proppant reacted in various fluids (Figure 25) appears to show a general reduction in stiffness. Of the samples tested, none performed better than the mean unreacted performance. The total variation among all reacted samples tested is also similar to that of the baseline unreacted tests. Because of limited test quantity for each reacted sample, it is not evident how significant RCS was affected by individual fluids. It is possible that being exposed to elevated heat and pressure may have resulted in a significant degradation in the resin stiffness regardless of the test fluid. More testing is required to isolate the individual contributions for the apparent stiffness loss for RCS.

Fluids reacted with ceramic proppant (Figure 26) did not appear to compromise the proppant performance. Collectively, for all proppants, greater strain was associated with proppants exposed to formation water. These data are provided in Figure 27 where the relative effects are provided. The greatest difference in strain from the baseline is evident for sand and RCS proppants. Greater strain was associated with RCS as compared to sand. Ceramic and RCS appear to produce greater strain rates at higher stress, whereas the apparent lack of strain in sand at high loading following exposure to formation brine is more likely due to the sands being so damaged at those loads that additional damage is insignificant. 


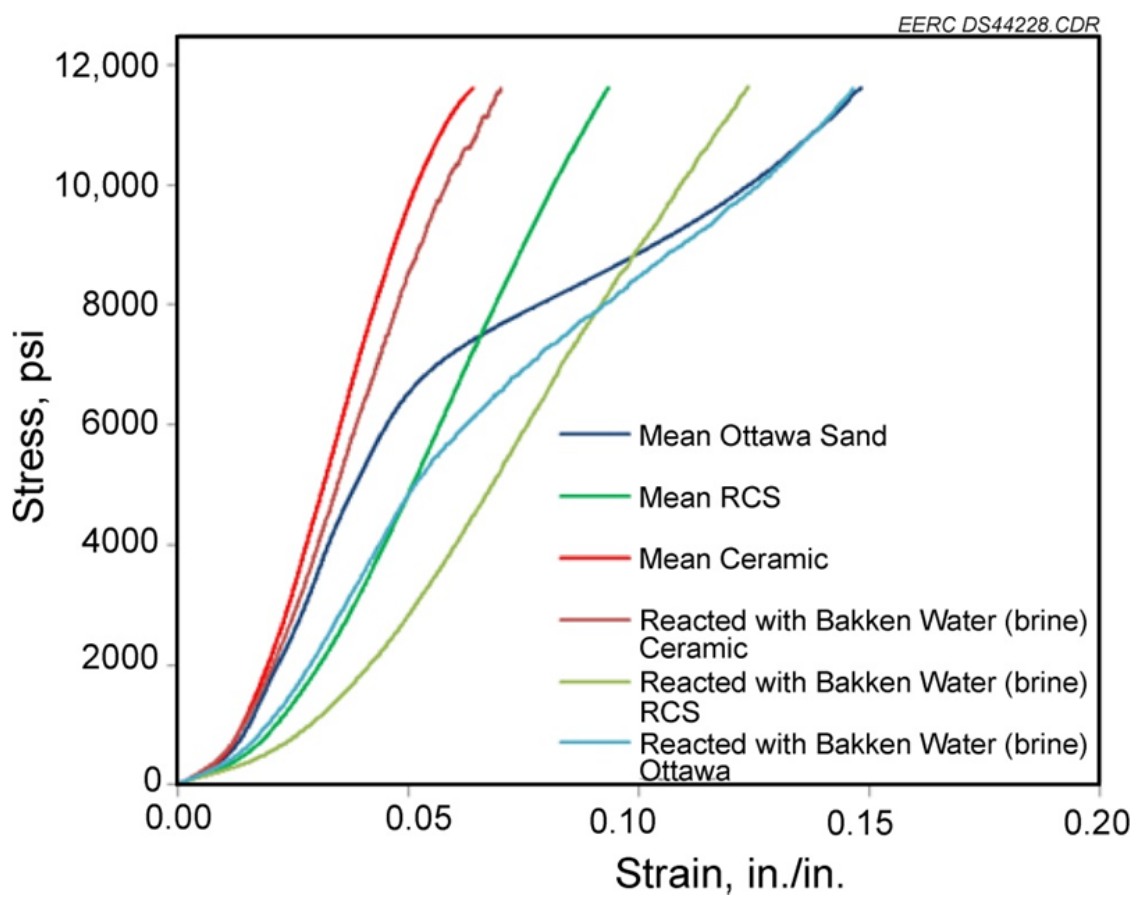

Figure 27. Comparison of proppants reacted with Bakken Formation water relative to proppants that were not reacted with fluids.

Crush data were evaluated for the proppants at a stress loading of 11,600 psi. All proppant tests included collection and sieving of the fines generated. The data are presented in Figure 28. Evaluating crush data at a lower stress, which would be more typical of fracture closure pressures in the Bakken Formation, was not possible because of the nature of the stress-strain test program. The primary interest was generating a complete stress-strain relationship for the proppant pack extending well into the plastic or failure zone of the material. Therefore, interpretation is in respect to crush results at high stress load. Generally, exposure of proppant to fluids appeared to result in a higher crushed percentage for RCS and ceramic proppants. There was no increase in crushed sand particles after fluid exposure; however, this may again be a result of the sand already being so highly damaged at baseline conditions that exposure to fluids makes little difference. Ceramic proppants tended to experience higher crush relative to RCS. However, it should be noted that there is no specific correlation between crush results and conductivity since the failure mechanisms are different for the various proppant types.

\section{Proppant Conductivity}

The goal of hydraulic fracturing is to increase the well productivity by altering the flow pattern in the formation near the wellbore from one that is radial to one that is linear, with flow that converges into a conductive fracture intersecting the wellbore. The fracture must be more conductive than the formation, and a granular propping agent is added to keep the walls of the fracture apart. A successfully propped fracture will retain conductivity during production, although mechanisms can be at work to degrade proppant or formation rock and allow fractures to decrease in width or reduce fracture permeability. 


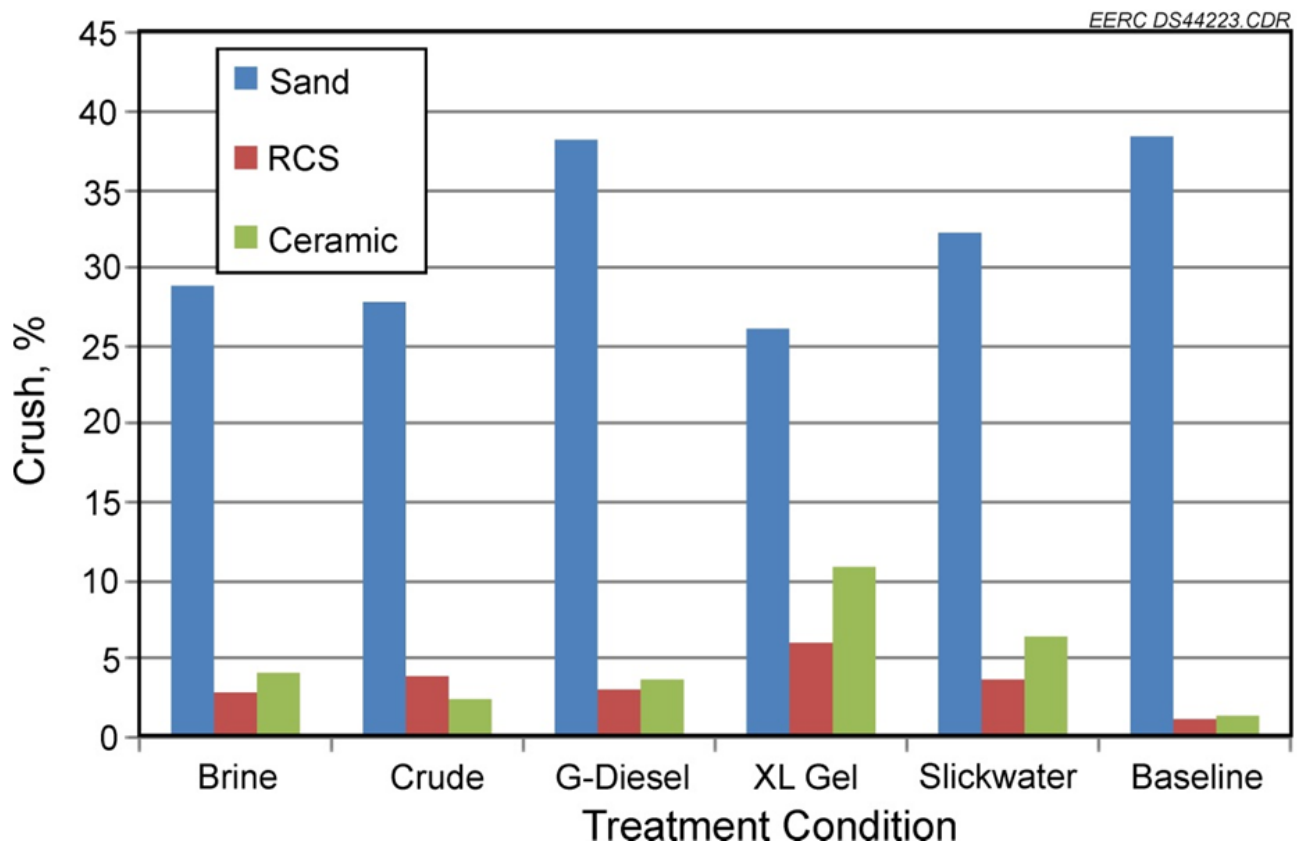

Figure 28. Crush results for various proppants exposed to Bakken Formation brine, Bakken Formation crude oil, gelled diesel, cross-linked gel, and slickwater. The baseline samples included washed proppant that was not exposed to any fluid.

Fracture conductivity can be affected by many factors (Palisch et al., 2007). High closure stress can crush proppant, embed the proppant into the rock, and generate fines that reduce permeability. Cycling of stress that occurs during well shut-in can also decrease conductivity irreversibly. Larger-particle-size proppants will have higher conductivity; however, fracture widths 2-3 times the largest grain diameter are recommended to allow proppant to enter the fracture during pumping. Fracture width is harder to achieve in deeper wells. High proppant concentrations will achieve greater conductivity. Other factors that affect conductivity include proppant strength, grain shape, long-term stability, gel damage, and fines movement. In addition, in actual fractures, non-Darcy and multiphase flow tremendously reduce the effective fracture conductivity, but these factors are not considered in standard reference testing (Palisch et al., 2007).

Fracture conductivity is calculated from Darcy's equation. Fracture conductivity is the product of the fracture permeability and the width according to Equation 1 (Gidley and others, 1989).

$$
k_{f} w=q \mu L_{f} / h \Delta p
$$

Where $\mathrm{w}=$ fracture opening (in.), $\mathrm{L}=$ length (ft) $\mathrm{h}=$ height (width across the cell, $\mathrm{ft}$ ), $\mu=$ viscosity (cP), $q=$ flow (cfs), and $\Delta p=$ differential pressure across the length of the cell (atm). 
A standard fracture conductivity test is conducted in an API conductivity cell in which flow and differential pressure are recorded to determine conductivity under a specified confining load. Standard tests are normally conducted over 50 hours.

With the exception of non-Darcy and multiphase flow, likely one of the most significant parameters affecting fracture conductivity is fracture closure pressure. Fracture closure pressure is the pressure required to initiate a hydraulic fracture. The stress on the proppant is closure pressure. Fracture closure pressures in the Bakken Formation can be on the order of 9500 psi (Terracina and others, 2010) for basin-centered locations and lower in more shallow locations. The Elm Coulee Field in Montana has been described by Wiley and others (2004) as having fracture gradients of $0.69-0.75 \mathrm{psi} / \mathrm{ft}$, initial pore pressures of $0.5 \mathrm{psi} / \mathrm{ft}$, and bottomhole temperature of $240^{\circ} \mathrm{F}$ at $10,000 \mathrm{ft}$. Given the high degree of reservoir pressure variability in the Bakken, a low stress (6500 psi) and a high stress (8000 psi) were selected for conductivity testing. While closure pressures may be greater than 8000 psi in some locations of the Bakken, the proppant type used in those high-stress conditions would likely be ceramic. The stresses selected for the conductivity testing encompass a broader range of conditions where various proppant types are likely to be used.

The results of the standard conductivity testing showed that regardless of rock type, the ceramic proppant exhibited the highest conductivity, followed by RCS, followed by Ottawa sand (Table 3; Figure 29). These results are consistent with the strength tests conducted herein. Interestingly enough, very little variance in conductivity was seen between the rock types, despite the higher Brinell hardness numbers associated with the Middle Bakken and Three Forks Formations when compared to the lower Bakken shale. Some variability is seen within the RCS within the Three Forks Formation; however, it is unclear as to what caused this variability, and no unusual conditions were reported during or following the test run for that sample (Appendix C).

Table 4 shows the percent decrease in fracture width following the completion of each test. On average, approximately a 5.3\%, 2.8\%, and 4.8\% decrease in fracture width was observed when using the Ottawa sand, RCS, and ceramic proppant, respectively. The lower percentage of fracture width loss within the RCS may be indicative of more evenly dispersed loading, one of the advertised advantages of RCS (Beckwith, 2011).

Table 3. Results of Conductivity Tests Using ISO Method 13503-5

\begin{tabular}{|c|c|c|c|c|c|c|c|c|c|}
\hline \multirow{4}{*}{$\begin{array}{l}\text { Stress,psi@ } \\
\text { Time, hours }\end{array}$} & \multicolumn{9}{|c|}{ Conductivity, $\mathrm{mD}-\mathrm{ft}$} \\
\hline & \multicolumn{3}{|c|}{ Middle Bakken } & \multicolumn{3}{|c|}{ Lower Bakken } & \multicolumn{3}{|c|}{ Three Forks } \\
\hline & Ottawa & & & Ottawa & & & Ottawa & & \\
\hline & Sand & $\mathrm{RCS}$ & Ceramic & Sand & $\mathrm{RCS}$ & Ceramic & Sand & $\mathrm{RCS}$ & Ceramic \\
\hline $6500 @ 0$ & 1241 & 1791 & 3656 & 1289 & 2232 & 4025 & 1060 & 2985 & 4043 \\
\hline $6500 @ 5$ & 1000 & 1543 & 3572 & 1014 & 1793 & 3772 & 920 & 2709 & 3861 \\
\hline $6500 @ 20$ & 847 & 1498 & 3503 & 944 & 1649 & 3714 & 763 & 2440 & 3708 \\
\hline $6500 @ 30$ & 802 & 1385 & 3336 & 925 & 1638 & 3680 & 749 & 2379 & 3652 \\
\hline $6500 @ 50$ & 798 & 1384 & 3304 & 887 & 1534 & 3623 & 726 & 2368 & 3641 \\
\hline $8000 @ 0$ & 790 & 1341 & 2662 & 818 & 1487 & 2919 & 686 & 2287 & 2884 \\
\hline $8000 @ 5$ & 589 & 1240 & 2475 & 666 & 1384 & 2717 & 557 & 2113 & 2574 \\
\hline $8000 @ 20$ & 477 & 1117 & 2364 & 558 & 1244 & 2610 & 478 & 1881 & 2457 \\
\hline
\end{tabular}




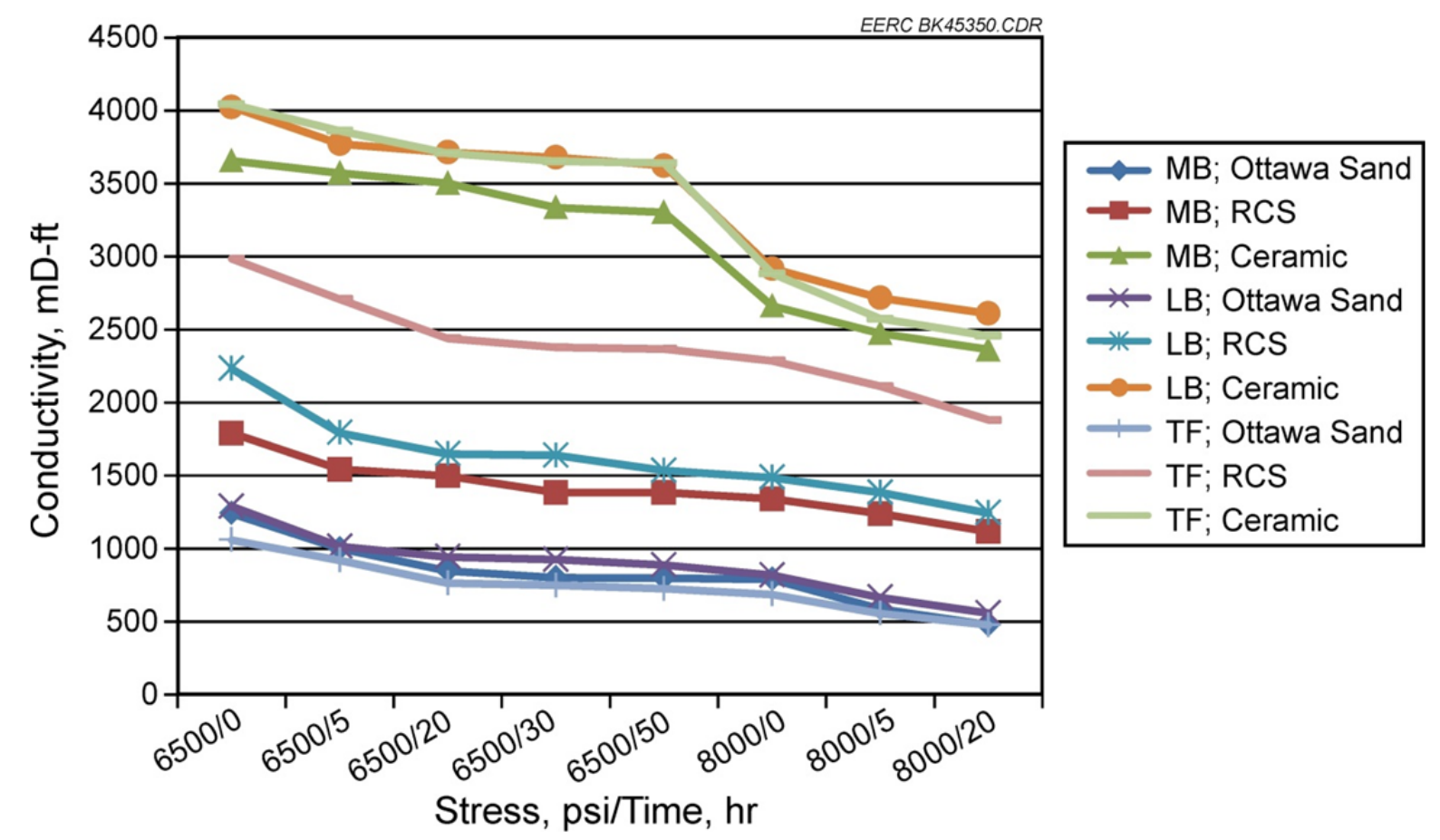

Figure 29. Graphical results of the conductivity tests using ISO Method 13503-5 (MB = Middle Bakken; LB = Lower Bakken; TF = Three Forks).

Table 4. Decrease in Fracture Width at the Completion of the Conductivity Testing

\begin{tabular}{lccc}
\hline & \multicolumn{3}{c}{ Proppant Type } \\
\cline { 2 - 4 } Rock Type & Ottawa Sand & RCS & $\begin{array}{c}\text { ECONOPROP } \\
\text { Ceramic }\end{array}$ \\
\hline Middle Bakken & $0.0098 / 4.8 \%$ & $0.0066 / 3.1 \%$ & $0.0103 / 4.8 \%$ \\
Lower Bakken & $0.0126 / 5.8 \%$ & $0.0061 / 2.9 \%$ & $0.0103 / 4.9 \%$ \\
Three Forks & $0.0103 / 5.2 \%$ & $0.0050 / 2.5 \%$ & $0.0100 / 4.6 \%$ \\
\hline Average & $\mathbf{0 . 0 1 0 9} / 5.3 \%$ & $\mathbf{0 . 0 0 5 9 / 2 . 8 \%}$ & $\mathbf{0 . 0 1 0 2} / \mathbf{4 . 8 \%}$ \\
\hline *Dan
\end{tabular}

*Data indicate decrease in fracture width in inches, as well as the \% decrease in overall fracture width.

After evaluating the conductivity results provided by CARBO Ceramics, the EERC decided to evaluate the proppant embedment and/or spalling within the rock slabs used to conduct the testing, since the results suggested that embedment may not be the driving factor in the conductivity tests but, rather, proppant strength. A Nanovea optical profiler was used to conduct detailed surface scans of each rock slab to conduct a qualitative comparison of the degree of proppant embedment and/or formation spalling within each rock type. The results of this work are discussed in the Embedment Evaluation section that follows.

Given the time-consuming nature and difficulty of producing rock slabs for use in the standard conductivity tests, an alternative method to measure conductivity using 1-in.-diameter rock plugs was evaluated. The experimental conditions and operating procedures for this work is contained in Appendix C. The technique included placing core plug samples into a Hoek cell 
while flowing crude oil through a simulated fracture (Figures 21 and 22). This apparatus exposed rock samples to confining loads similar to those found in the reservoir (up to 6500 psi net) while maintaining pore pressure (1000 psi) and hydraulic flow across the sample. In particular, the experiment measured the pressure drop required to flow reservoir fluid through a simulated fracture over increasing loading and time.

The conductivity of each proppant type was evaluated using rock samples from the Middle Bakken Formation, Lower Bakken shale, and Three Forks Formation. However, the results were inconsistent and irreproducible using the 1-in. cell. Several issues were encountered with the Hoek cell design for this application, including sealing problems and rupturing of the gasket material at reservoir temperatures and pressures. Ultimately, the EERC determined that significant changes in the design of the apparatus would be needed to better understand the relationship between the customized apparatus and the standard method.

\section{Embedment Evaluation}

As previously mentioned, a Nanovea PS50 optical profiler was used to qualitatively evaluate the proppant embedment within each of the rock slabs used for the standard conductivity testing. The optical profiler measures the height of a surface by projecting a beam of white light onto the target and measuring the wavelength of the reflected light returned to the sensor. This allows for collection of high-resolution scans of the surface roughness of a sample. In these tests, the resolution of the $\mathrm{Y}$ and $\mathrm{X}$ axes was set to $18 \mu \mathrm{m}$, and the vertical resolution was $5 \mathrm{~nm}$. In all cases, the samples were scanned so that the $\mathrm{Y}$ axis was oriented in the direction of flow in the conductivity cell. All of the profiler scans can be found in Appendix D. It should be noted that not all of the slabs remained together after shipping, thus some of the fractures and broken pieces are readily apparent in the scans.

Several interesting features were seen from the embedment scans. For example, in six out of nine samples, the top rock slab of each set showed larger and deeper embedment craters than the bottom slab, suggesting that sorting occurs either during proppant loading or during testing, or that the top layer of proppant is not as fully packed as the bottom, causing high pressure and greater embedment in the top layer. In two of the Three Forks samples, there was so little embedment, it was difficult to determine if the slabs exhibited the same pattern. This difference in embedment between the top and bottom rock slabs is shown in Figures 30 and 31, which depict surface scans of the Lower Bakken rock slabs that were run with ECONOPROP ceramic proppant. The surface scans clearly show deeper and wider embedment craters in the top slab, shown in Figures 32-34.

Between the different rock types, the Lower Bakken displayed the highest degree of embedment, followed by the Middle Bakken. The Three Forks slabs showed significantly less embedment than the Bakken rocks. Few patterns were apparent between proppant types, except that within the Lower and Middle Bakken, there appears to be a greater degree of ceramic proppant embedment than with the other two proppant types. This is shown in Figures 32-35, which depict cross sections across the top slabs of Lower Bakken rocks that were used in the conductivity testing of each proppant type. This is likely a result of the high strength of the 

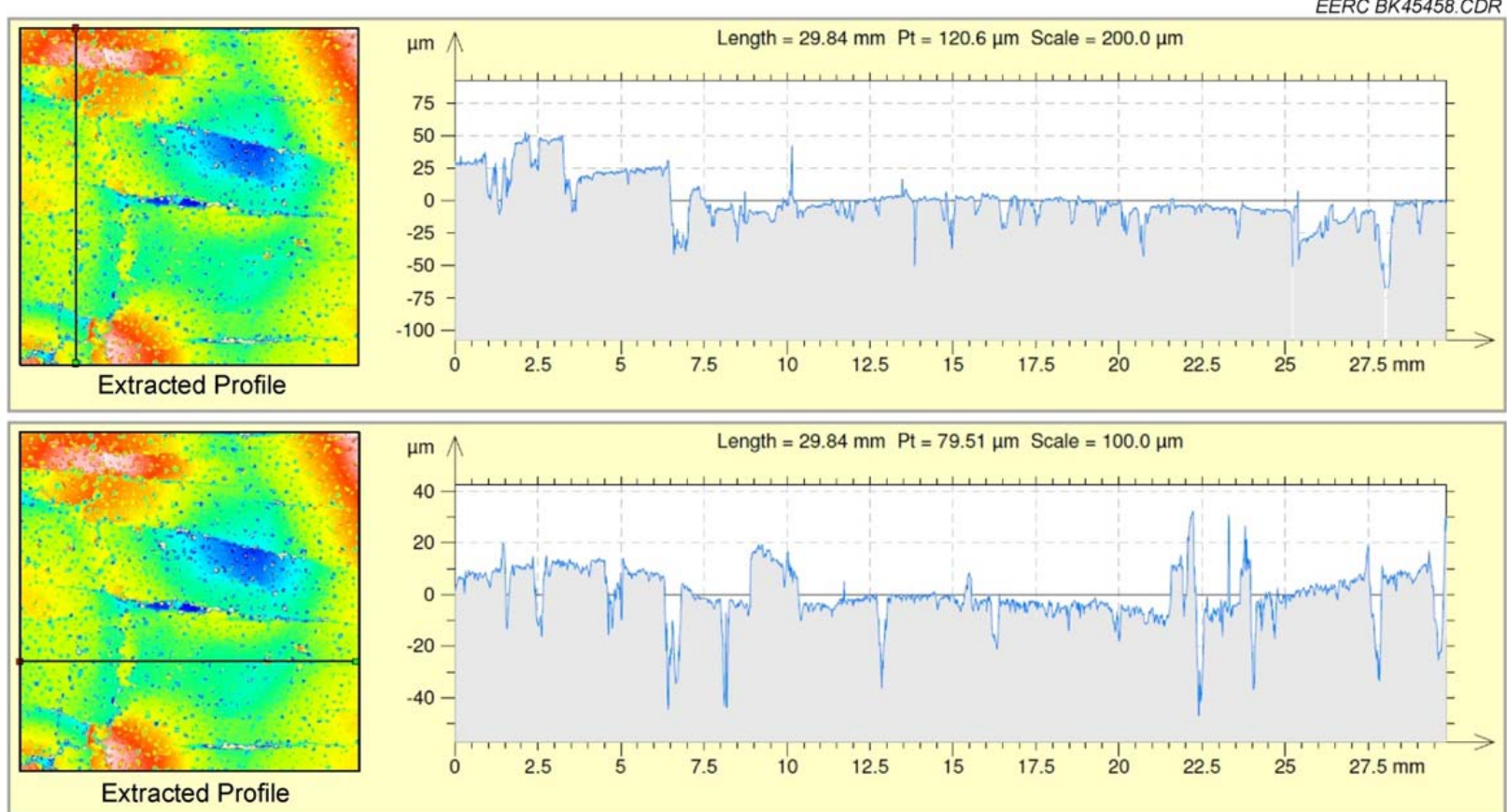

Figure 30. Cross sections taken from the top slab of the Lower Bakken rock that was run with Ottawa sand proppant.

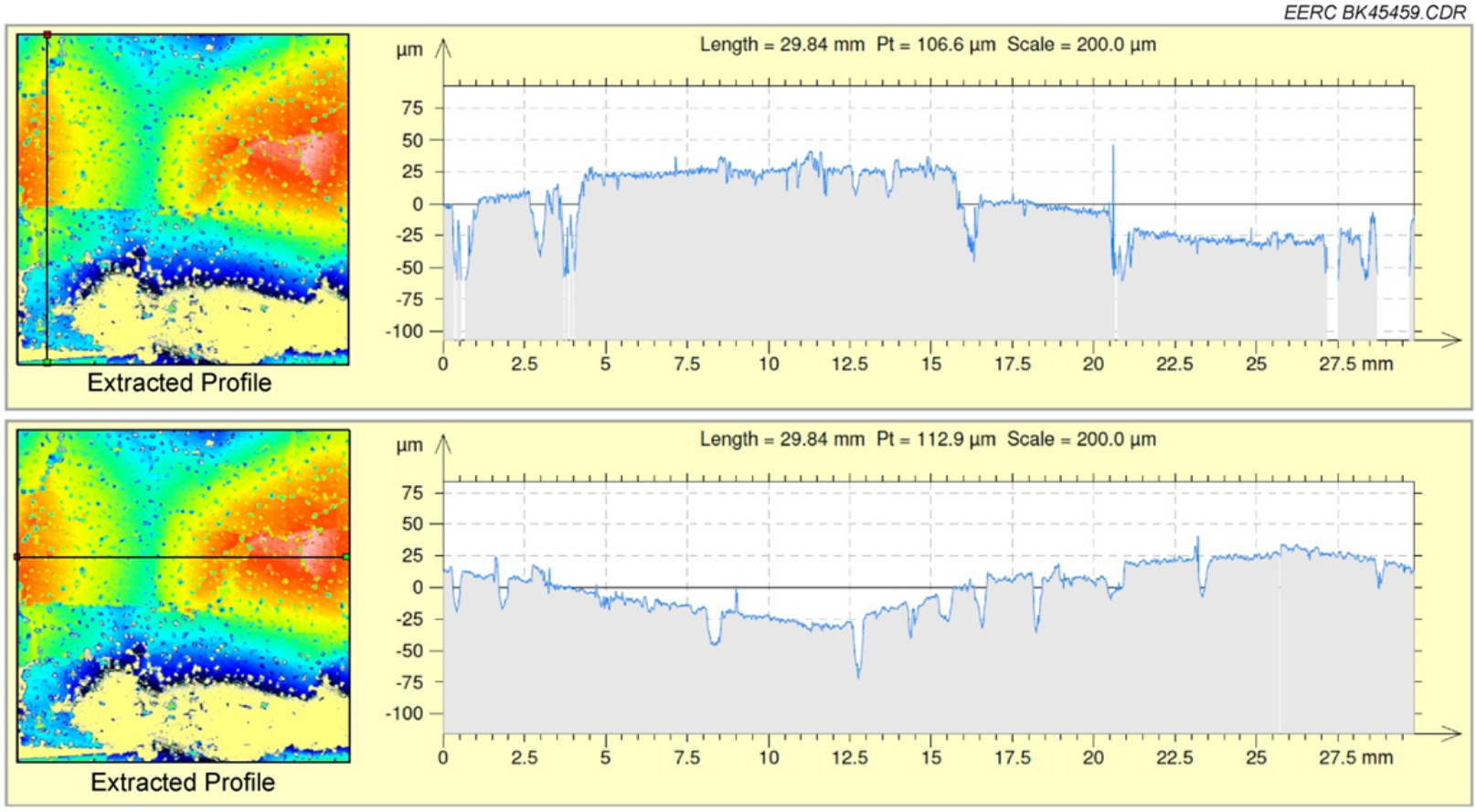

Figure 31. Cross sections taken from the top slab of the Lower Bakken rock that was run with RCS proppant. 


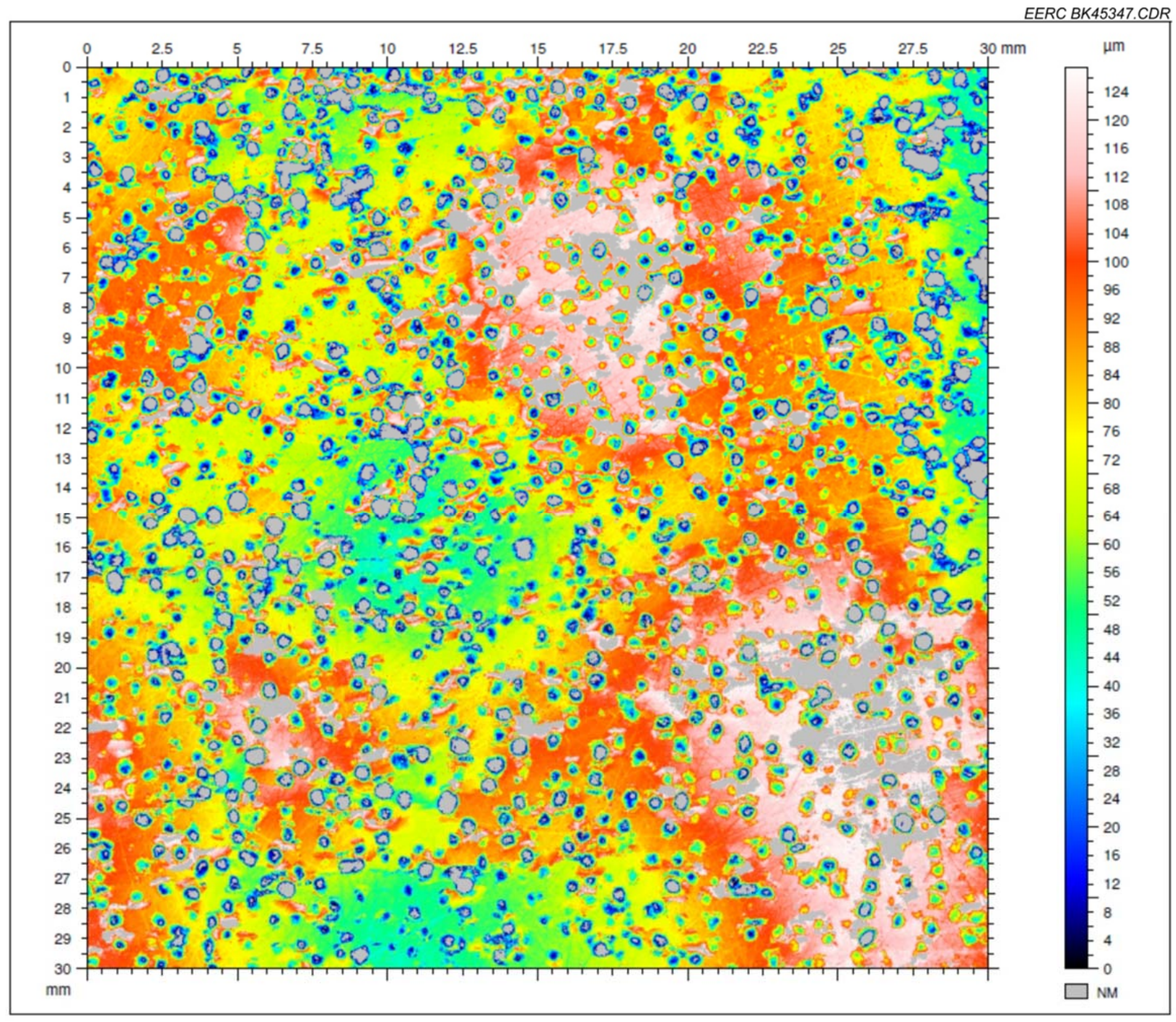

Figure 32. Optical profiler image of the top Lower Bakken slab run with ECONOPROP ceramic proppant. The areas marked as "NM" were beyond the $130-\mu \mathrm{m}$ range of the optical pen and, therefore, were not measured.

ceramic proppants, which allows for a greater degree of embedment rather than proppant failure. In both the Lower and Middle Bakken, there also appears to be a significant amount of formation spalling.

While quantifying the degree of embedment and spalling within the rock slabs used for conductivity testing was beyond the scope of this project, the software package used with the Nanovea optical profiler has the capability of doing so. This information would be very useful in determining factors such as how much embedment can account for the total amount of closure performed during the conductivity testing. Using the Lower Bakken as an example, Table 5 shows the total loss in fracture width during the conductivity testing of each proppant type, as 


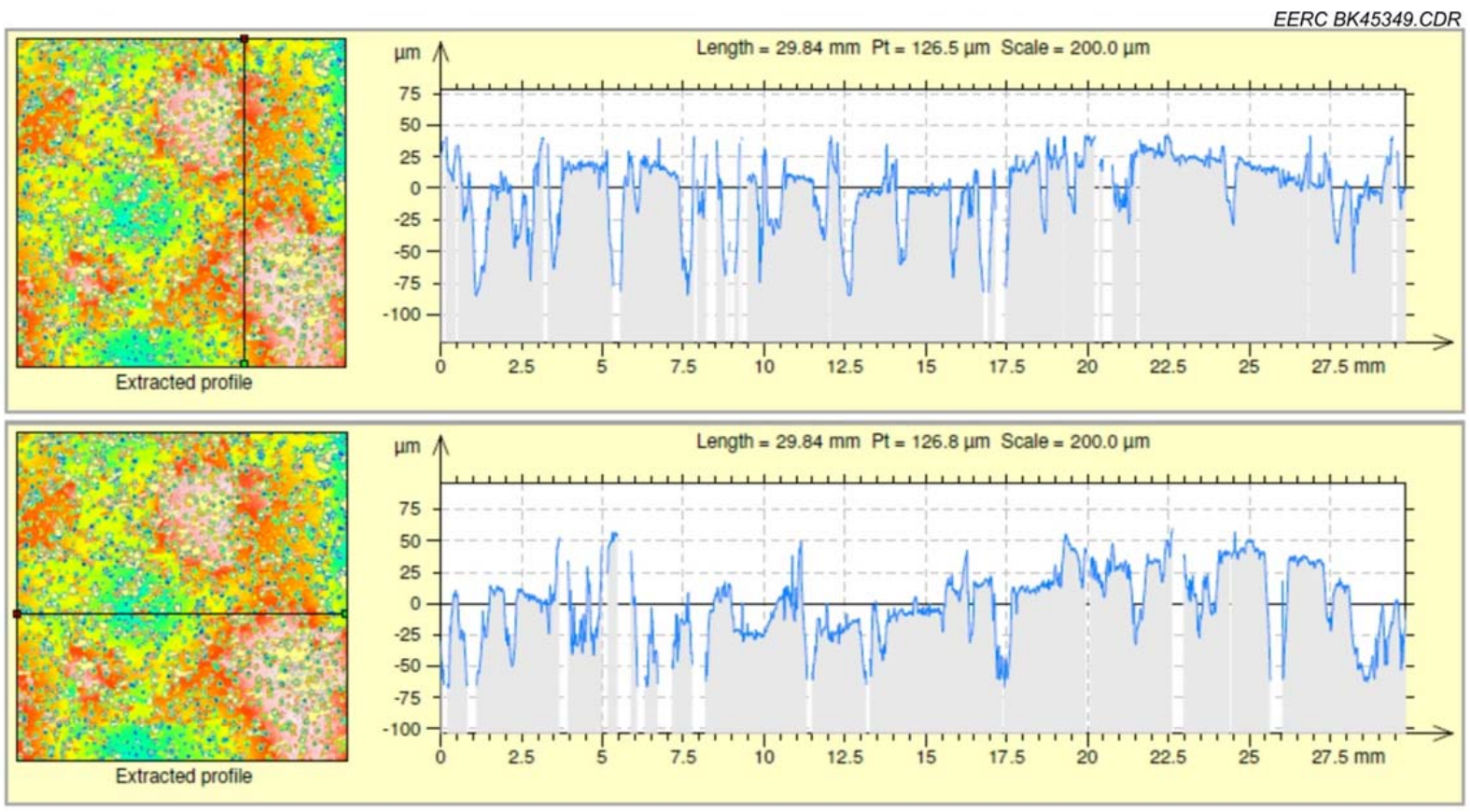

Figure 33. Cross sections taken from the top slab of the Lower Bakken rock run with ECONOPROP ceramic proppant.

well as the estimated average depth of the embedment cratering in both the top and bottom slabs of the equivalent samples. As would be expected, the percentage of fracture closer due to embedment was much lower with the Ottawa sand than with the ceramic proppant. This is because the sand fails at higher pressure and forms a more consolidated pack (with less porosity) rather than embed into the formation face. On the other hand, the ceramic proppant is able to withstand higher pressures without failure and maintain the integrity of the individual proppant grains, resulting in a higher degree of stress being applied to each individual grain. This translates to a greater degree of embedment. While the RCS embedment craters were not as deep or pronounced as the ceramic proppant craters, there was not as much fracture width loss during conductivity testing, thus embedment also accounted for about half the loss in width. It should be noted that this example was for illustrative purposes only and these numbers are only a general estimate. Ideally, the embedment data would be processed to determine a more accurate estimate of the cratering depth and the volume of proppant embedment within each slab, as well as the volume of spalling. This should be an avenue of future work.

Because very little is understood regarding the impacts of embedment and formation spalling on conductivity loss in unconventional reservoirs, this approach would be an excellent means of better understanding those factors. While this effort focused on a qualitative evaluation of embedment to better understand the conductivity results, much more data can be gleaned from this approach, including the quantification of the embedment and spalling using a variety of statistical parameters commonly used to describe surface roughness. 
EERC BK45346.CDR

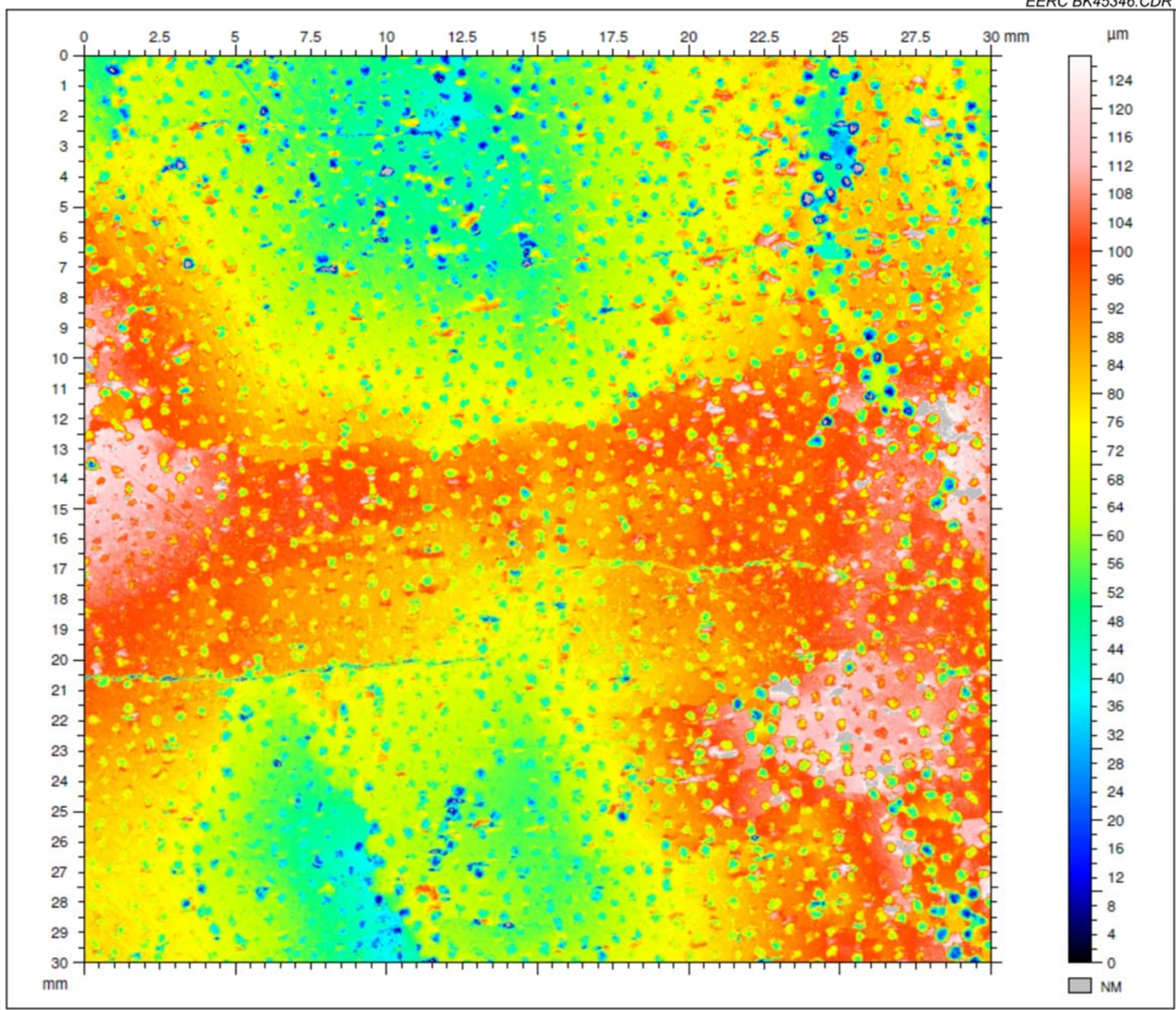

Figure 34. Optical profiler image of the bottom Lower Bakken slab run with ECONOPROP ceramic proppant. The areas marked as "NM" were beyond the $130-\mu \mathrm{m}$ range of the optical pen and, therefore, were not measured.

Table 5. Total Loss in Fracture Width During Conductivity Testing

Ottawa Sand RCS Ceramic

\begin{tabular}{lccc}
\hline Total Fracture Closure, $\mu \mathrm{m}$ & 320 & 155 & 262 \\
Approximate Top Slab Embedment Depth, $\mu \mathrm{m}$ & 40 & 50 & 75 \\
Approximate Bottom Slab Embedment Depth, $\mu \mathrm{m}$ & 15 & 25 & 50 \\
Total Approximate Embedment Depth, $\mu \mathrm{m}$ & 55 & 75 & 125 \\
Total Embedment as a Percentage of Fracture Closure & $17 \%$ & $48 \%$ & $48 \%$ \\
\hline
\end{tabular}




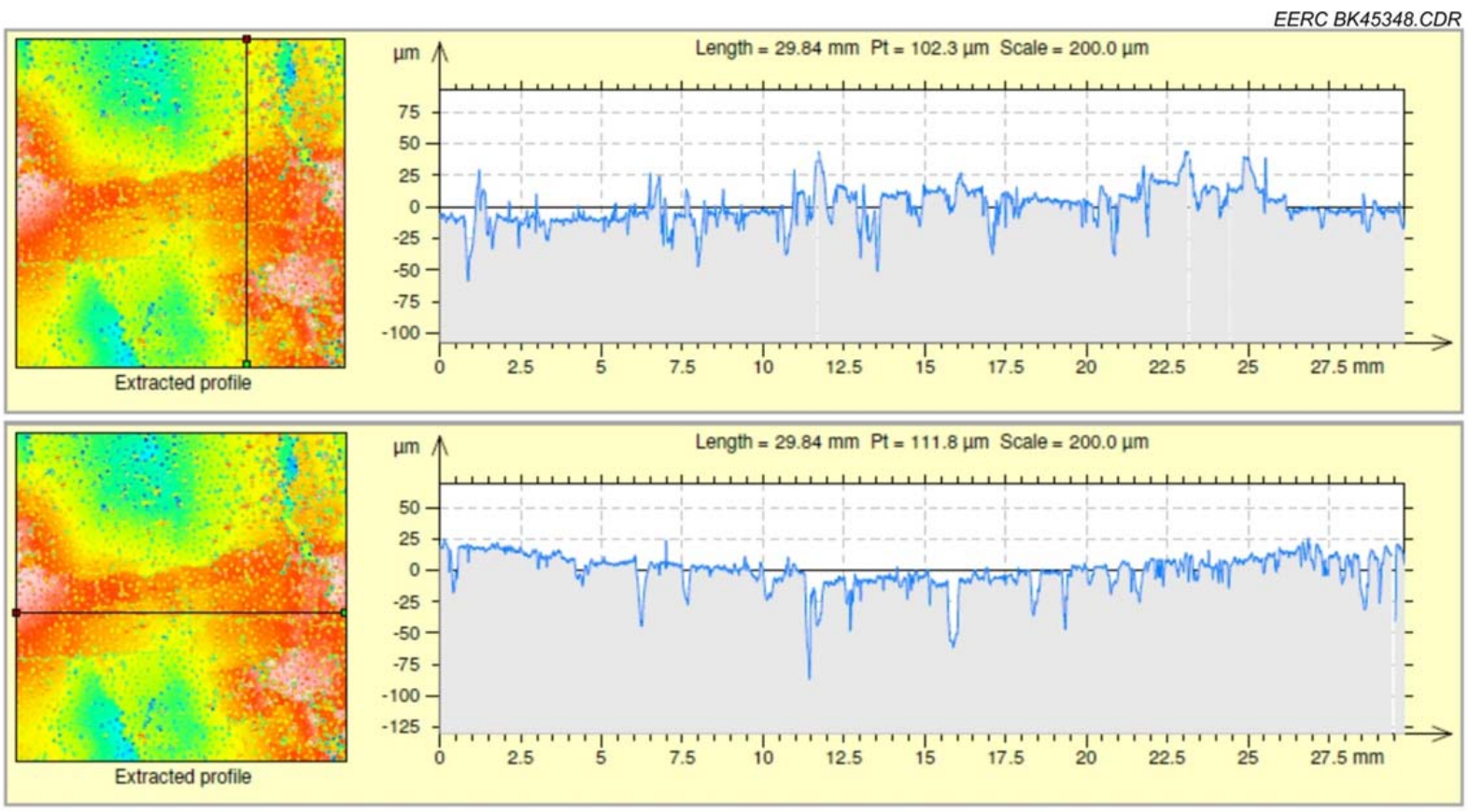

Figure 35. Cross sections taken from the bottom slab of the Lower Bakken rock run with ECONOPROP ceramic proppant.

\section{CONCLUSIONS}

Laboratory testing was conducted to examine the mechanisms that may lead to a decrease in propped fracture conductivity. Tests were completed to examine rock strength relative to fluid exposure, and tests were conducted to examine proppant strength relative to fluid exposure. The exposure studies help to isolate circumstances that may contribute to a decrease in material strength over time. Conductivity tests were conducted utilizing different proppants, and actual formation core utilized a range of proppants' actual formation cores. The conductivity tests measure propped fracture conductivity over time and provide relative performance of proppant and formation rocks. Postmortem analysis enabled an evaluation of the mechanisms that may contribute to reduced conductivity, such as spalling, embedment, or proppant crush.

Brinell hardness testing of formation core samples after exposure to fluids revealed that slickwater, and cross-linked gel to a lesser extent, consistently decreased the hardness of the formation face for Middle Bakken, Lower Bakken, and Three Forks samples. Slickwater produced the greatest decrease in rock hardness and appeared to have less of an impact on the shale than on the other formations (Middle Bakken and Three Forks). The Middle Bakken samples appeared more susceptible to strength loss when exposed to fluids than the other formations did. Rocks exposed to gelled diesel experienced very little change in rock hardness.

Proppants exposed to Bakken Formation water (brine) consistently experienced the greatest increase in strain relative to proppants that were not exposed. The strength of RCS appeared to be detrimentally affected by all fluids as compared to sand and ceramic. Fluids that 
had the greatest effect on RCS included cross-linked gel and formation oil and water. Crush test results were consistent with elastic strength results for the various proppants and fluids, noting that resin-coated products do not normally release a large quantity of crushed particles.

All types of proppants have been utilized in the Bakken Formation. While anecdotal evidence suggests that sand is an effective proppant in some areas of the Bakken (Williston Basin Petroleum Conference, May 2012), the results of this work demonstrated that the ceramic proppant was relatively unreactive and exhibited superior strength characteristics than the other proppant types following fluid exposures. RCS proppants are normally chosen to help prevent proppant flowback. However, these experiments suggest that fluid reactions with resin change the stress-strain relationship for RCS and that fluid considerations are important relative to the chosen resin.

The examination of the hardness testing in concert with the proppant strength revealed that consistency could be found relative to gelled diesel in that very little effect was evident after exposure to formation rocks and proppants. No particular fluid produced a consistent degradation of both core samples and proppant, although cross-linked gel did have a less pronounced detrimental effect on RCS and rock strength.

The results of the conductivity testing demonstrated that at effective stress ranges from 6500 to 8000 psi, the ceramic proppant exhibited much higher conductivity than Ottawa sand (as much as 5 times greater) and moderately higher conductivity than the RCS (as much as 2.3 times greater). However, this was using a solution of $2 \mathrm{wt} \% \mathrm{KCl}$. Given that the fluid exposure tests suggest that the strength of the RCS may be affected by reservoir and fracturing fluids, and that slickwater and cross-linked gels have the potential to affect rock strength, advanced conductivity testing using the various fluids would be more representative of actual reservoir conditions. Given lab results to date, we anticipate that conductivity testing using fluids more reactive than $2 \% \mathrm{KCl}$ would penalize the performance of RCS to a greater extent than sand or ceramic proppants.

A Nanovea optical profiler was used to conduct a qualitative evaluation of embedment within the rock slabs used for standard conductivity testing. The results showed that among the different rock types, the Lower Bakken displayed the highest degree of embedment and spalling, followed by the Middle Bakken. The Three Forks slabs showed significantly less embedment than the Bakken rocks. Few patterns were apparent between proppant types, except that within the Lower and Middle Bakken, there appears to be a greater degree of ceramic proppant embedment than with the other two proppant types. This is likely because of the higher strength of the ceramic proppant. While the degree of embedment and spalling would need to be fully quantified, a semiquantitative example using the Lower Bakken suggests that as much as 50\% of the fracture width loss with RCS and ceramic proppants may be due to embedment. The estimated width loss from Ottawa sand embedment was less than $20 \%$. In general, within the Bakken rock samples, the top slab of each pair showed deeper and wider embedment craters than in the bottom slab. This likely indicates some sort of particle sorting either during loading of the conductivity apparatus or during testing or an incomplete top layer of proppant in contact with the formation face, resulting in a higher degree of stress on each proppant particle. If that uneven 
distribution is not representative of field conditions, it suggests the need for an improved method of loading the conductivity apparatus.

Overall, the results of this study indicated that fluid exposure may affect both rock and proppant strength and needs to be considered in the field. In addition, conductivity decreases within the Lower and Middle Bakken appear to be a function of a variety of factors, including proppant and rock strength as well as formation embedment and spalling. Formation embedment and spalling appear to be less significant within the Three Forks Formation. Ultimately, the results of this study highlight the need for conductivity testing using actual formation and/or fracturing fluids, coupled with quantification of formation embedment and spalling. Given the importance of proppant performance on conductivity loss and, ultimately, oil recovery, a better understanding the effects of these various factors on proppant and rock strength in the field is vital for more efficient production within unconventional oil and gas reservoirs.

\section{REFERENCES}

Beckwith, R., 2011, Proppants - where in the world?: Journal of Petroleum Technology, www.spe.org/jpt/print/archives/2011/04/11ProppantShortage.pdf (accessed July 2012).

Chaudhary, A.S., Ehlig-Economides, C.E., and Wattenbarger, R., 2011, Shale oil production performance from a stimulated reservoir volume: SPE 147596.

Continental Resources Inc., 2009, Q3 earnings call transcript: November 5, 2009.

Donovan, L., 2010, Dorgan asks agency to re-evaluate Bakken: Bismarck Tribune, December 29, 2010.

Ferris, G.W., 2000, An elastic plastic approach-modeling deformation of dense sand: Department of Civil and Geological Engineering, University of Manitoba, February 2000.

Fjaer, E., Holt, R.M., Horsrud, P., Raaen, A.M., and Risnes, R., 2008, Petroleum related rock mechanics, 2d ed.: Elsevier.

Geertsma, J., 1985, Some rock mechanical aspects of oil and gas well completions: Soc. Petr. Eng. J., v. 25, p. 848-856.

Gidley, J.L., Holditch, S.A., Nierode, D.E. and Veatch, R.W., 1989, Recent advances in hydraulic fracturing: SPE Monograph Volume 12, SPE, Richardson, TX

Helms, L., Director of the Department of Mineral Resources of the Industrial Commission of the State of North Dakota, 2009, Testimony Submitted to the House Committee on Energy and Commerce, Subcommittee on Energy and Mineral Resources: June 4, 2009.

Newfield Exploration, 2009, Q\&A: http://milliondollarway.blogspot.com/2010/07/newfielddirectionalwells-in-utah.html (accessed 2010). 
Palisch, T., Duenckel, R., Bazan, L., Heidt, H., and Turk, G. 2007, Determining realistic fracture conductivity and understanding its impact on well performance - theory and field examples: SPE 106301.

Palisch, T., Duenckel, R., Chapman, M., Woolfolk, S., and Vincent, M.C., 2009, How to use and misuse proppant crush tests - exposing the top 10 myths: SPE 119242.

Panjaitan, M.L., Cherian, B.V., Mata, D., Krishnamurthy, J., and Lewis, R., 2011, A study of completion effectiveness in the Williston Basin: SPE 142388.

Rankin, R., Thibodeau, M., Vincent, M.C., and Palisch, T.T., 2010, Improved production and profitability achieved with superior completions in horizontal wells - a Bakken/Three Forks case history: SPE 134595.

Roberts, J., 2009, Gas fuels proppant prospects: docs.google.com/viewer?url= http://www.victorynickel.ca/_=resources/SF_Proppants_1109.pdf\&chrome=true $\quad$ (accessed 2010).

Sorensen, J.A., Schmidt, D.D., Smith, S.A., Bailey, T.P., Mibeck, B.A.F., and Harju, J.A., 2010, Subtask 1.2-Evaluation of key factors affecting successful oil production in the Bakken Formation, North Dakota: Final Report (October 1, 2008 - March 30, 2010) for U.S. Department of Energy National Energy Technology Laboratory Cooperative Agreement No. DE-FC26-08NT43291, Grand Forks, North Dakota, Energy \& Environmental Research Center, March.

Taylor, A., 2010, Mathistad \#1 and \#2 case history-evaluating drainage, fracturing, well performance and optimum spacing in the Bakken and Three Forks: Presented at the 2010 Maximizing Tight Oil in the Bakken Society of Petroleum Engineers Applied Technology Workshop, Keystone, Colorado, August 4-6, 2010.

Terracina, J.M., Turner, J.M., Collins, D.H., and Spillars, S.E., 2010, Proppant selection and its effect on the results of fracturing treatments performed in shale formations: SPE 135502.

Vincent, M., 2011, Optimizing transverse fractures in liquid-rich formations: Society of Petroleum Engineers, SPE 146376.

Wiley, C., Barree, B., Eberhard, M., and Lantz, T., 2004, Improved horizontal well stimulations in the Bakken Formation, Williston Basin, Montana: SPE 90697. 


\section{APPENDIX A}

\section{EXPERIMENTAL METHODS}




\section{EXPERIMENTAL METHODS}

\section{BRINELL HARDNESS ROCK STRENGTH}

\section{Preexposure Sample Preparation}

Middle Bakken Formation, Lower Bakken shale, and Three Forks Formation core was cut into rectangular cubes for performing rock strength testing with of a Brinell hardness tester. These samples were cut using a waterjet to attain the proper geometry without destroying the core (Figure A-1). Samples were prepared as follows:

- The loading surfaces of the samples were sanded flat; up to 400-grit sandpaper was used to provide a smooth surface for indentation and measurement.

- Samples were placed into jars and filled with the designated hydraulic fracturing fluids.

\section{Postexposure Sample Preparation}

After the samples were removed from the reactor, they were lightly wiped with a towel to remove surface moisture. Samples were prepared as follows:

- Upon receipt of exposed samples, the loading surfaces were very gently passed over with 400-grit sand paper to knock off any debris before testing.

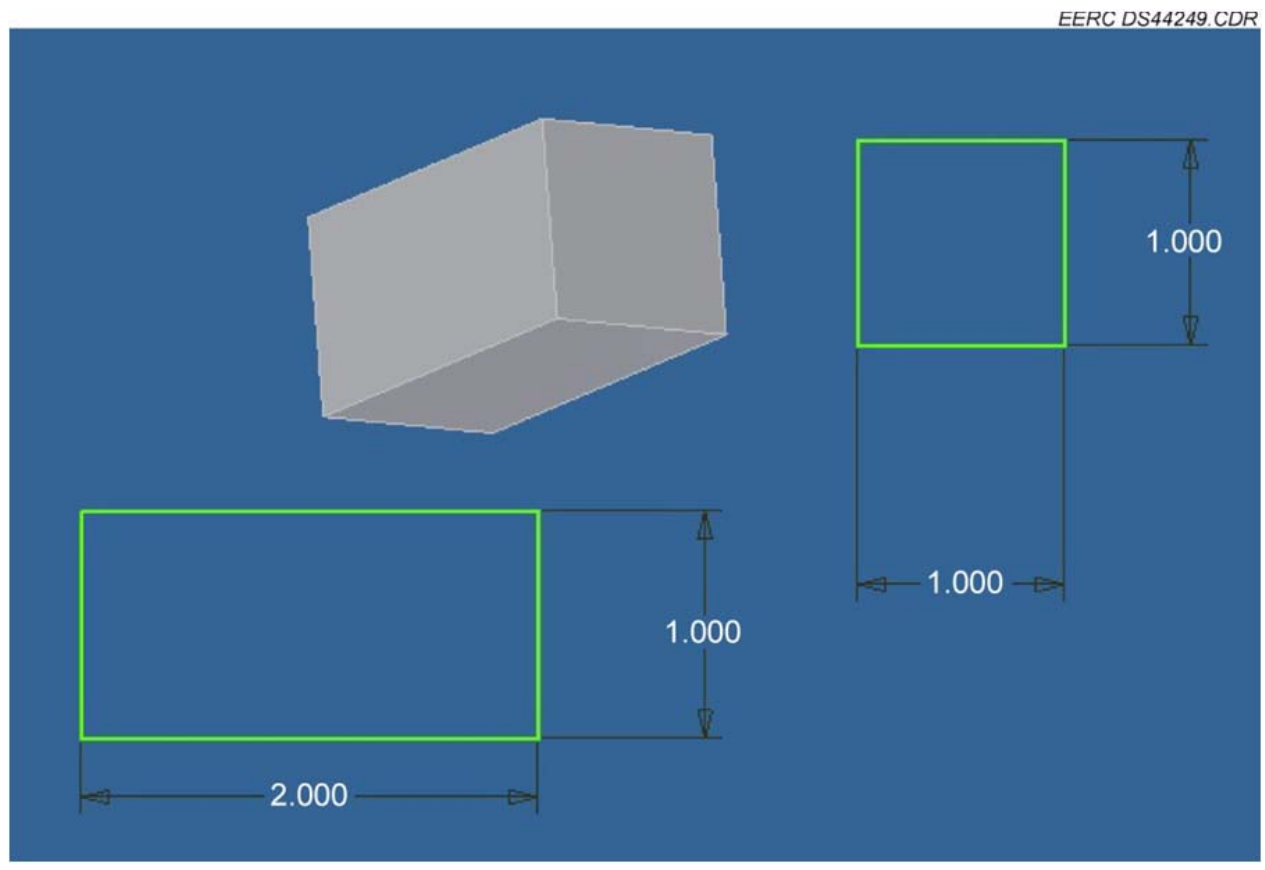

Figure A-1. Sample geometry for rock strength testing with of a Brinell hardness tester. 
- The samples were then epoxied into steel frames. RenCast 6444 was used to permanently mount each sample in the frame (Figure A-2).

- The epoxy was allowed to set for $36-48$ hours before testing to ensure it was fully hardened.

\section{Brinell Hardness Testing Procedure}

Brinell hardness test procedures for rock core samples were developed based on "Draft ISRM Suggested Method for Determination of Indentation Hardness of Rock Materials" and modified slightly during experimental testing to reduce instances of complete material failure as a result of the limited sample size and the extremely brittle nature of the material being tested. The International Society for Rock Mechanics (ISRM) method suggests the following parameters:

- Load rates between 0.05 and $0.15 \mathrm{kN} / \mathrm{s}(5.1$ and $15.3 \mathrm{kgf} / \mathrm{s})$.

- Load is applied until a 1-mm crater depth is reached or until $20 \mathrm{kN}$ (2039.4 kgf) maximum load is reached.

- Indenter consists of a 10-mm-diameter spherical tip that transitions into a 60 degree cone made of tungsten carbide or hardened steel.

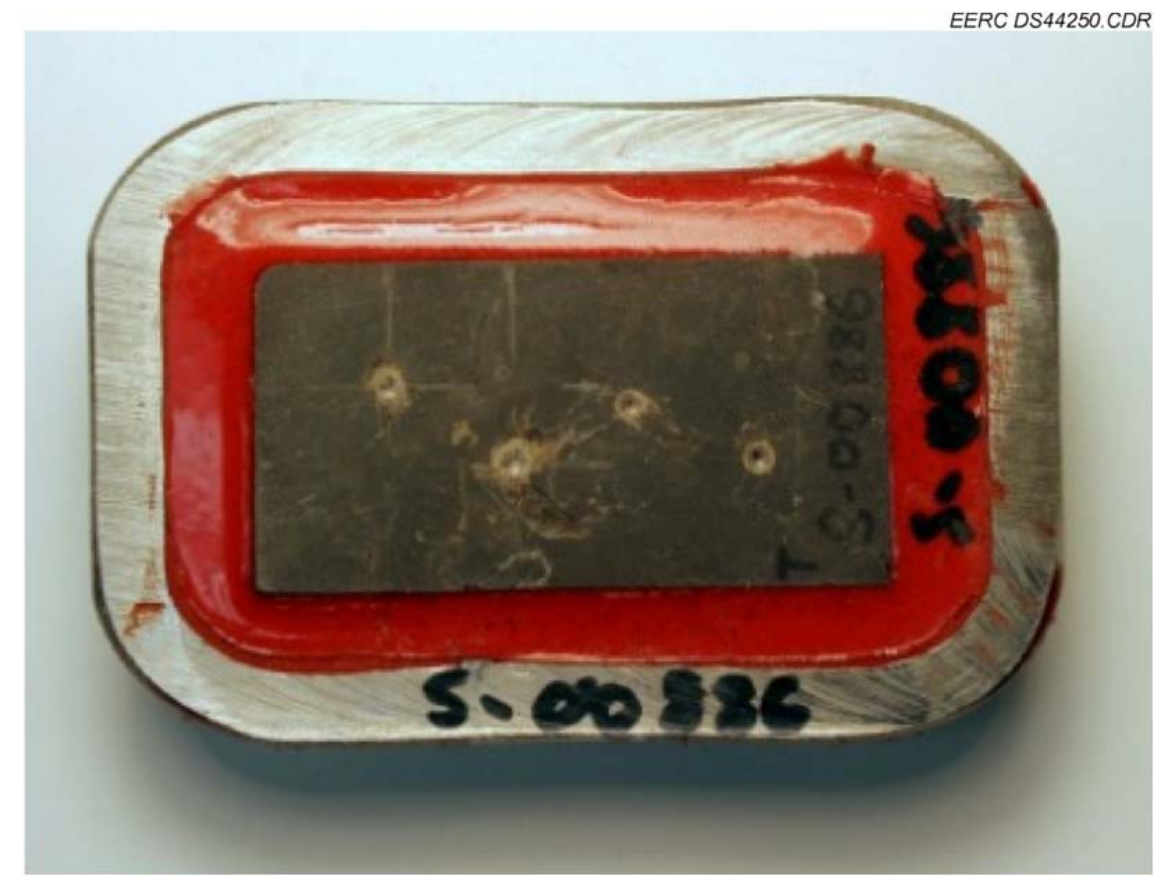

Figure A-2. Rock sample (posttesting) epoxied in a steel ring to assist in sample competency without giving it any drastic increase in strength. 
- The preferred sample is a disk cut from rock core with a height-to-diameter ratio of 1:2. - Block samples with a width of $50 \mathrm{~mm}$ or larger.

- Samples should be cemented in a steel frame using high-strength plaster, epoxy resin, or sulfur.

- Indentations must be performed at least $10 \mathrm{~mm}$ from other indentations and the edge of the sample.

- Spherical indentation tips can range in size from 1 to $10 \mathrm{~mm}$.

- Standard sizes include $2.5,5$, and $10 \mathrm{~mm}$.

- A standard test consists of applying a 3000-kg load with a dwell time of 15 seconds, during which the load is maintained, and uses a 10-mm indentation tip.

- Current standards specify that the indentation tip be made of tungsten carbide. Hardened steel is no longer recommended.

- The recorded load and the indentation tip diameter are to be displayed with the calculated hardness.

- Example: BHN $150(10 / 3,000)$, where:

$$
\begin{array}{ll}
>150 & =\text { Brinell hardness } \\
>10 & =\text { indentation tip diameter } \\
>3000 & =\text { applied load }
\end{array}
$$

\section{Developed Test Procedure}

- Brinell hardness is currently more widely used and accepted than the draft ISRM method. Samples were roughly $50 \%$ smaller than that recommended by the ISRM standard for indentation of rock core and were primarily shale samples that were expected to be extremely delicate. A 5-mm-diameter indentation tip was used, as opposed to the 10-mm tip suggested by the ISRM standard. Reducing the indentation tip to $5 \mathrm{~mm}$ was determined to be appropriate because of the small grain size and the tight nature of the rock to be tested. The smaller tip allowed the use of significantly reduced loading requirements for creating a measureable indentation. This was a requirement to help prevent catastrophic failure of the samples during testing because of their small size. Using the smaller tip also allowed more indentations per sample in an effort to obtain multiple measurements of good quality.

- Pierre shale was used to verify load application methods. Testing of Pierre shale revealed that a maximum of a $350-\mathrm{kg}$ load could be applied, and the indentation depth would be limited to $0.4 \mathrm{~mm}$. Loading was maintained for 15 seconds when either of these limits were reached. Indentations in excess of a $0.5-\mathrm{mm}$ depth caused sporadic material failure in Pierre shale samples. Indentations with a depth of $0.4 \mathrm{~mm}$ were measured with optical methods. During the course of testing Bakken shale samples, it was determined that excessive cracking and 
breakage were occurring in some samples, prompting reduction of both the maximum load applied and maximum indentation depth to $200 \mathrm{~kg}$ and $0.325 \mathrm{~mm}$, respectively.

\section{EXAMINATION OF PROPPANT PACK MECHANICAL PROPERTIES}

Five samples of each type of proppant were weighed and loaded into vials. Appropiate hydraulic fracturing fluids were added. Vials were loaded into pressure reactors, and a vial of distilled water was included as a ballast to limit vaporization.

\section{Postexposure Sample Preparation}

The following is the washing method used for removal of the proppant from the vials after reaction at $3000 \mathrm{psi}$ and $250^{\circ} \mathrm{F}$; each sample:

- Was washed out of its respective vial using distilled water.

- Decanted.

- Submerged in toluene, agitated for 15 seconds, and let sit for 30 seconds.

- Decanted; if not clear, the toluene wash step was repeated.

- Submerged in 10\% $\mathrm{HCl}$ solution, agitated for 15 seconds, and let sit for 30 seconds.

- Decanted; if still not clear, the $\mathrm{HCl}$ wash step was repeated (note: only the cross-linked gel sample required this extra step).

- Washed with distilled water and placed into labeled weigh trays.

- Decanted of any excess fluids.

- Was placed into the vented hood oven at a low setting $\left(\sim 125^{\circ} \mathrm{F}\right)$.

\section{Preexposure and Postexposure Strength Testing and Sieve Analysis}

Sieve analysis, grain-size distribution, and elastic test procedure:

- After being removed from the reactor vessel, samples were cleaned and dried.

- Each sample was sieved with a sonic sifter sieve for 10 minutes using the pulse/shift setting.

- The mass of each size component of the proppant was recorded, and the sample was carefully mixed back together in a sealed glass jar. 
- The sample was carefully poured from the jar and loaded into the crush apparatus until a 25.4-mm-diameter by 10 -mm-deep proppant bed was attained. The proppant depth measurement accuracy was $\pm 0.05 \mathrm{~mm}$.

- The assembly was then placed into the load frame and loaded at a rate of $4 \mu \mathrm{m} / \mathrm{s}$. The load rate was maintained by closed-loop computer control until a load of 11,675 psi was reached.

- The load was then slowly retracted.

- The crushed sample was removed from the apparatus for final sieve analysis.

- Any leftover sample that was not crushed was saved and also sieved. 
APPENDIX B

\section{FORMATION FLUID ANALYSIS}




\section{FORMATION FLUID ANALYSIS}

\section{FRACTURE FLUID COMPOSITIONS}

\section{Cross-Linked Gel (for 1 liter of water)}

Guar

Borate cross-linker solution

$\mathrm{NaOH}$ solution

Biocide (glutaraldehyde) solution

Scale inhibitor phosphate
$3 \mathrm{~g}$ (stir vigorously to dissolve)

$0.65 \mathrm{~mL}$ (stir vigorously to dissolve) add dropwise to adjust $\mathrm{pH}$ to $10.5-11$

$1.5 \mathrm{~mL}$ (stir vigorously)

$1.5 \mathrm{~g}$ (stir vigorously)

\section{Slickwater (for 1 liter of water)}

Polyacrylamide $0.76 \mathrm{~g}$ (stir vigorously to dissolve)

Biocide $1.5 \mathrm{~mL}$ (stir vigorously to dissolve)

No scale inhibitor added according to instructions

\section{Gelled Diesel (for 1 liter of No. 2 diesel fuel)}

Dioctyl phosphate $10 \mathrm{~g}$ (stir vigorously to dissolve)

Sodium aluminate $4 \mathrm{~g}$ (stir vigorously to dissolve)

No scale inhibitor or biocide needed 


\section{ASTRO-CHEM LAB, INC.}

4102 2nd Ave. West

Williston, North Dakota 58802-0972

P.O. Box 972

WATER ANALYSIS REPORT

SAMPLE NUMBER W-11-4705 DATE OF AINALYSIS 9-2E-11

COMPANY EERC

CITY Grand Forks

STATE ND

WELL NAME AND/OR NUMBER

Phoenix 1-18H (Slawson) \#4

DATE RECEIUED $\quad 9-7-11$

DST NUMBER

SAMPLE SOURCE

LOCATION OF SEC.

EORMATION Bakken

DEPTH

\section{DISTRIBUTION Darren Schmidt}

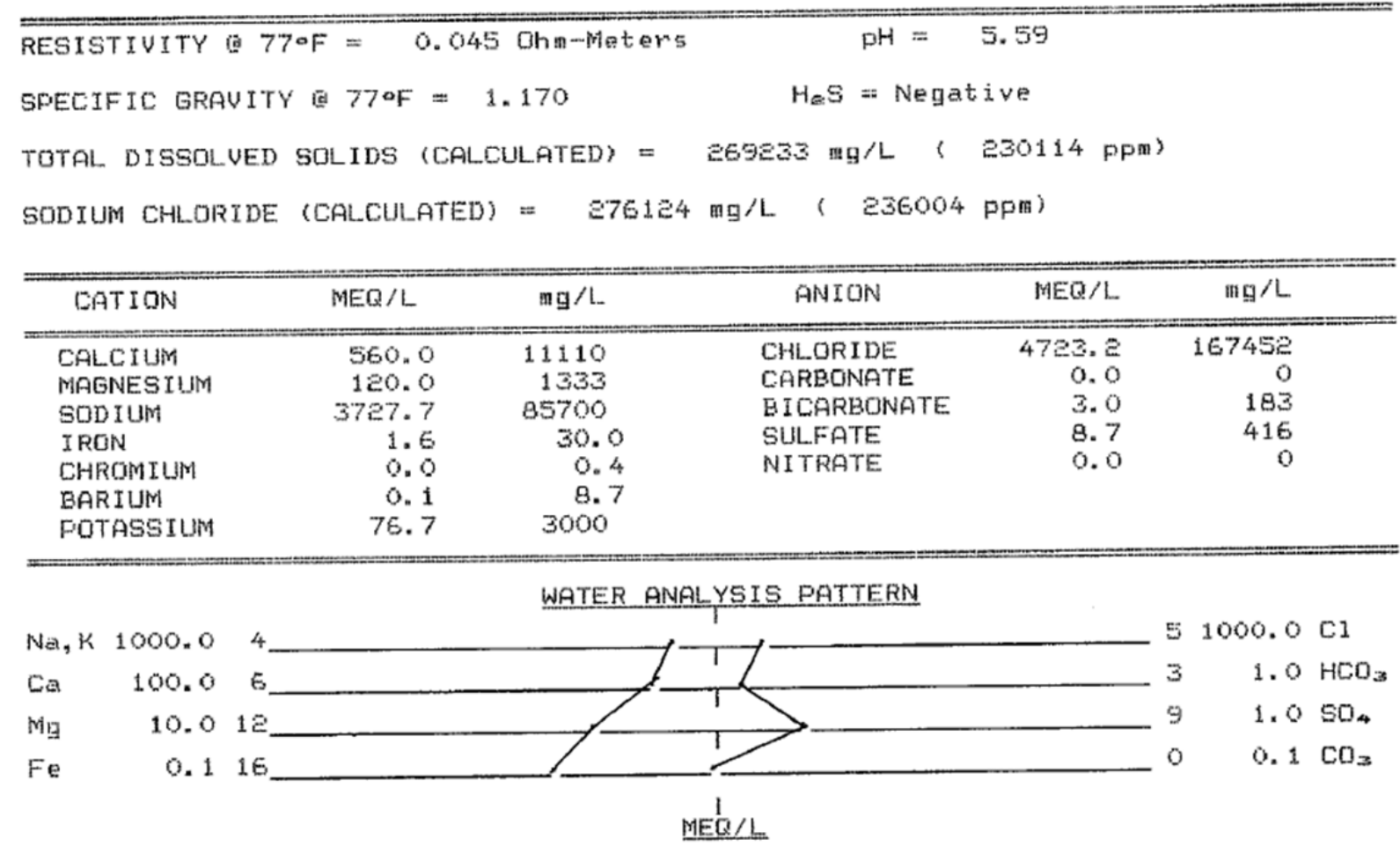

REMARKS Sampled 3-6-11 


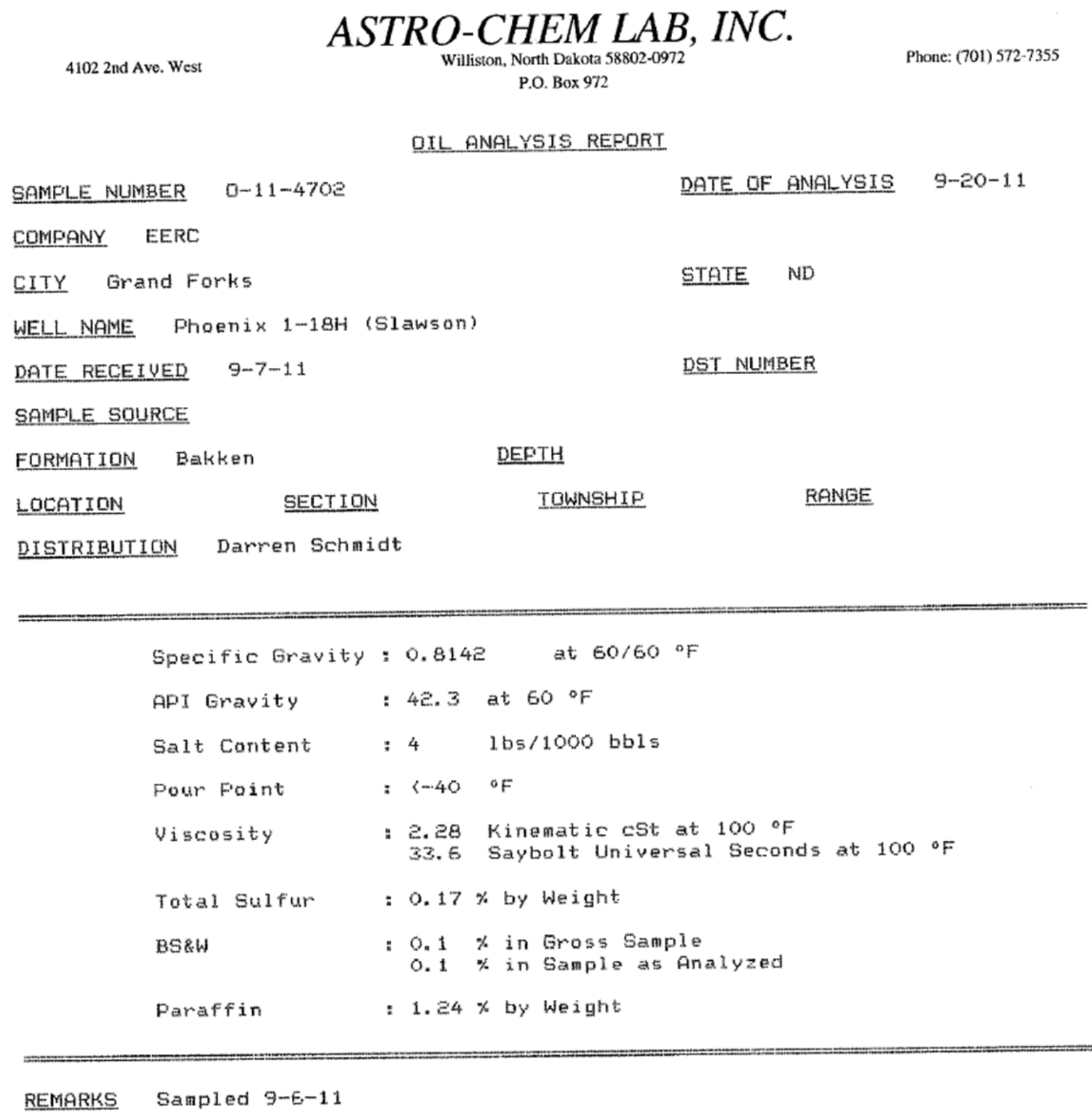

Notice how the sand-based proppant in Figure 28 is exhibits elastic behavior at stresses less than 7000 psi and begins to exhibit more plastic behavior above 7000 psi. It is at this point in which the sand appears to begin to crush. The failure sand can be described as similar to glass in which numerous small shards and particles are produced. The resin-coated sand exhibits a linear behavior throughout the majority of the stress-strain relationship. Above 7000 psi, it is anticipated that the resin is preventing increased strain by encapsulating the particles produced from grain failure. The ceramic proppant exhibits a linear behavior much like the RCS; however, some increase in strain is evident above 9000 psi. Ceramic proppants behave similar to brick during failure in which they cleave into fewer larger pieces. There is less strain associated with this type of failure as compared to the fracturing of sand which produces a greater number of smaller particles. 
APPENDIX C

\section{CONDUCTIVITY TESTING}




\section{LAB REPORT}

For: Darren Schmidt, University of North Dakota

Date:

April 22, 2012

From: Tom Palamara

Electronic Copy To: Bob Duenckel

Technical Summary

\section{$\underline{\text { Subject }}$}

Long Term Comparison of various proppant utilizing Bakken shale cores and Ohio sandstone cores.

\section{Purpose}

Long term conductivity testing was completed on Ottawa sand 20/40, Slawson Resin Coated sand 20/40, and CARBOECONOPROP20/40 in Middle Bakken shale cores, Lower Bakken shale cores, and Three Forks shale cores. CARBOECONOPROP20/40 was also evaluated in each of three tests utilizing Ohio sandstone cores. The shale cores were supplied to CARBO Ceramics Inc by The University of North Dakota Energy and Environmental Research Center.

\section{Procedures}

ISO 13503-5 Procedures for measuring the long-term conductivity of proppants were utilized.

\section{Conditions}

Bakken shale cores and Ohio sandstone cores

6500 psi net closure stress for $0,5,20,30$, and 50 hours

8000 psi net closure stress for 0,5 , and 20 hours

500 psi backpressure

$2.0 \mathrm{lb} / \mathrm{ft}^{2}$ loading

$2 \mathrm{wt} \% \mathrm{KCl}$ solution

$200^{\circ}$ Fahrenheit 


\section{List of Tables and Figures}

Table 1: Long Term Test Conditions and Product Properties

Table 2: Long Term Conductivity Test Results

Figure 1: Long Term Conductivity Results

Figure 2: Long Term Permeability Results

Figure 3: Long Term Fracture Width Results

\section{Results and Discussion}

Long term conductivity testing was completed on Ottawa sand 20/40, Slawson RCS 20/40, and CARBOECONOPROP20/40 utilizing Middle Bakken shale cores, Lower Bakken shale cores, Three Forks shale cores and Ohio sandstone cores.

All of the shale cores were supplied to CARBO Ceramics Inc by The University of North Dakota Energy and Environment Research Center, EERC. EERC also supplied the samples of Ottawa sand 20/40 and Slawson RCS 20/40. These samples were tested as received. CARBO Ceramics provided the CARBOECONOPROP20/40.

The Middle Bakken shale cores were supplied as whole pieces while the Lower Bakken and Three Forks were $1 / 2$ cores, approximately 3.5 " in length each. The Ohio sandstone cores were whole cores.

For all of the shale cores, the cores were glued to a stainless steel shim to facilitate loading the cores without breaking the fragile shale cores. In some cases, the cores as supplied were broken. Loctite Super Glue was utilized. Prior to gluing the shale cores to the shims, the broken areas, or seamed areas were coated with Loctite 2 part Weld Bonding adhesive. After gluing and drying, the core surfaces were machined to yield a core within the end to end thickness difference of $+/-0.003$ ".

The long term run numbers, sample identifications, product properties, and testing conditions are shown in Table 1. Three long term tests were completed: CCLT1-1206 with three cells of Middle Bakken cores, CCLT1-1207 with three cells of Lower Bakken shale cores, and CCLT1-1208 with three cells of Three Forks shale cores. A fourth cell in each test was also included utilizing Ohio sandstone cores. In each of the tests, Ottawa sand 20/40 was always in cell 1, Slawson RCS 20/40 in cell 2, CARBOECONOPROP20/40 with shale cores in cell 3, and CARBOECONOPROP20/40 with Ohio sandstone cores in cell 4. Note the Slawson RCS $20 / 40$ sieve distribution with $2.3 \mathrm{wt} \%$ of the material in the pan. As noted earlier, the product was tested as received.

The conductivity performance results for each of the tests are shown in Table 2.

Figure 1 shows the conductivity performance results for all of the tests. The Ottawa 20/40 sand shows the lowest performance for each of the products tested. The Ottawa sand 20/40 performance in Lower Bakken cores provided the highest results for this sand.

Also in Figure 1, the performance for Slawson RCS 20/40 is shown to be greater than that of Ottawa 20/40 sand however less than that of CARBOECONOPROP20/40 in all shale cores testing and Ohio sandstone. The spread of the data for Slawson RCS 20/40, specifically the data for Three Forks shale, seems abnormally high relative to Middle and Lower Bakken shale data. It is not fully clear in post test observation what may have happened in the cell interior to cause this increased performance - ie lower $\mathrm{dP}$ for equivalent product and proppant concentration. 
The performance data for CARBOECONOPROP20/40 is superior to both Ottawa 20/40 sand and Slawson RCS 20/40. The data for Middle Bakken shale cores is the lowest of the set with five remaining tests showing similar performance. The data for Slawson RCS 20/40 is also the lowest for Middle Bakken shale cores possibility indicating the cores is responsible for some of the observed conductivity differences.

The permeability performance results for all of the tests are shown in Figure 2 with the Fracture Width measurement data shown in Figure 3. The fracture width comparisons are difficult to see significant trend difference for any of the materials of effects of the various cores. All of the products have very similar bulk densities so measured widths should be similar for equivalent concentration.

The post test cores and materials form these tests have been returned EERC.

\section{Conclusions}

- CARBOECONOPROP20/40 is superior in performance to Ottawa 20/40 sand and Slawson RCS 20/40 in both Bakken shale cores and Ohio sandstone cores.

- Slawson RCS 20/40 is superior in performance to Ottawa 20/40 sand in both Bakken shale cores and Ohio sandstone cores.

- The Slawson RCS 20/40 material was received out of ISO specifications with $>1.0 \mathrm{wt} \%$ material in the sieve test pan.

- CARBO Ceramics Luoyang long term laboratory successfully completed multiple tests with 9 pairs of various Bakken shale cores as supplied by EERC. 


\section{Table 1}

\section{Long Term Tests: CCLT1 -1206, CCLT1-1207, CCLT1-1208}

Cell 1: Ottawa 20/40 sand, 2/27/12

Cell 2: Slawson RCS 20/40, 2/27/12
Property of CARBO Ceramics

Cell 3: CEP20/40, 41108, 8/12-14/11

Cell 4: CEP20/40, 41108, 8/12-14/11

\begin{tabular}{|c|c|c|c|c|c|c|}
\hline \multicolumn{7}{|l|}{ Cell 2. S } \\
\hline \multicolumn{7}{|c|}{ Test Conditions } \\
\hline & & & Cell 1 & Cell 2 & Cell 3 & Cell 4 \\
\hline CCLT1-1206 Cores & & & Middle Bakken \#2 & Middle Bakken \#5 & Middle Bakken \#7 & Ohio \\
\hline CCLT1-1207 Cores & & & Lower Bakken \#11 & Lower Bakken \#18 & Lower Bakken \#19 & Ohio \\
\hline CCLT1-1208 Cores & & & Three Forks \#28 & Three Forks \#33 & Three Forks \#34 & Ohio \\
\hline Proppant Loading & & \#/sqft & 2 & 2 & 2 & 2 \\
\hline Stress or Stress Range & & psi & $6.5 \mathrm{k} \& 8 \mathrm{k}$ & $6.5 \mathrm{k} \& 8 \mathrm{k}$ & $6.5 \mathrm{k} \& 8 \mathrm{k}$ & $6.5 \mathrm{k} \& 8 \mathrm{k}$ \\
\hline Fluid - Concentration & & & $2 \mathrm{wt} \%-\mathrm{KCl}$ & $2 \mathrm{wt} \%-\mathrm{KCl}$ & $2 \mathrm{wt} \%-\mathrm{KCl}$ & $2 w t \%-K C l$ \\
\hline Temperature & & $\operatorname{Deg} F$ & $200 \mathrm{~F}$ & $200 \mathrm{~F}$ & $200 \mathrm{~F}$ & $200 \mathrm{~F}$ \\
\hline Backpressure & & psi & 500 & 500 & 500 & 500 \\
\hline Time- Hours at $6.5 \mathrm{kpsi}$ net pressure & & Hrs & $0,5,20,30,50$ & $0,5,20,30,50$ & $0,5,20,30,50$ & $0,5,20,30,50$ \\
\hline Time- Hours at $8.0 \mathrm{kpsi}$ net pressure & & Hrs & $0,5,20$ & $0,5,20$ & $0,5,20$ & $0,5,20$ \\
\hline \multicolumn{7}{|c|}{ Product Properties } \\
\hline \multirow{24}{*}{ Sieves } & Diameter( $\mu \mathrm{m})$ & Mesh & Cell 1 & Cell 2 & Cell 3 & Cell 4 \\
\hline & $4750^{\prime}$ & 4 & & & & \\
\hline & $3350^{\prime}$ & 6 & & & & \\
\hline & $2360^{\prime}$ & 8 & & & & \\
\hline & $2000^{r}$ & 10 & & & & \\
\hline & $1700^{\prime}$ & 12 & & & & \\
\hline & $1400^{\prime}$ & 14 & & & & \\
\hline & $1180^{\prime}$ & 16 & 0.0 & 0.5 & 0.0 & 0.0 \\
\hline & $1000^{r}$ & 18 & & & & \\
\hline & 850 & 20 & 1.0 & 7.1 & 3.6 & 3.6 \\
\hline & 710 & 25 & 7.3 & 32.3 & 22.0 & 22.0 \\
\hline & 600 & 30 & 20.2 & 41.0 & 44.3 & 44.3 \\
\hline & 500 & 35 & 39.6 & 11.6 & 29.7 & 29.7 \\
\hline & 425 & 40 & 25.8 & 3.0 & 0.4 & 0.4 \\
\hline & $355^{\prime}$ & 45 & & & & \\
\hline & $300^{\prime}$ & 50 & 5.8 & 2.2 & 0.0 & 0.0 \\
\hline & $250^{\prime}$ & 60 & & & & \\
\hline & 212 & 70 & & & & \\
\hline & $180^{\prime}$ & 80 & & & & \\
\hline & $150^{\prime}$ & 100 & & & & \\
\hline & 125 & Pan & 0.3 & 2.3 & 0.0 & 0.0 \\
\hline & Total & & 100.0 & 100.0 & 100.0 & 100.0 \\
\hline & MPD & $\mu \mathrm{m}$ & 555 & 681 & 660 & 660 \\
\hline & MPD Dev & $\mu \mathrm{m}$ & 113.3 & 150.0 & 97.2 & 97.2 \\
\hline BD & & $g / c c$ & 1.52 & 1.54 & 1.51 & 1.51 \\
\hline \multirow[t]{3}{*}{ ASG } & & & 2.64 & 2.43 & 2.67 & 2.67 \\
\hline & $5.0 \mathrm{k}$ & $w t \%$ & & & 0.9 & 0.9 \\
\hline & 7.5 & $w t \%$ & & & 4.2 & 4.2 \\
\hline \multirow[t]{3}{*}{ API Crush } & $10.0 \mathrm{k}$ & $w t \%$ & & & 9.4 & 9.4 \\
\hline & $12.5 \mathrm{k}$ & $w t \%$ & & & & \\
\hline & $15.0 \mathrm{k}$ & $w t \%$ & & & & \\
\hline LOI & & $\mathrm{wt} \%$ & & & & \\
\hline Acid Solubility & & $\mathbf{w t} \%$ & & & 2.2 & 2.2 \\
\hline Roundness & & & & & 0.88 & 0.88 \\
\hline Sphericity & & & & & 0.87 & 0.87 \\
\hline Turbidity & & NTU & & & 71 & 71 \\
\hline
\end{tabular}


Table 2

Long Term Conductivity Test Results

\begin{tabular}{|c|c|c|c|c|c|c|c|c|c|c|c|c|}
\hline & $\begin{array}{c}\text { CCLT1-1206 - } \\
\text { Cell } 1\end{array}$ & $\begin{array}{c}\text { CCLT1-1206 - } \\
\text { Cell } 2\end{array}$ & $\begin{array}{c}\text { CCLT1-1206 - } \\
\text { Cell } 3\end{array}$ & $\begin{array}{l}\text { CCLT1-1206 - } \\
\text { Cell } 4\end{array}$ & $\begin{array}{l}\text { CCLT1-1207 - } \\
\text { Cell } 1\end{array}$ & $\begin{array}{l}\text { CCLT1-1207 - } \\
\text { Cell } 2\end{array}$ & $\begin{array}{l}\text { CCLT1-1207 - } \\
\text { Cell } 3\end{array}$ & $\begin{array}{l}\text { CCLT1-1207 - } \\
\text { Cell } 4\end{array}$ & $\begin{array}{l}\text { CCLT1-1208 - } \\
\text { Cell } 1\end{array}$ & $\begin{array}{l}\text { CCLT1-1208 - } \\
\text { Cell 2 }\end{array}$ & $\begin{array}{l}\text { CCLT1-1208 - } \\
\text { Cell } 3\end{array}$ & $\begin{array}{l}\text { CCLT1-1208 } \\
\text { Cell } 4\end{array}$ \\
\hline Product & $\begin{array}{l}\text { Ottawa 20/40 } \\
\text { sand }\end{array}$ & $\begin{array}{c}\text { Slawson RCS } \\
20 / 40\end{array}$ & CEP20/40 & CEP20/40 Ohio & $\begin{array}{l}\text { Ottawa 20/40 } \\
\text { sand }\end{array}$ & $\begin{array}{c}\text { Slawson RCS } \\
20 / 40\end{array}$ & CEP20/40 & CEP20/40 Ohio & $\begin{array}{l}\text { Ottawa 20/40 } \\
\text { sand }\end{array}$ & $\begin{array}{c}\text { Slawson RCS } \\
20 / 40\end{array}$ & CEP20/40 & CEP20/40 Ohic \\
\hline Stress (psi) & \multicolumn{12}{|c|}{ Permeability (D) } \\
\hline 6500 (0hrs) & 73 & 102 & 206 & 228 & 71 & 128 & 231 & 233 & 64 & 177 & 221 & 220 \\
\hline 6500 (5hrs) & 59 & 89 & 202 & 225 & 57 & 104 & 217 & 224 & 56 & 162 & 213 & 214 \\
\hline 6500 (20hrs) & 50 & 87 & 199 & 224 & 53 & 96 & 215 & 221 & 47 & 148 & 207 & 213 \\
\hline 6500 (30hrs) & 48 & 81 & 191 & 222 & 52 & 96 & 214 & 220 & 46 & 144 & 204 & 212 \\
\hline 6500 (50hrs) & 48 & 81 & 190 & 221 & 50 & 90 & 212 & 219 & 45 & 144 & 203 & 212 \\
\hline 8000 (0hrs) & 47 & 78 & 156 & 178 & 47 & 87 & 173 & 180 & 42 & 138 & 163 & 174 \\
\hline 8000 (5hrs) & 36 & 72 & 146 & 163 & 39 & 82 & 163 & 167 & 35 & 129 & 148 & 159 \\
\hline 8000 (20hrs) & 29 & 66 & 140 & 163 & 33 & 74 & 158 & 162 & 30 & 115 & 141 & 157 \\
\hline Stress (psi) & \multicolumn{12}{|c|}{ Conductivity (mD・ft) } \\
\hline 6500 (Ohrs) & 1241 & 1791 & 3656 & 3967 & 1289 & 2232 & 4025 & 3924 & 1060 & 2985 & 4043 & 3930 \\
\hline $6500(5 \mathrm{hrs})$ & 1000 & 1543 & 3572 & 3897 & 1014 & 1793 & 3772 & 3752 & 920 & 2709 & 3861 & 3810 \\
\hline 6500 (20hrs) & 847 & 1498 & 3503 & 3877 & 944 & 1649 & 3714 & 3680 & 763 & 2440 & 3708 & 3767 \\
\hline 6500 (30hrs) & 802 & 1385 & 3336 & 3822 & 925 & 1638 & 3680 & 3663 & 749 & 2379 & 3652 & 3759 \\
\hline 6500 (50hrs) & 798 & 1384 & 3304 & 3810 & 887 & 1534 & 3623 & 3653 & 726 & 2368 & 3641 & 3747 \\
\hline 8000 (0hrs) & 790 & 1341 & 2662 & 3013 & 818 & 1487 & 2919 & 2950 & 686 & 2287 & 2884 & 3056 \\
\hline 8000 (5hrs) & 589 & 1240 & 2475 & 2747 & 666 & 1384 & 2717 & 2675 & 557 & 2113 & 2574 & 2753 \\
\hline 8000 (20hrs) & 477 & 1117 & 2364 & 2722 & 558 & 1244 & 2610 & 2587 & 478 & 1881 & 2457 & 2701 \\
\hline Stress (psi) & \multicolumn{12}{|c|}{ Fracture Width - inches } \\
\hline 6500 (0hrs) & 0.2050 & 0.2101 & 0.2131 & 0.2084 & 0.2175 & 0.2086 & 0.2091 & 0.2022 & 0.1995 & 0.2018 & 0.219 & 0.214 \\
\hline 6500 (5hrs) & 0.2037 & 0.2081 & 0.2119 & 0.2074 & 0.2152 & 0.2078 & 0.2081 & 0.2014 & 0.1982 & 0.2001 & 0.217 & 0.213 \\
\hline 6500 (20hrs) & 0.2017 & 0.2076 & 0.2109 & 0.2074 & 0.2122 & 0.2058 & 0.2069 & 0.1994 & 0.1942 & 0.1981 & 0.215 & 0.212 \\
\hline $6500(30 \mathrm{hrs})$ & 0.2002 & 0.2063 & 0.2091 & 0.2069 & 0.2120 & 0.2058 & 0.2061 & 0.1994 & 0.1950 & 0.1978 & 0.215 & 0.212 \\
\hline 6500 (50hrs) & 0.2002 & 0.2063 & 0.2089 & 0.2069 & 0.2122 & 0.2056 & 0.2054 & 0.1999 & 0.1940 & 0.1978 & 0.215 & 0.212 \\
\hline 8000 (0hrs) & 0.1997 & 0.2060 & 0.2051 & 0.2032 & 0.2109 & 0.2053 & 0.2026 & 0.1967 & 0.1939 & 0.1985 & 0.212 & 0.210 \\
\hline 8000 (5hrs) & 0.1974 & 0.2058 & 0.2041 & 0.2022 & 0.2069 & 0.2035 & 0.1996 & 0.1924 & 0.1904 & 0.1970 & 0.209 & 0.207 \\
\hline 8000 (20hrs) & 0.1952 & 0.2035 & 0.2028 & 0.2009 & 0.2049 & 0.2025 & 0.1988 & 0.1919 & 0.1892 & 0.1968 & 0.209 & 0.207 \\
\hline Remarks & \multicolumn{12}{|c|}{ Property of CARBO Ceramics } \\
\hline
\end{tabular}




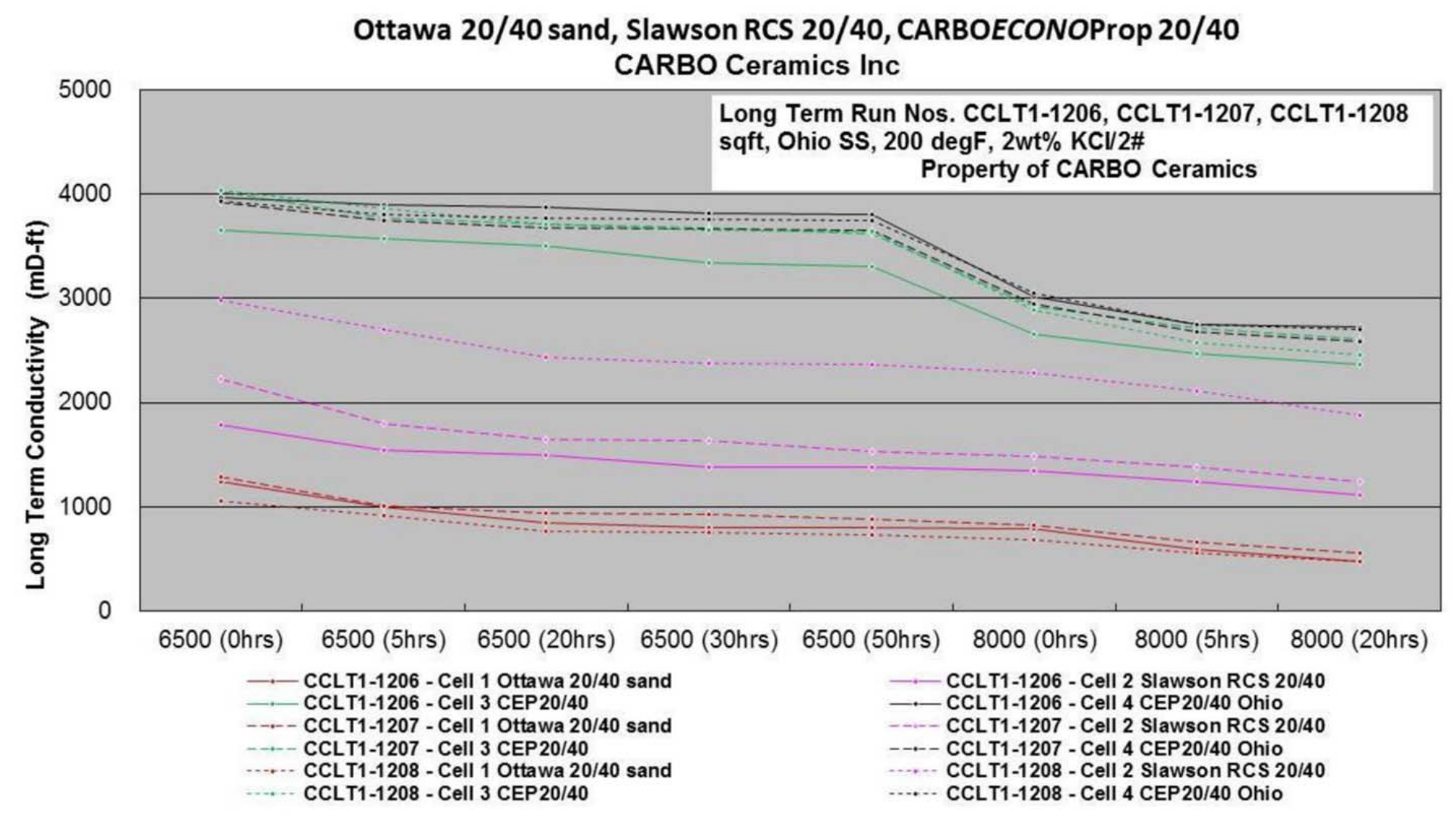

Stress (psi)

Figure 1. Long term conductivity results. 
Ottawa 20/40 sand, Slawson RCS 20/40, CARBOECONOProp 20/40

CARBO Ceramics Inc

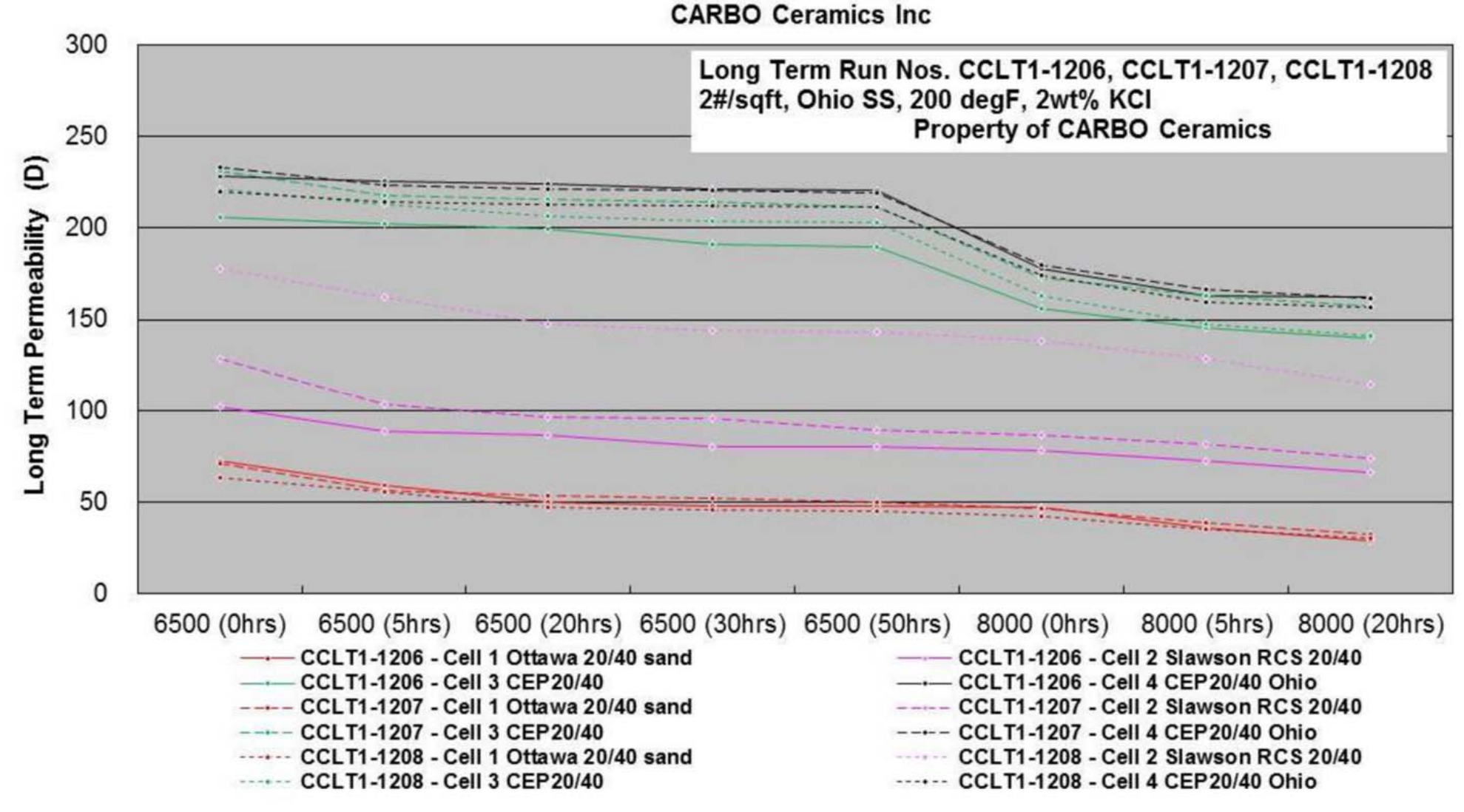

Stress (psi)

Figure 2. Long term permeability results. 
Ottawa 20/40 sand, Slawson RCS 20/40, CARBOECONOProp 20/40

CARBO Ceramics

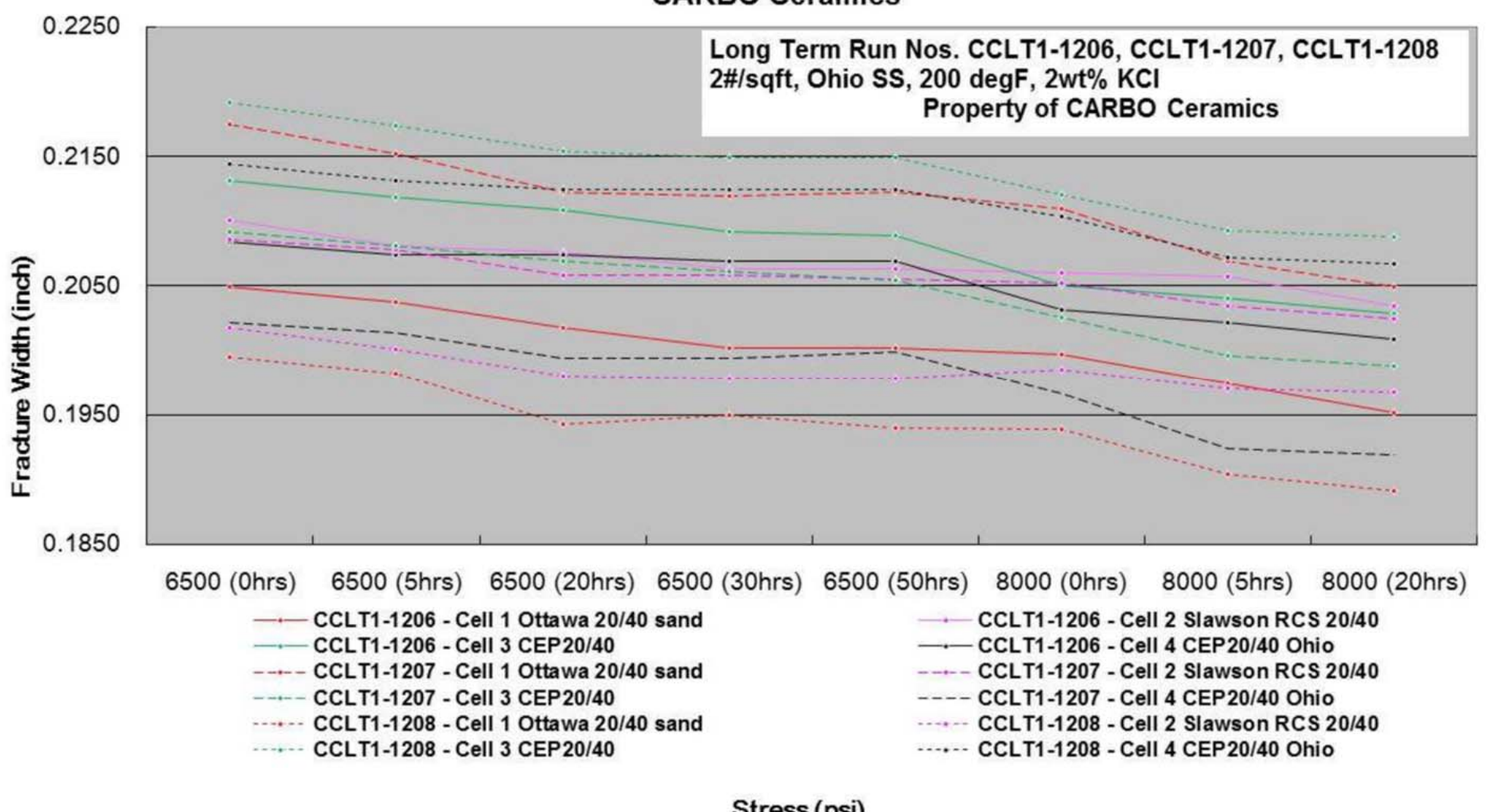

Figure 3. Long term fracture width results. 


\section{EERC CONDUCTIVITY TESTING PROCEDURE USING THE HOEK CELL}

- One-half plug, stainless steel shim, and $1 / 8$-inch proppant pack were loaded into a Hoek cell membrane.

- The cell was pressurized with a confining load of 200 psi with water while the inside was pressurized to 100 psi with Bakken crude oil.

- The cell outlet was vented to remove air from the system. Oil flowed through the system until air no longer came out.

- $\quad$ The confining load was brought to $1500 \mathrm{psi}$, and pore pressure was brought to $1000 \mathrm{psi}$.

- A constant flow rate of $0.2 \mathrm{~mL} / \mathrm{min}$ was imparted on the sample, with back pressure set to maintain 1000 psi. Pressures were logged at a logarithmically increasing time pattern $(0.1$, $0.25,0.5,1,2,4,8,16,32,64,100$ minutes). If near-constant pressure was observed over the test duration, then the test proceeded; otherwise, time was increased.

- $\quad$ The confining load was increased to 3500 psi. Repeat schedule.

- $\quad$ The confining load was increased to 7000 psi. Repeat schedule.

- $\quad$ The sample was removed from cell, sample surface impact was analyzed, and proppant and rock samples were retained for analysis. 
APPENDIX D

\section{EMBEDMENT SCANS}


APPENDIX D1

\section{LOWER BAKKEN OTTAWA SAND TOP SLAB}




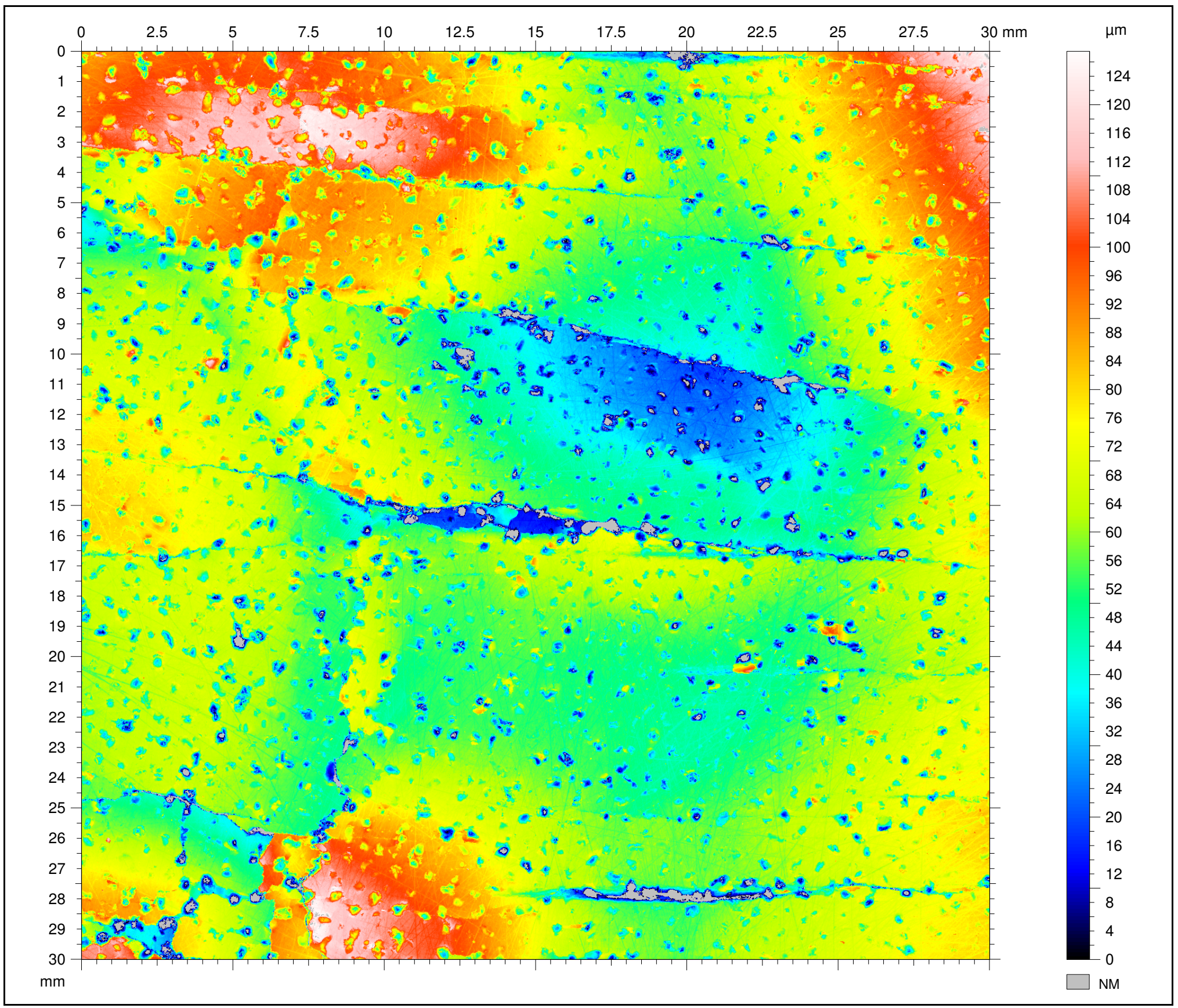

\section{Identity card}

Name: Low erBakken_20-40_Ottaw aSand_Top_Height Measured by: Chris Beddoe

Created on: $\quad$ 6/22/2012 2:23:57 AM

Measure duration: 2 h 23 m $57.000000 \mathrm{~s}$

\section{Axis: $X$}

$\begin{array}{ll}\text { Length: } & 30.01 \mathrm{~mm} \\ \text { Size: } & 1668 \text { points }\end{array}$

Spacing: $0.0180 \mathrm{~mm}$

Offset: $\quad-30.0 \mathrm{~mm}$

\section{Axis: $Y$}

Length: $\quad 30.01 \mathrm{~mm}$

Size: $\quad 1668$ lines

Spacing: $0.0180 \mathrm{~mm}$

Offset: $\quad-30.0 \mathrm{~mm}$

\section{Abbot- Firestone Curve}

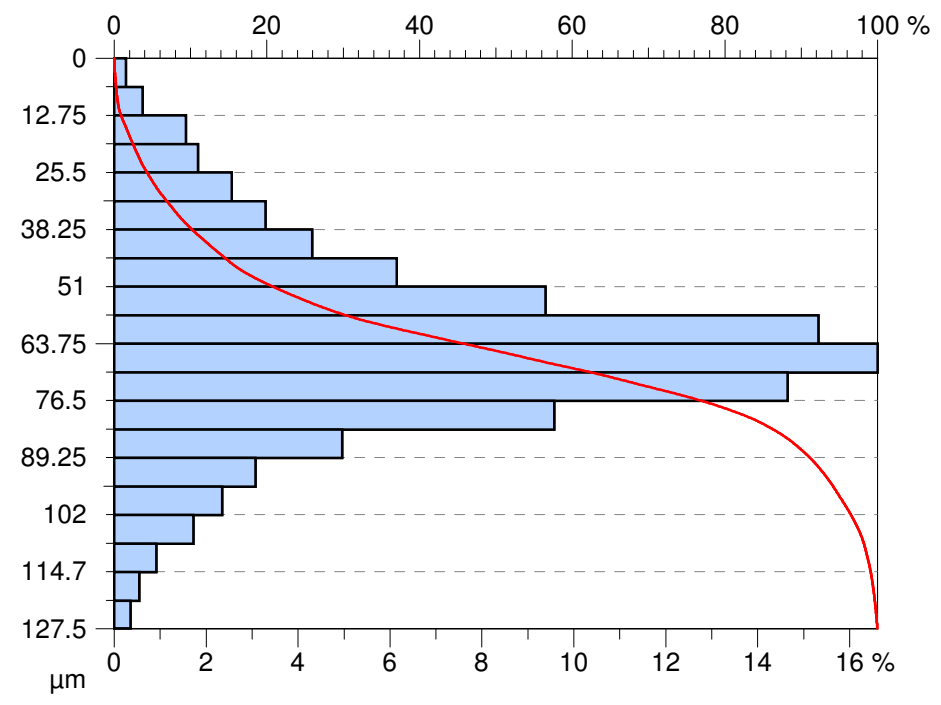



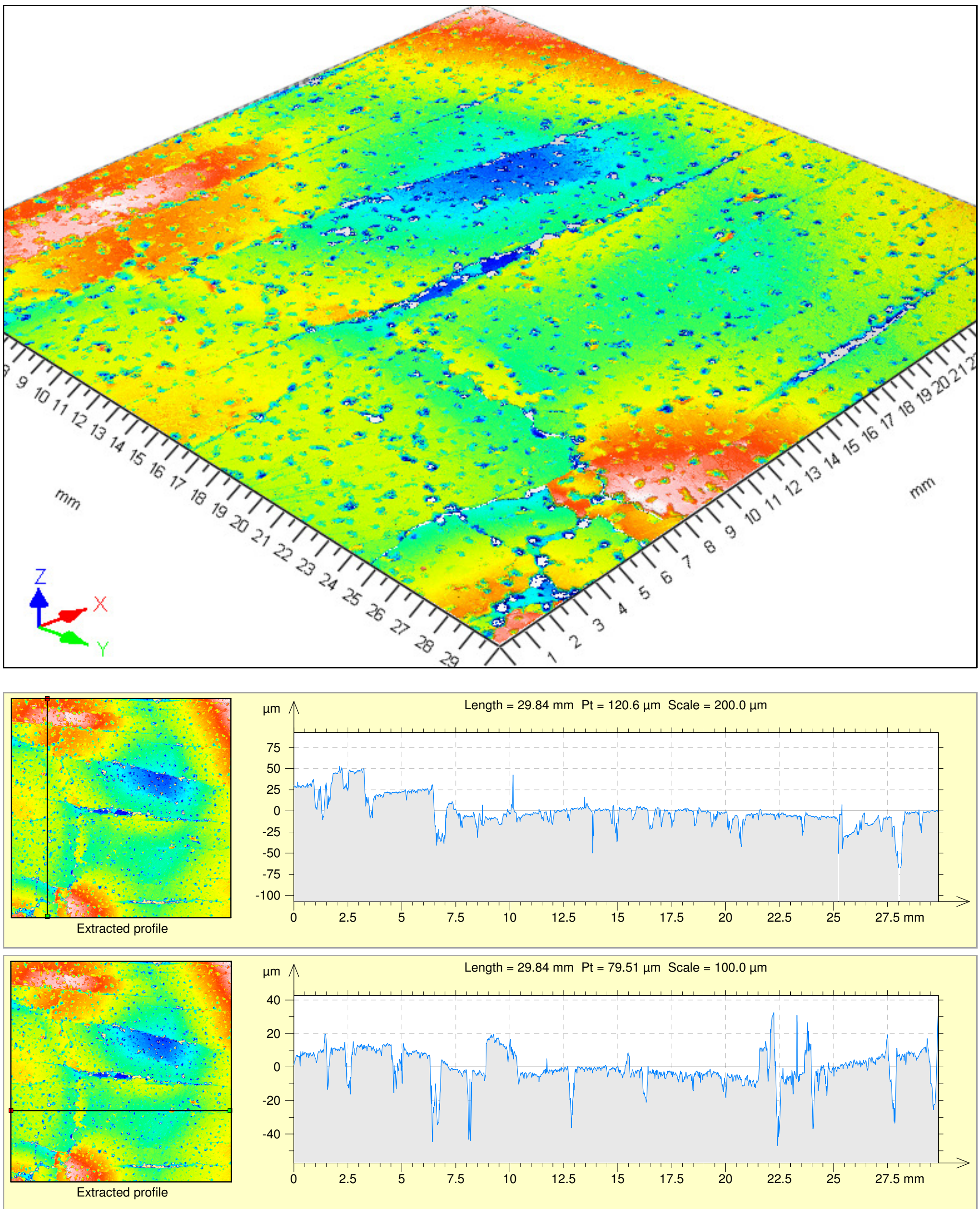
APPENDIX D2

\section{LOWER BAKKEN OTTAWA SAND BOTTOM SLAB}




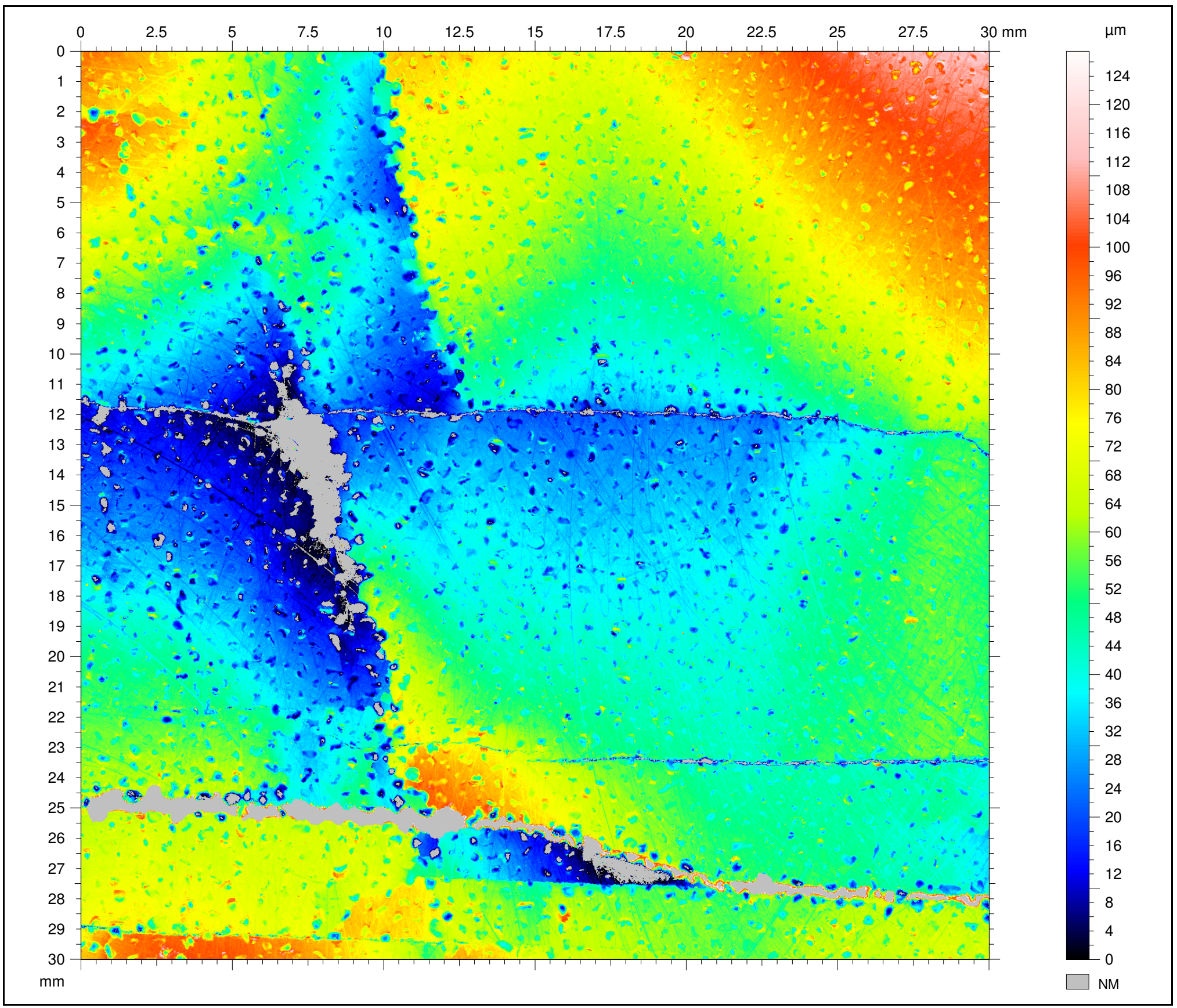

\section{Identity card}

Name: Low erBakken_20-40_Ottaw aSand_Bottom_Height

Measured by: Chris Beddoe

Created on: $\quad$ 6/21/2012 2:23:28 AM

Measure duration: 2 h $23 \mathrm{~m} 28.687500 \mathrm{~s}$

\section{Axis: $X$}

$\begin{array}{ll}\text { Length: } & 30.01 \mathrm{~mm} \\ \text { Size: } & 1668 \text { points }\end{array}$

Spacing: $0.0180 \mathrm{~mm}$

Offset: $\quad-30.0 \mathrm{~mm}$

\section{Axis: Y}

Length: $\quad 30.01 \mathrm{~mm}$

Size: $\quad 1668$ lines

Spacing: $0.0180 \mathrm{~mm}$

Offset: $\quad-30.0 \mathrm{~mm}$

\section{Abbot- Firestone Curve}

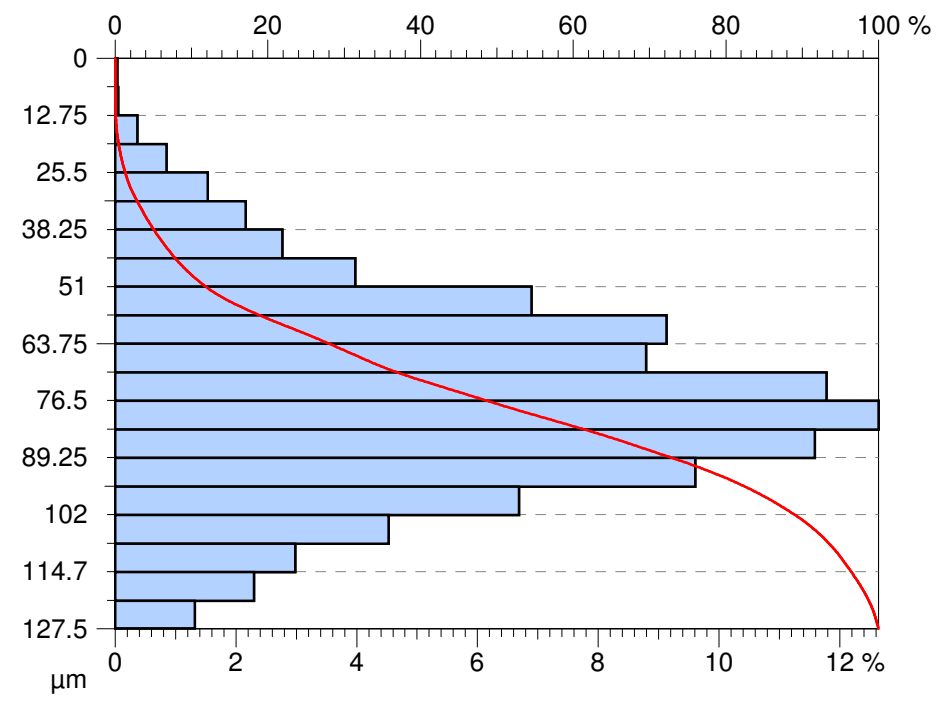



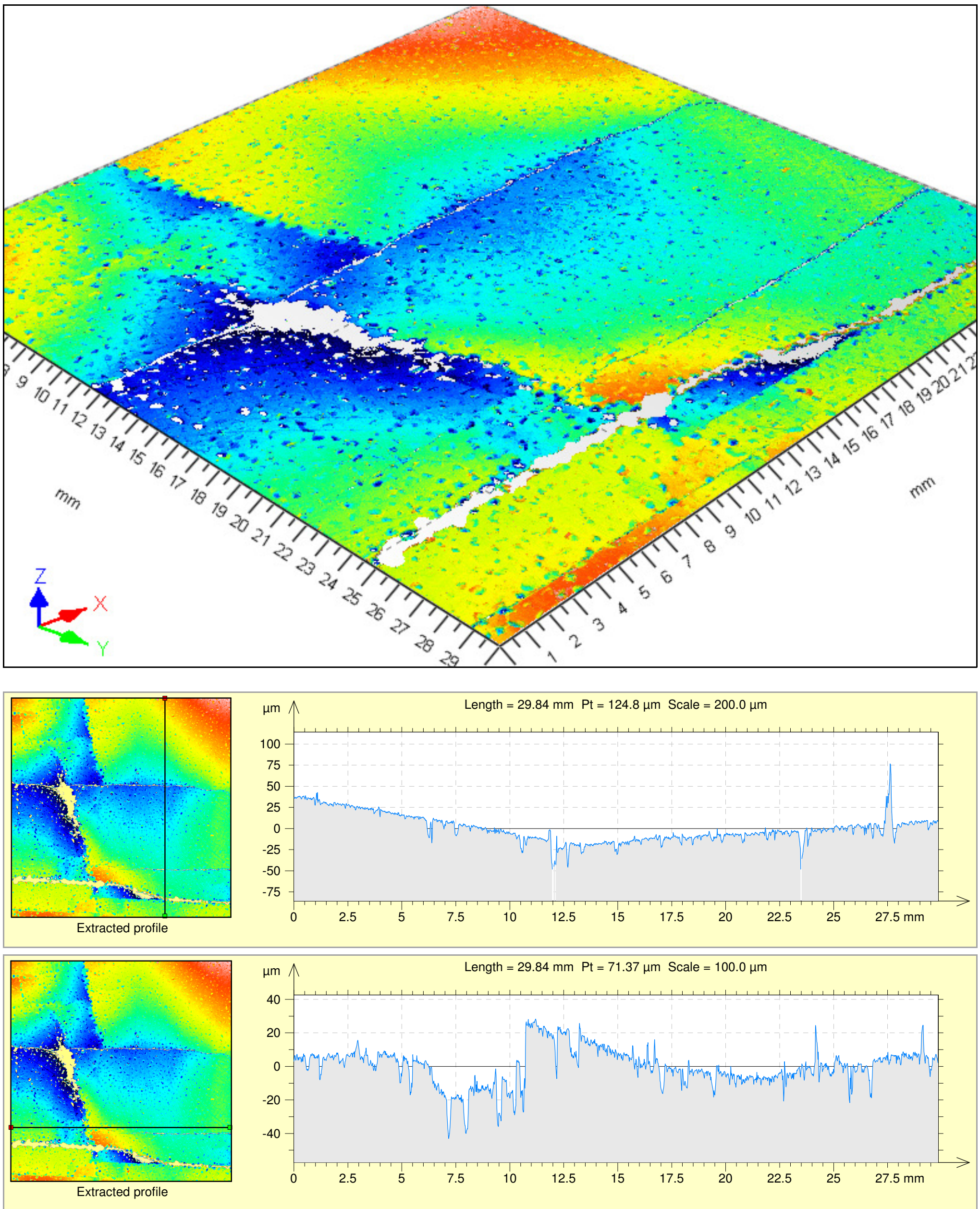
APPENDIX D3

\section{LOWER BAKKEN RESIN-COATED SAND TOP SLAB}




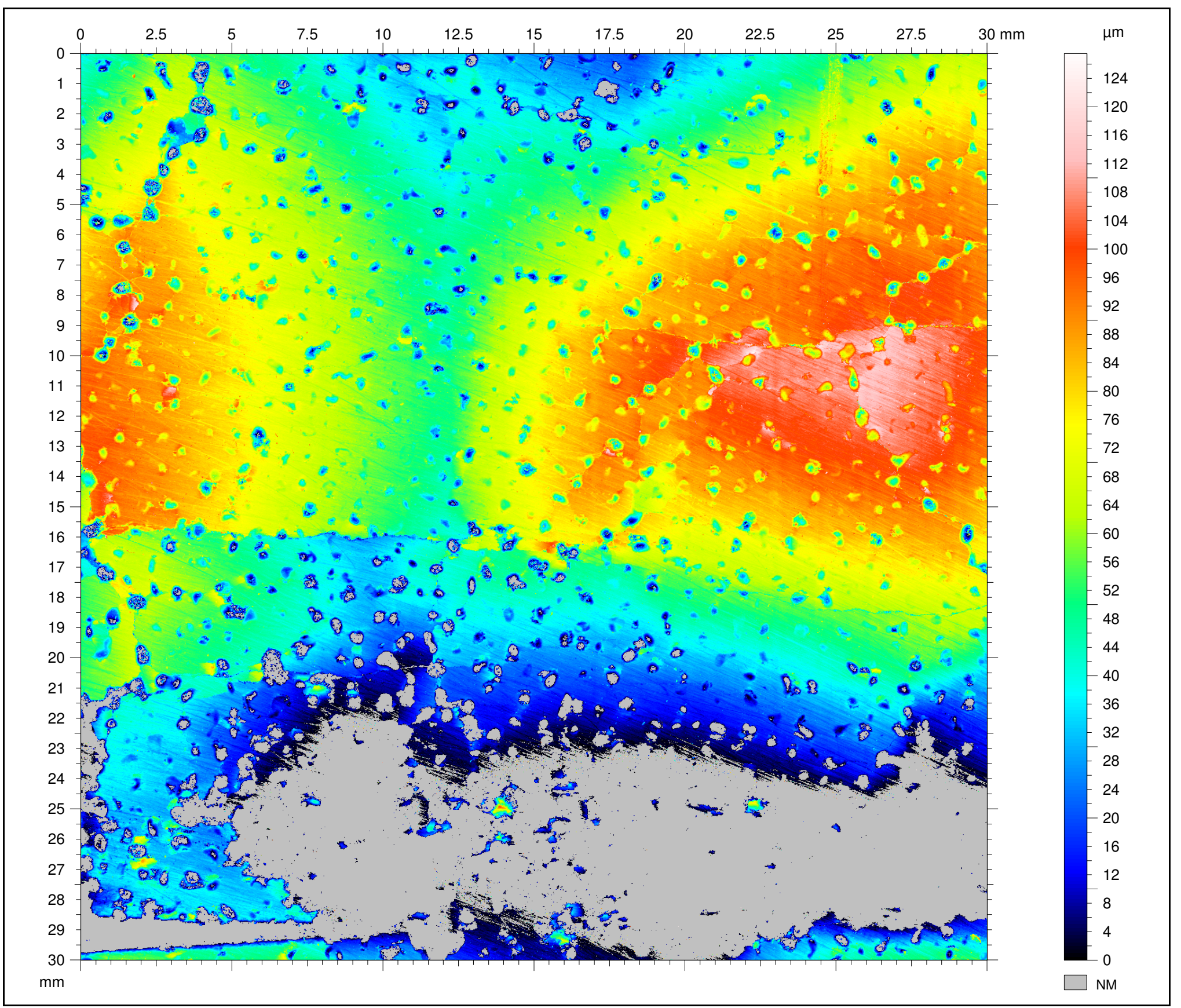

\section{Identity card}

Name: Low erBakken_20-40_ResinCoatedSand_Top_Height Measured by: Chris Beddoe

Created on: $\quad$ 6/27/2012 2:23:23 AM

Measure duration: 2 h 23 m $23.787109 \mathrm{~s}$

\section{Axis: $X$}

$\begin{array}{ll}\text { Length: } & 30.01 \mathrm{~mm} \\ \text { Size: } & 1668 \text { points }\end{array}$

Spacing: $0.0180 \mathrm{~mm}$

Offset: $\quad 0.000 \mathrm{~mm}$

Axis: $Y$

Length: $\quad 30.01 \mathrm{~mm}$

Size: $\quad 1668$ lines

Spacing: $0.0180 \mathrm{~mm}$

Offset: $\quad-30.0 \mathrm{~mm}$

\section{Abbot- Firestone Curve}

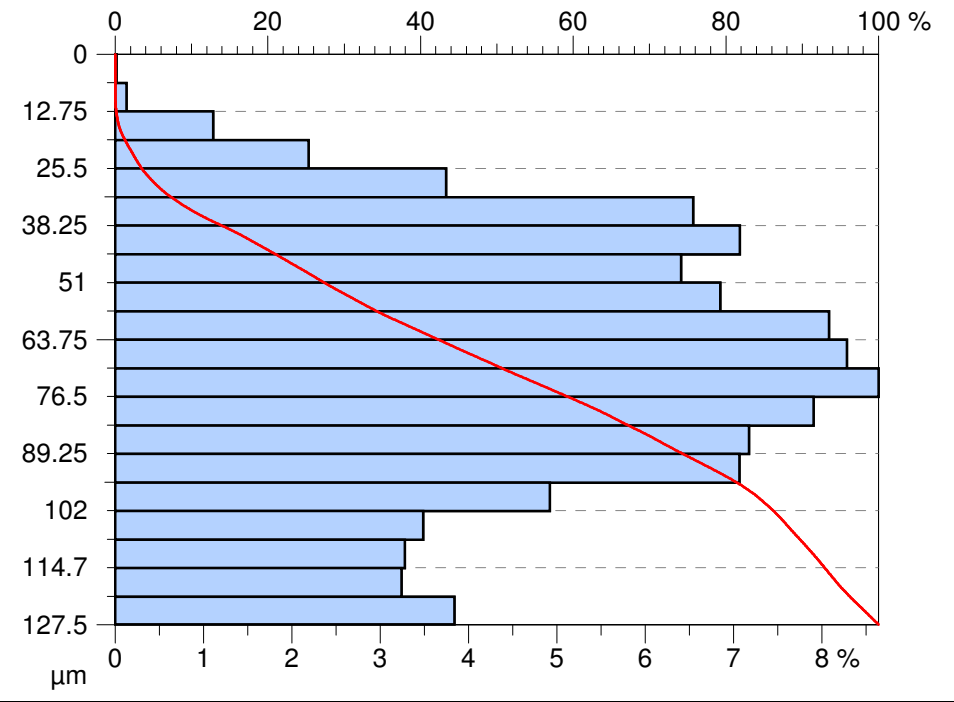



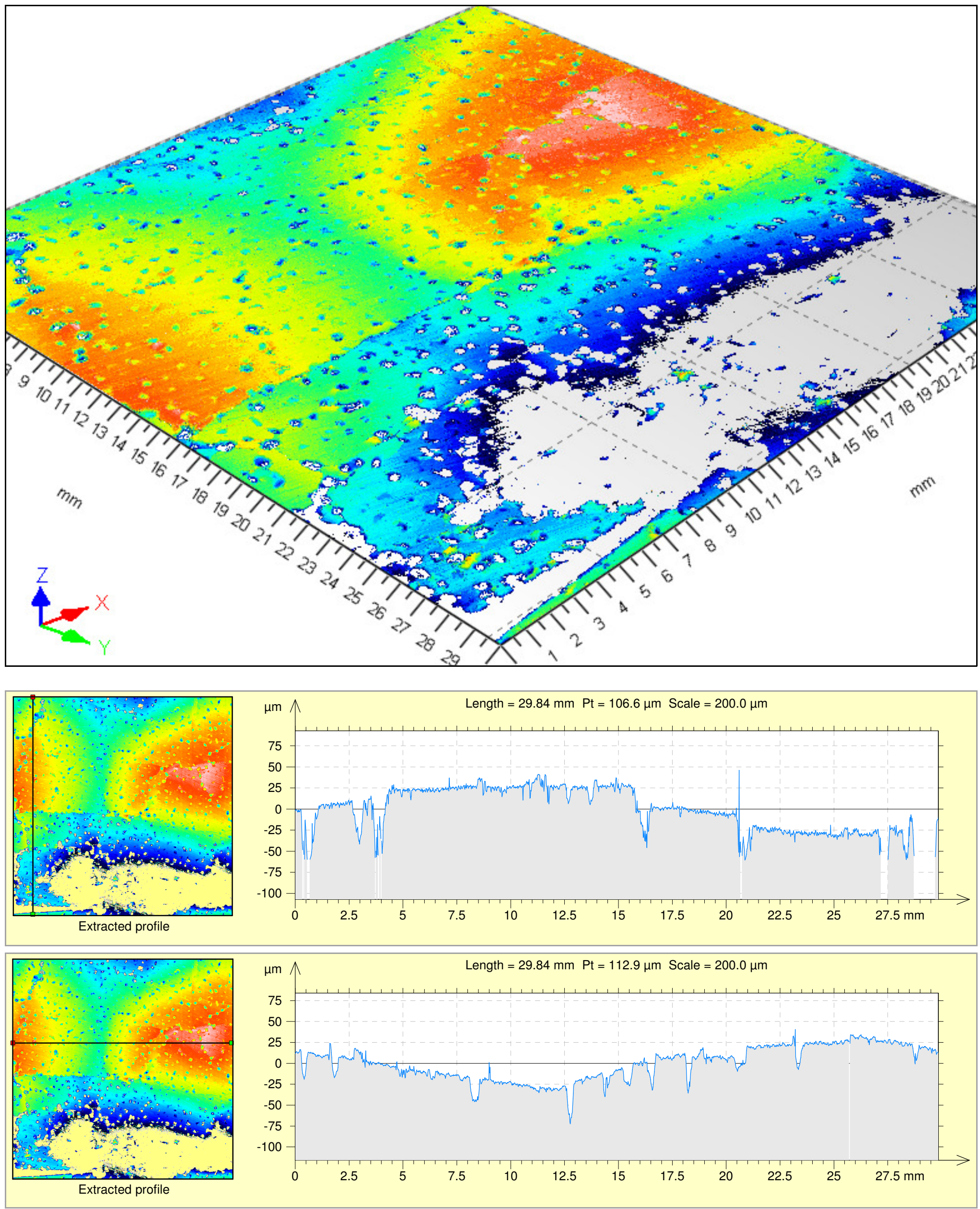


\section{APPENDIX D4}

\section{LOWER BAKKEN RESIN-COATED SAND BOTTOM SLAB}




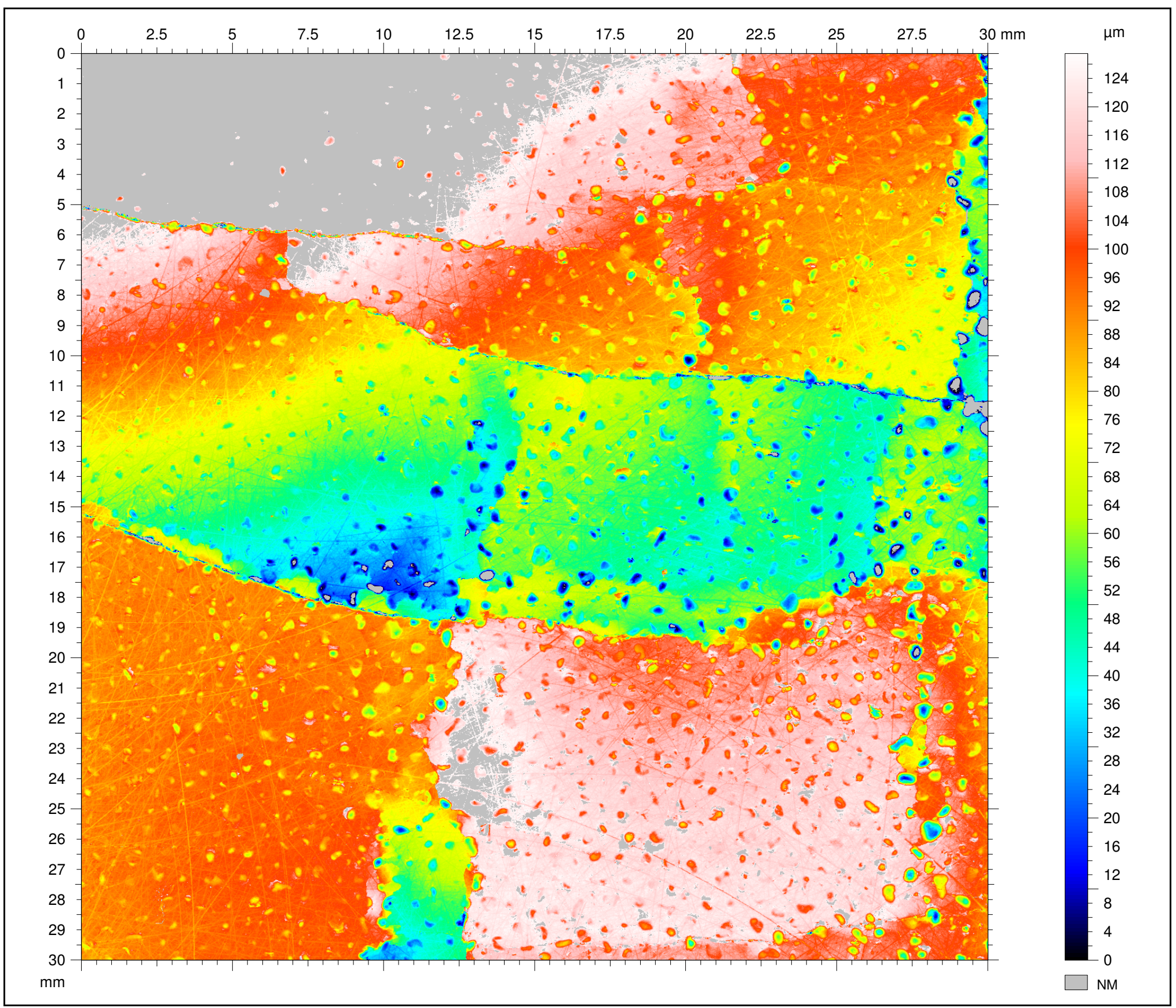

\section{Identity card}

Name: Low erBakken_20-40_ResinCoatedSand_Bottom_Height Measured by: Chris Beddoe

Created on: $\quad$ 6/28/2012 2:24:04 AM

Measure duration: 2 h $24 \mathrm{~m} 4.046875 \mathrm{~s}$

\section{Axis: $X$}

Length: $\quad 30.01 \mathrm{~mm}$

Spacing: $0.0180 \mathrm{~mm}$

Offset: $\quad 0.000 \mathrm{~mm}$

\section{Axis: Y}

Length: $\quad 30.01 \mathrm{~mm}$

Size: $\quad 1668$ lines

Spacing: $0.0180 \mathrm{~mm}$

Offset: $\quad-30.0 \mathrm{~mm}$

\section{Abbot- Firestone Curve}

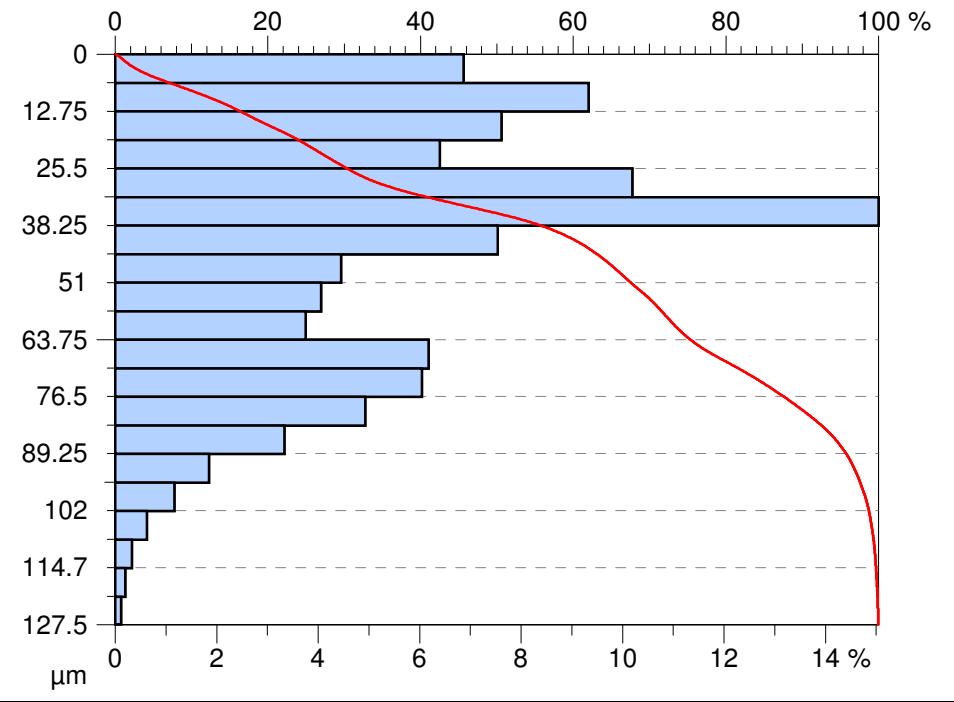



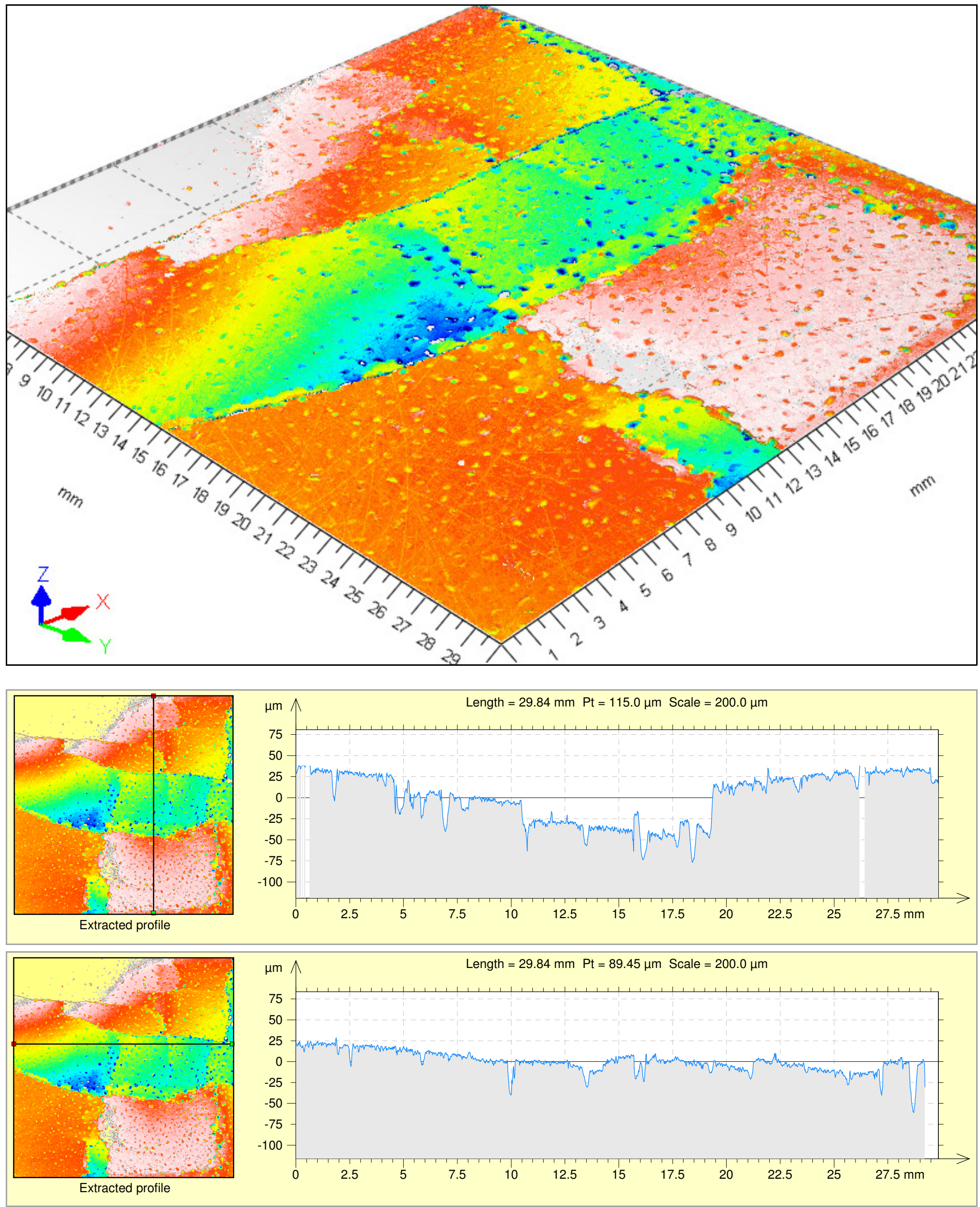
APPENDIX D5

\section{LOWER BAKKEN CERAMIC TOP SLAB}




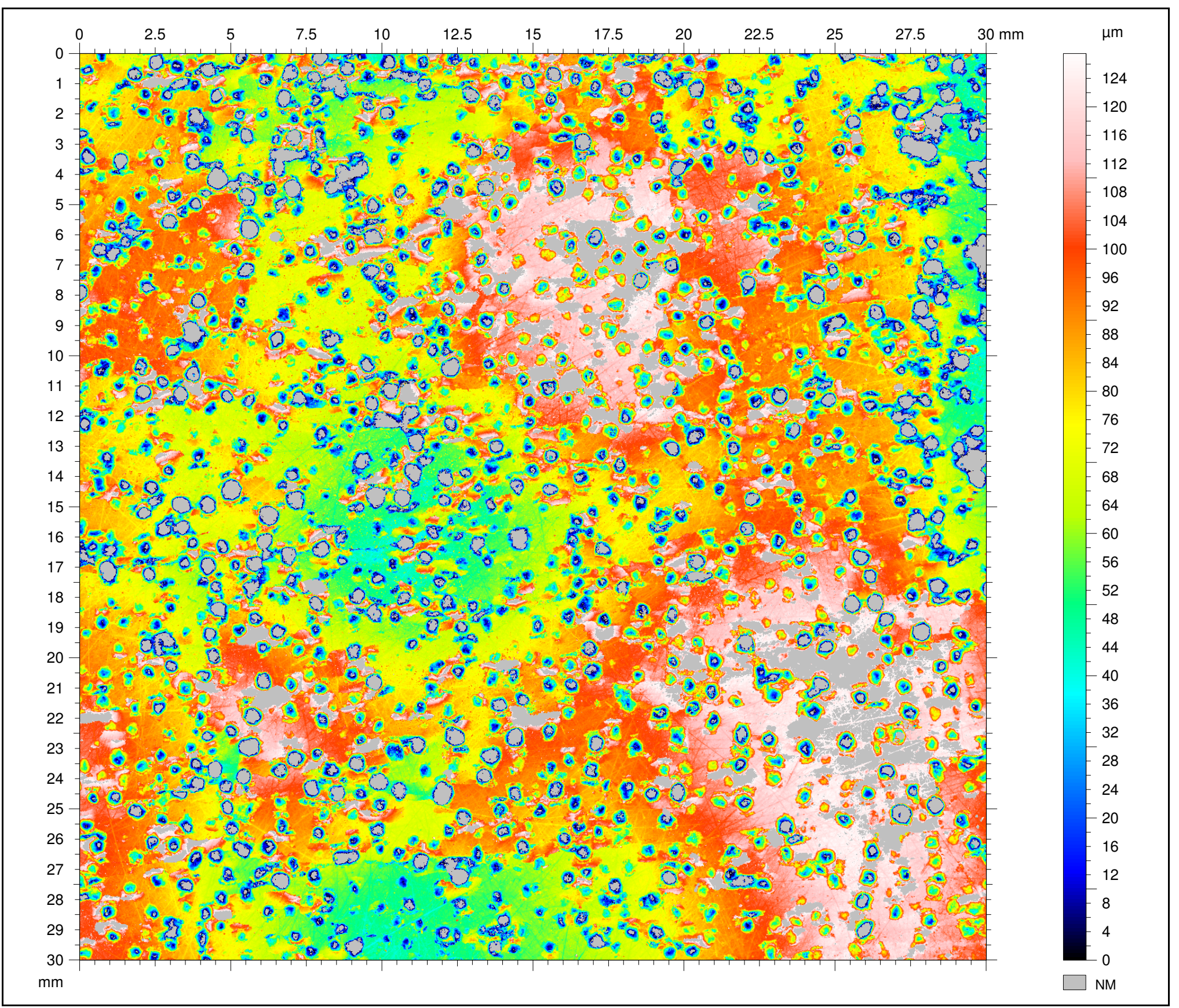

\section{Identity card}

Name: Low erBakken_20-40_Ceramic_Top_Height

Measured by: Chris Beddoe

Created on: $\quad$ 6/19/2012 2:23:56 AM

Measure duration: 2 h 23 m $56.031250 \mathrm{~s}$

\section{Axis: $X$}

Length: $\quad 30.01 \mathrm{~mm}$

Size: $\quad 1668$ points

Spacing: $\quad 0.0180 \mathrm{~mm}$

Offset: $\quad-30.0 \mathrm{~mm}$

\section{Axis: Y}

Length: $\quad 30.01 \mathrm{~mm}$

Size: $\quad 1668$ lines

Spacing: $0.0180 \mathrm{~mm}$

Offset: $\quad-30.0 \mathrm{~mm}$

\section{Abbot- Firestone Curve}

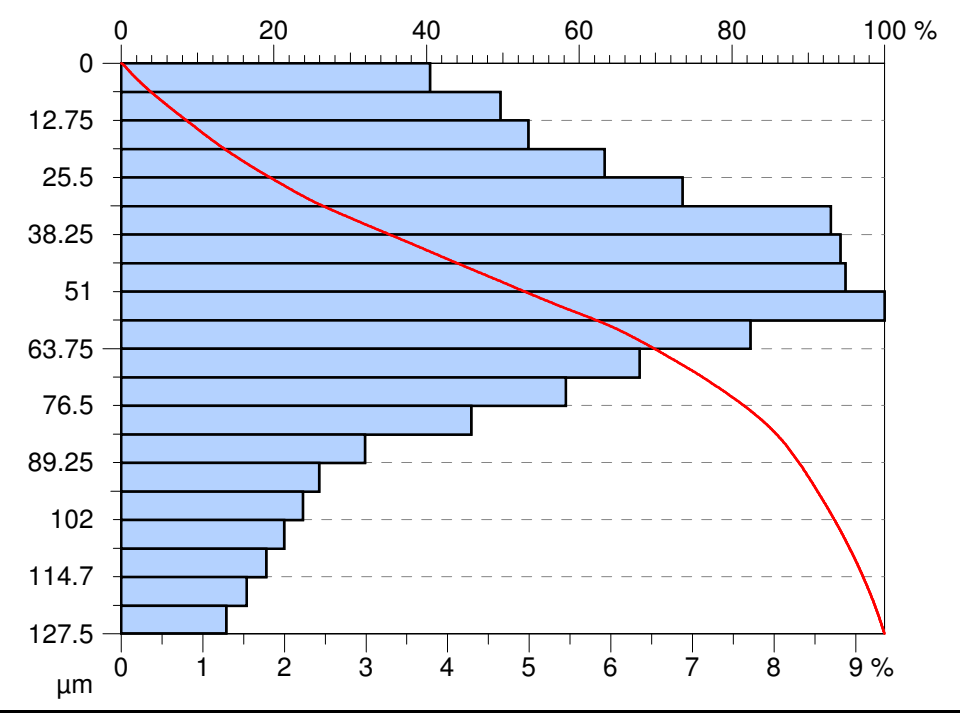



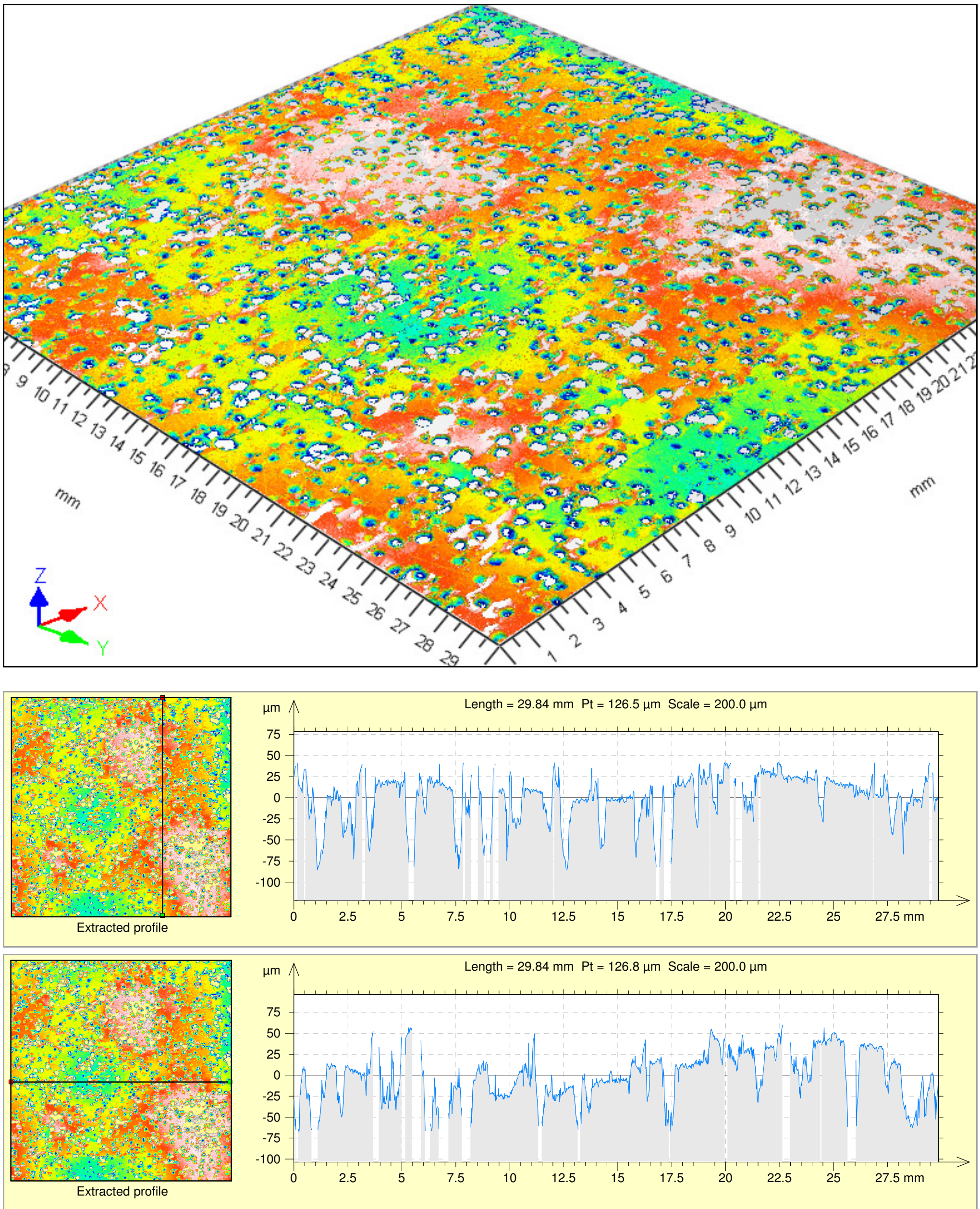
APPENDIX D6

\section{LOWER BAKKEN CERAMIC BOTTOM SLAB}




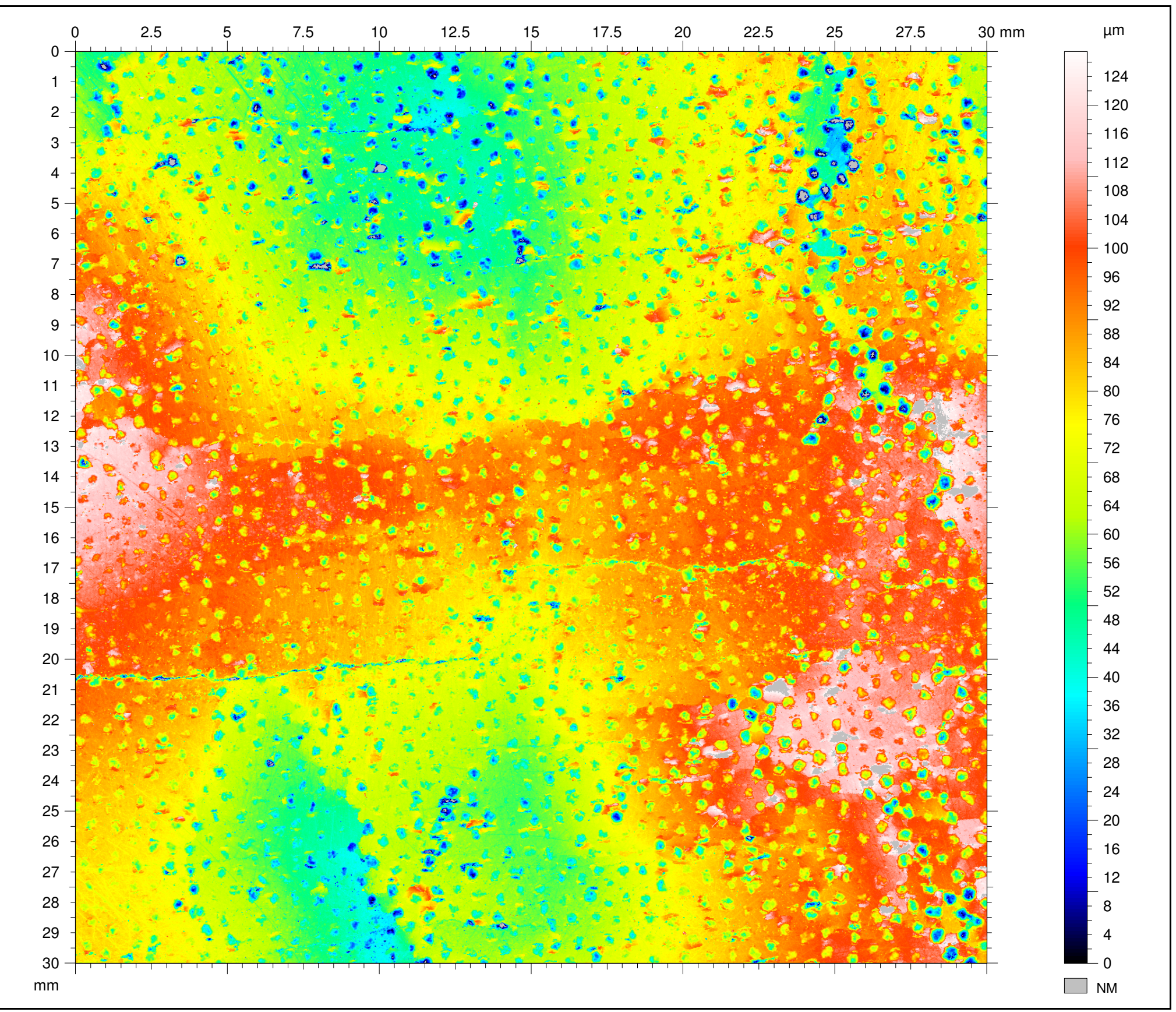

\section{Identity card}

Name: Low erBakken_20-40_Ceramic_Bottom_Height

Measured by: Chris Beddoe

Created on: $\quad$ 6/18/2012 2:18:50 AM

Measure duration: 2 h $18 \mathrm{~m} 50.671875 \mathrm{~s}$

\section{Axis: $X$}

$\begin{array}{ll}\text { Length: } & 30.01 \mathrm{~mm} \\ \text { Size: } & 1668 \text { points }\end{array}$

Spacing: $0.0180 \mathrm{~mm}$

Offset: $\quad 3.301 \mathrm{~mm}$

\section{Axis: $Y$}

Length: $\quad 30.01 \mathrm{~mm}$

Size: $\quad 1668$ lines

Spacing: $0.0180 \mathrm{~mm}$

Offset: $\quad-30.0 \mathrm{~mm}$

\section{Abbot- Firestone Curve}

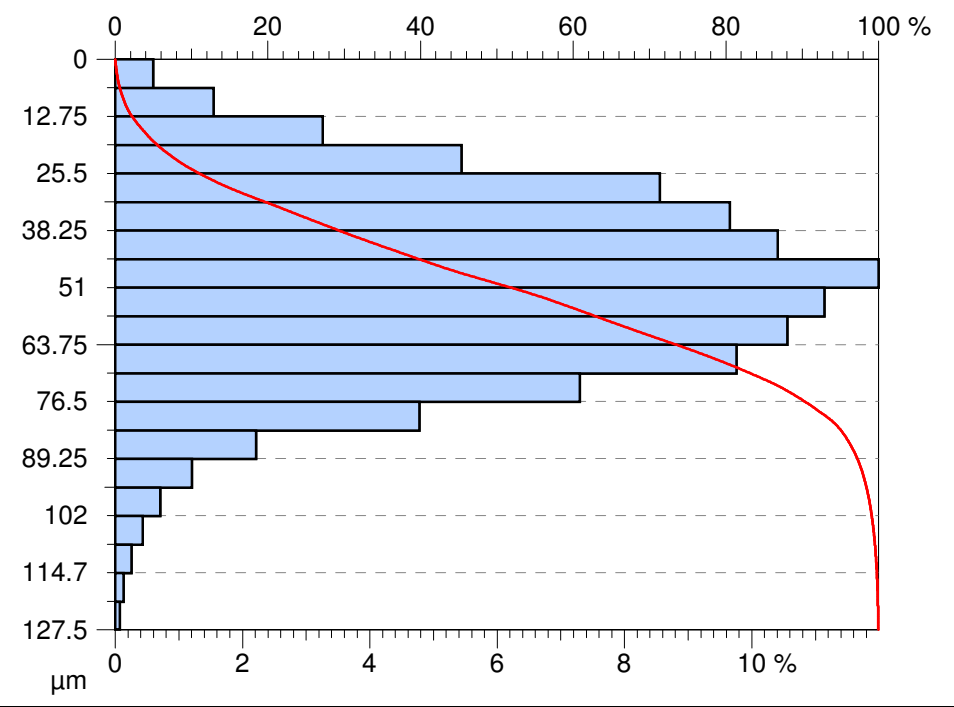



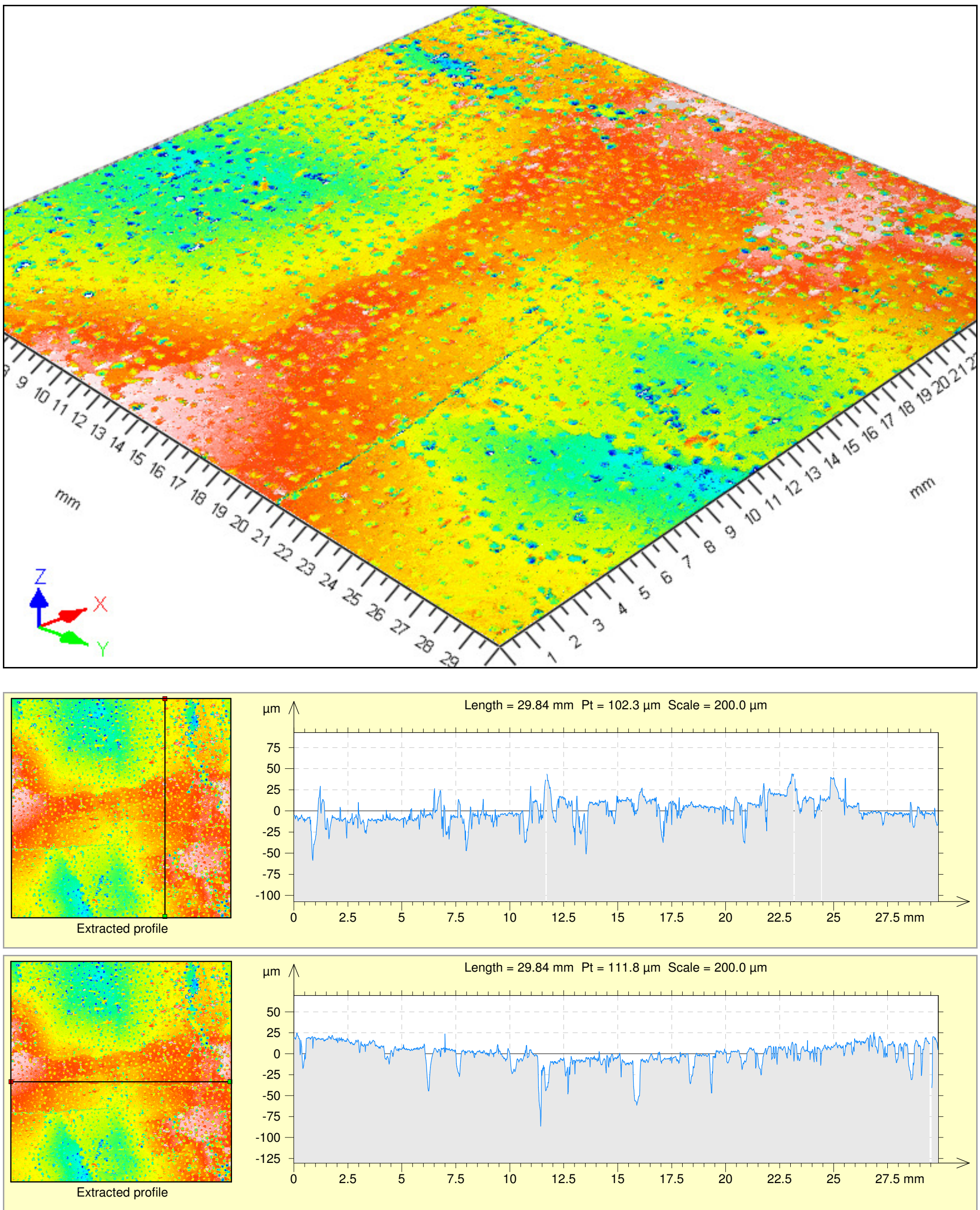
APPENDIX D7

MIDDLE BAKKEN OTTAWA SAND TOP SLAB 


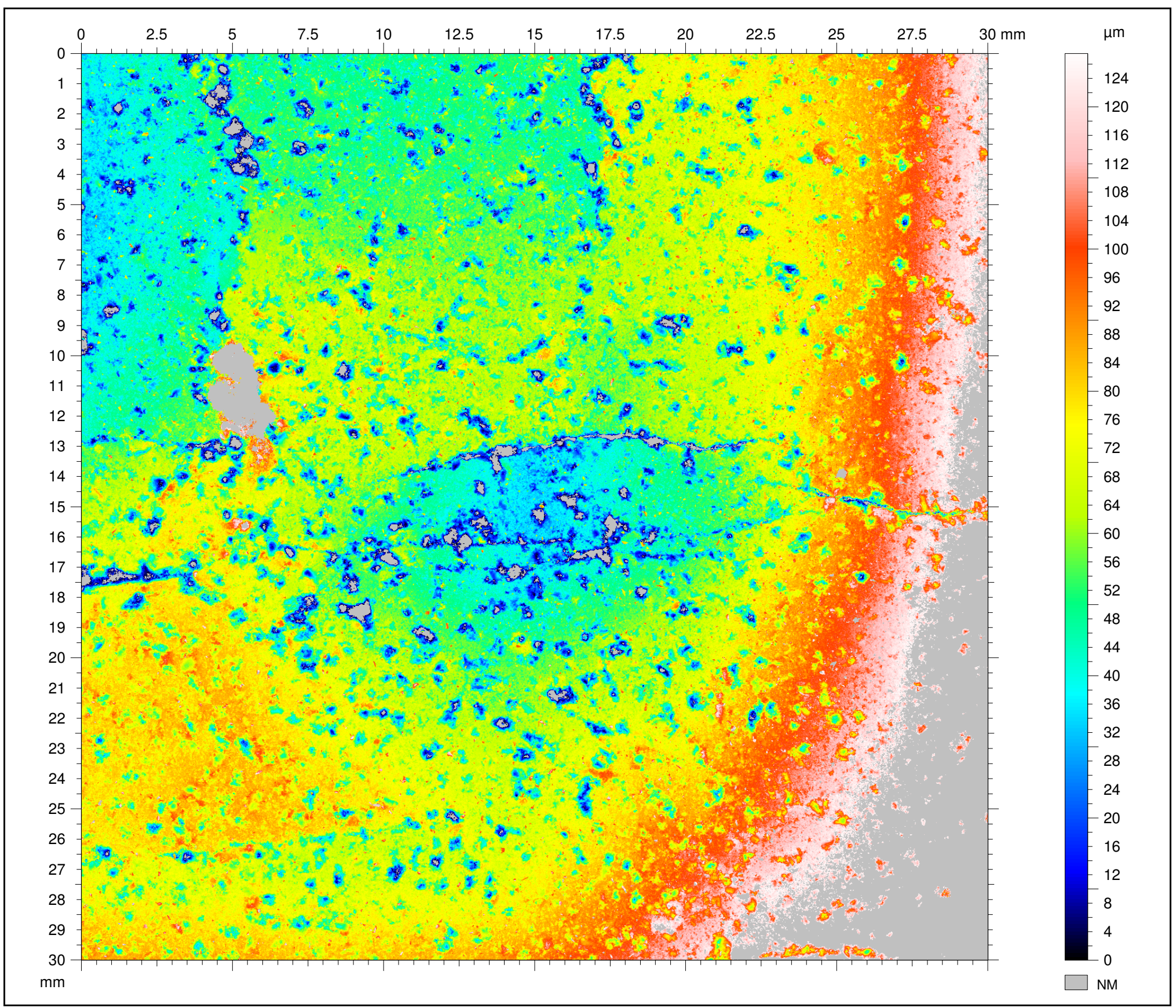

\section{Identity card}

Name: MiddleBakken_20-40_Ottaw aSand_Top_Height

Measured by: Chris Beddoe

Created on: $\quad$ 7/3/2012 2:24:31 AM

Measure duration: 2 h 24 m $31.953125 \mathrm{~s}$

\section{Axis: $\mathrm{X}$}

$\begin{array}{ll}\text { Length: } & 30.01 \mathrm{~mm} \\ \text { Size: } & 1668 \text { points }\end{array}$

Spacing: $\quad 0.0180 \mathrm{~mm}$

Offset: $\quad 0.000 \mathrm{~mm}$

\section{Axis: $Y$}

Length: $\quad 30.01 \mathrm{~mm}$

Size: $\quad 1668$ lines

Spacing: $\quad 0.0180 \mathrm{~mm}$

Offset: $\quad-30.0 \mathrm{~mm}$

\section{Abbot- Firestone Curve}

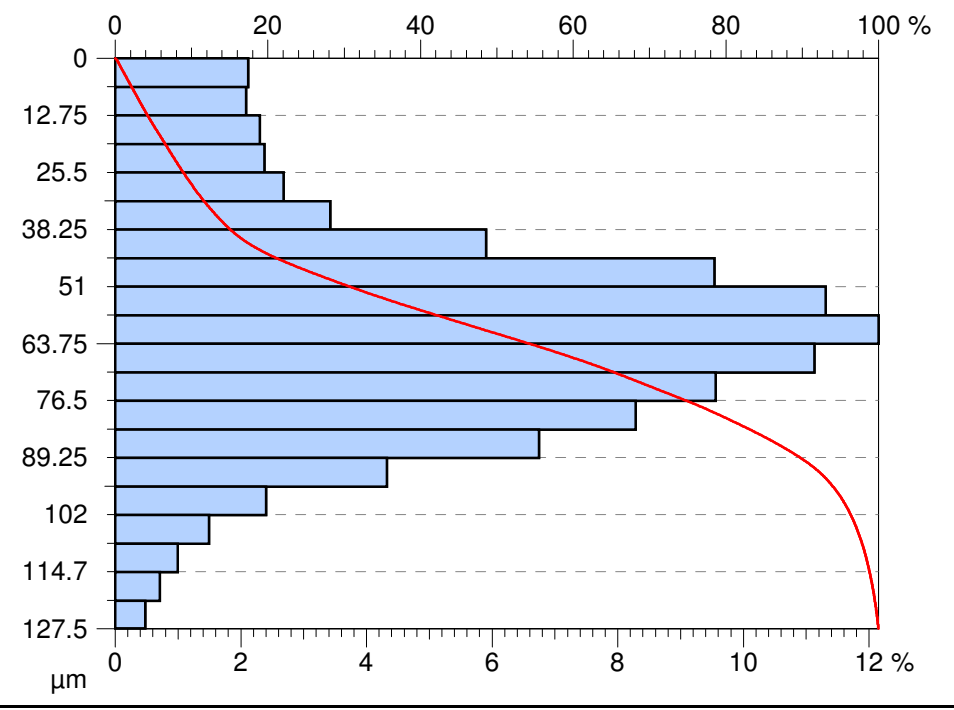



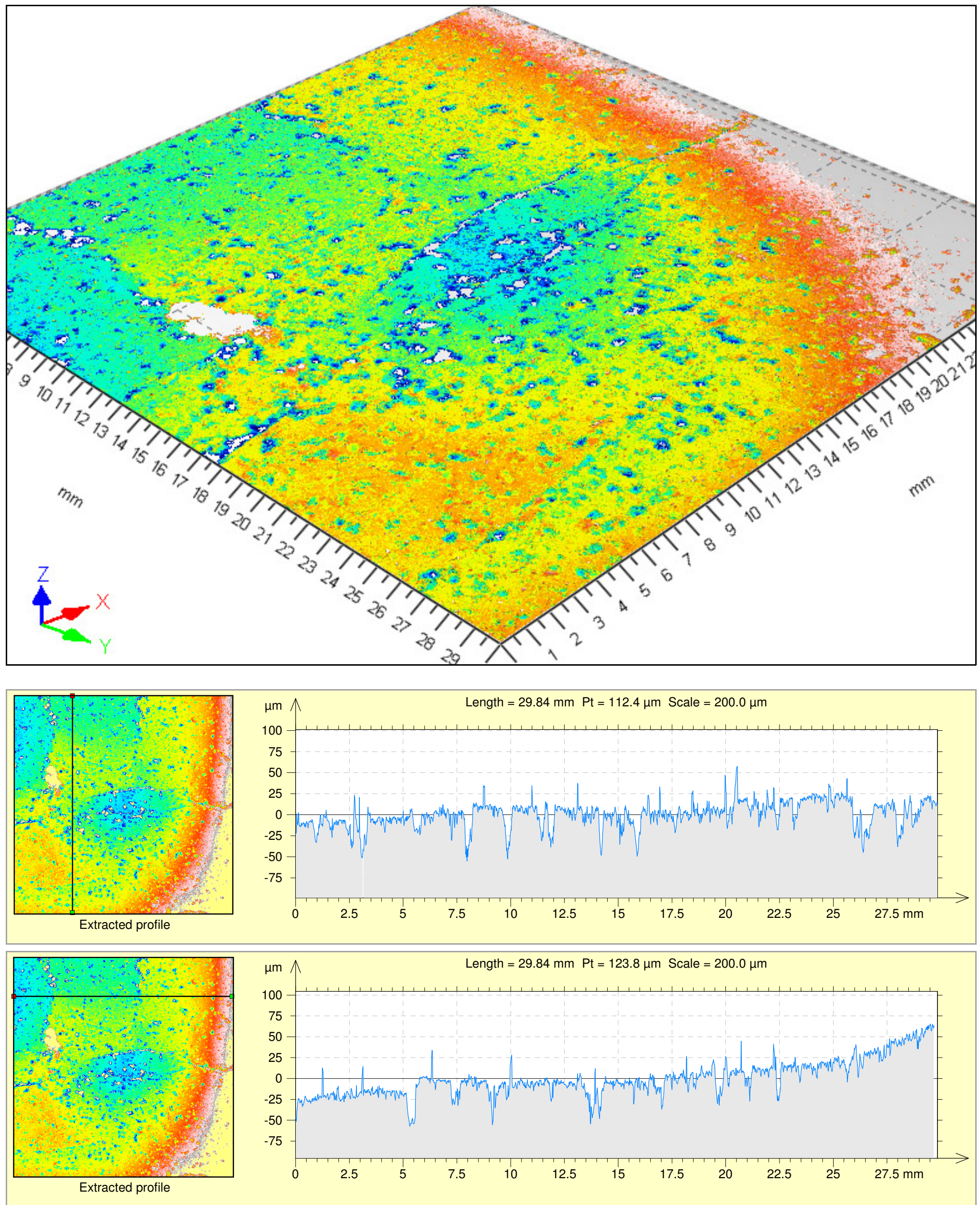
APPENDIX D8

\section{MIDDLE BAKKEN OTTAWA SAND BOTTOM SLAB}




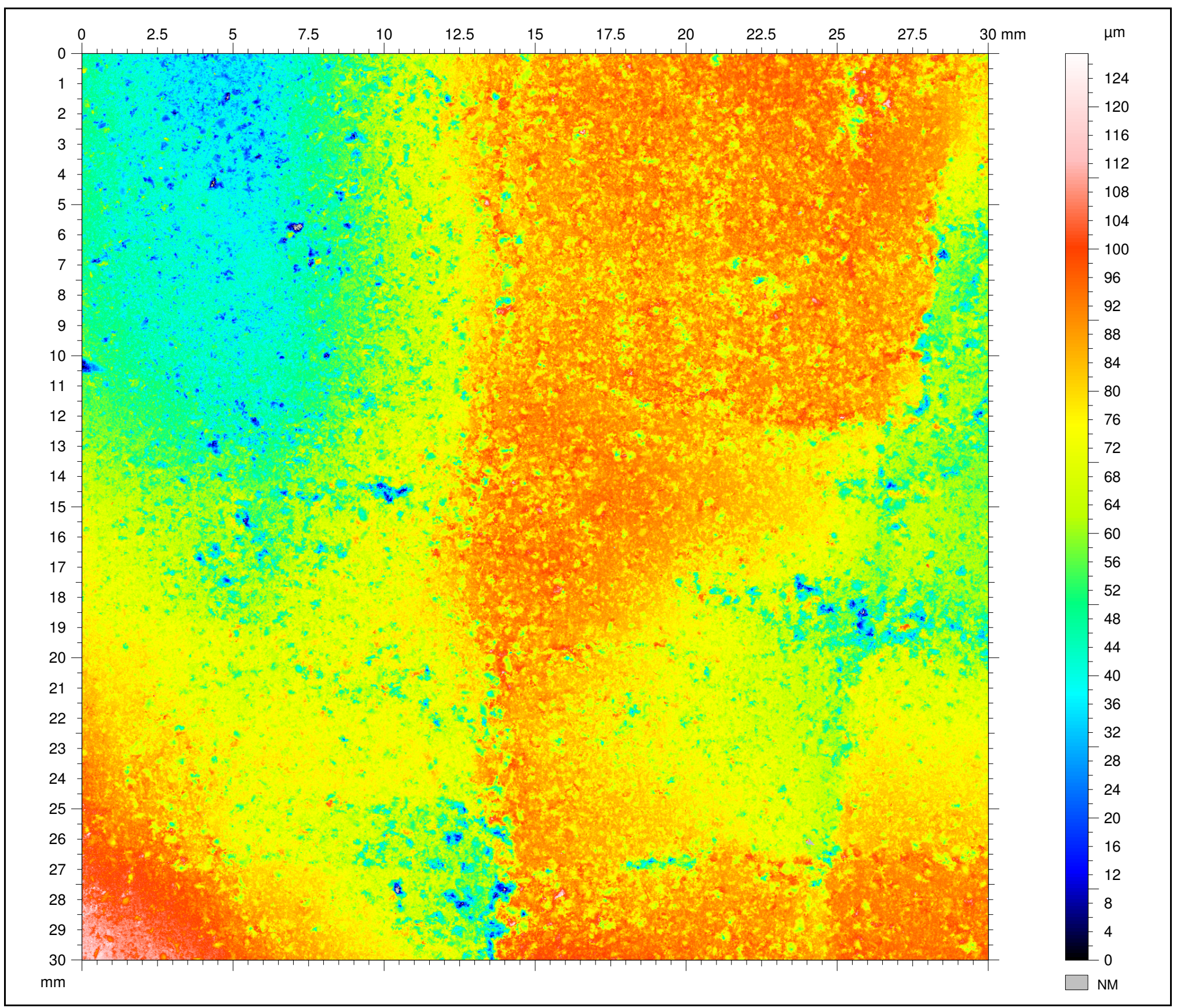

\section{Identity card}

Name: MiddleBakken_20-40_Ottaw aSand_Bottom_Height

Measured by: Chris Beddoe

Created on: $\quad$ 7/3/2012 2:22:27 AM

Measure duration: 2 h $22 \mathrm{~m} 27.968750 \mathrm{~s}$

\section{Axis: $\mathrm{X}$}

$\begin{array}{ll}\text { Length: } & 30.01 \mathrm{~mm} \\ \text { Size: } & 1668 \text { points } \\ \text { Spacing: } & 0.0180 \mathrm{~mm} \\ \text { Offset: } & 0.000 \mathrm{~mm}\end{array}$

Axis: $Y$

Length: $\quad 30.01 \mathrm{~mm}$

Size: $\quad 1668$ lines

Spacing: $0.0180 \mathrm{~mm}$

Offset: $\quad-30.0 \mathrm{~mm}$

\section{Abbot- Firestone Curve}

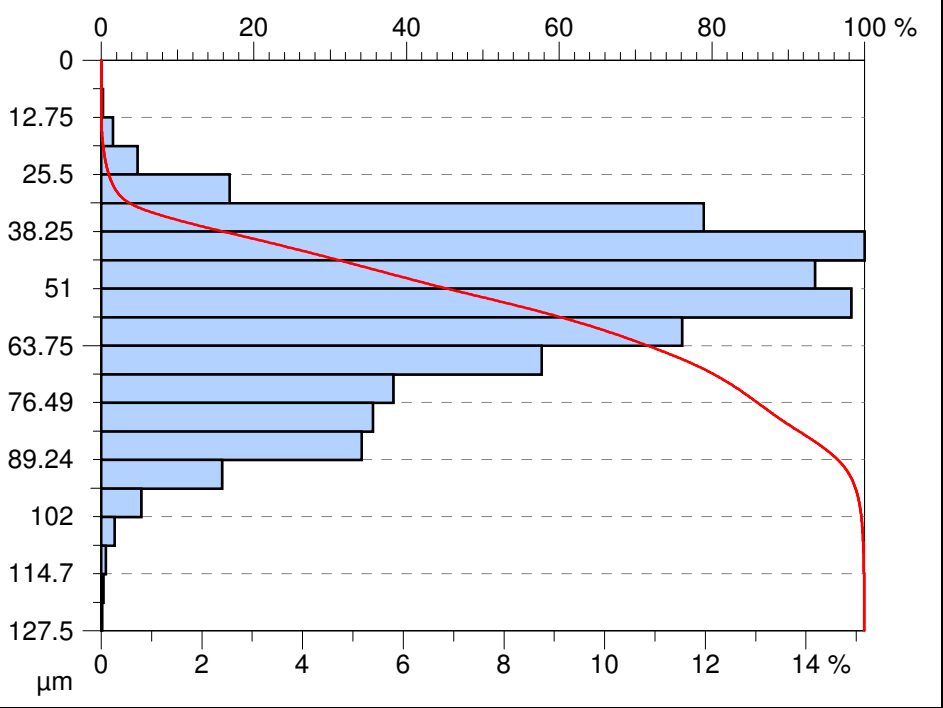



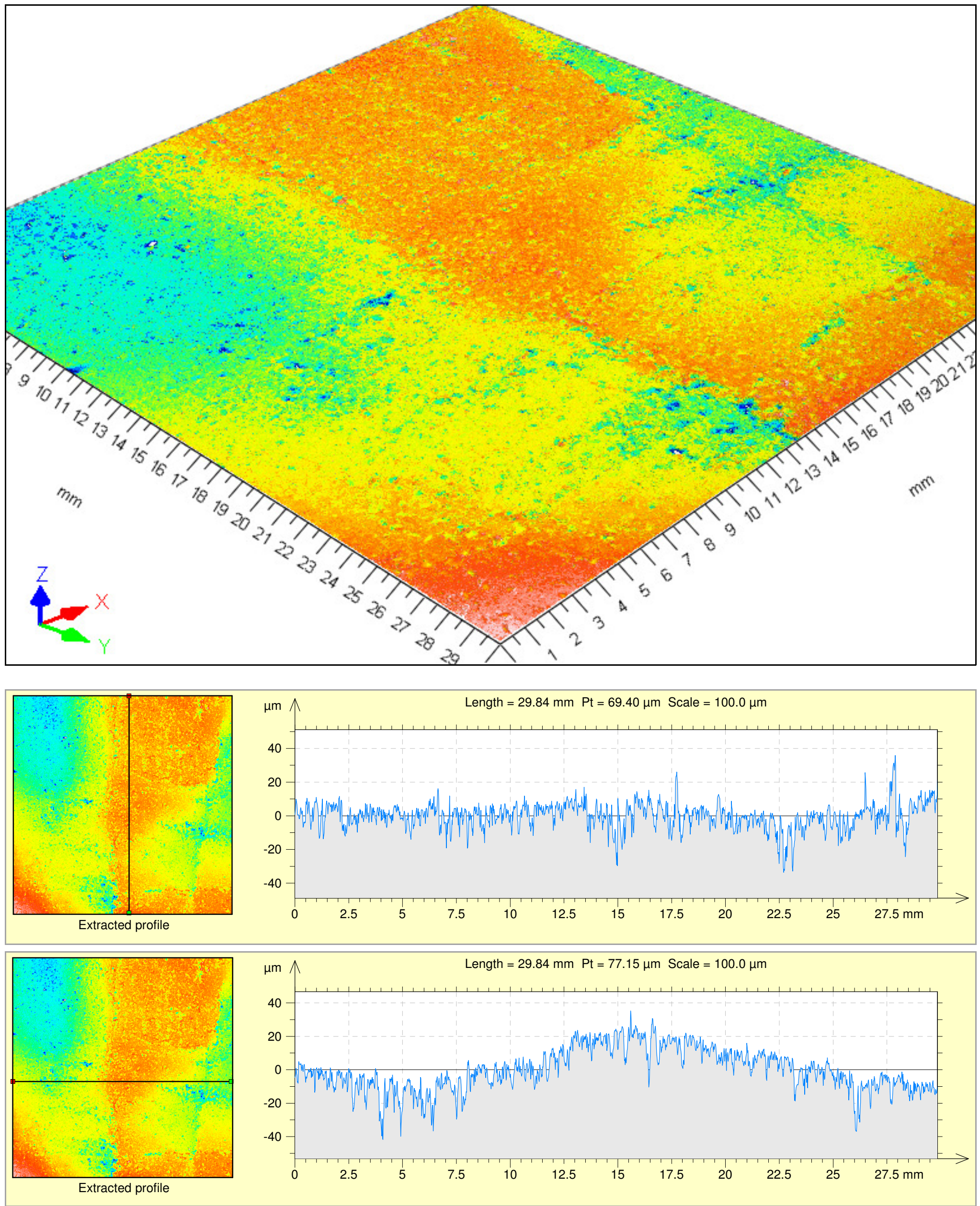
APPENDIX D9

\section{MIDDLE BAKKEN RESIN-COATED SAND TOP SLAB}




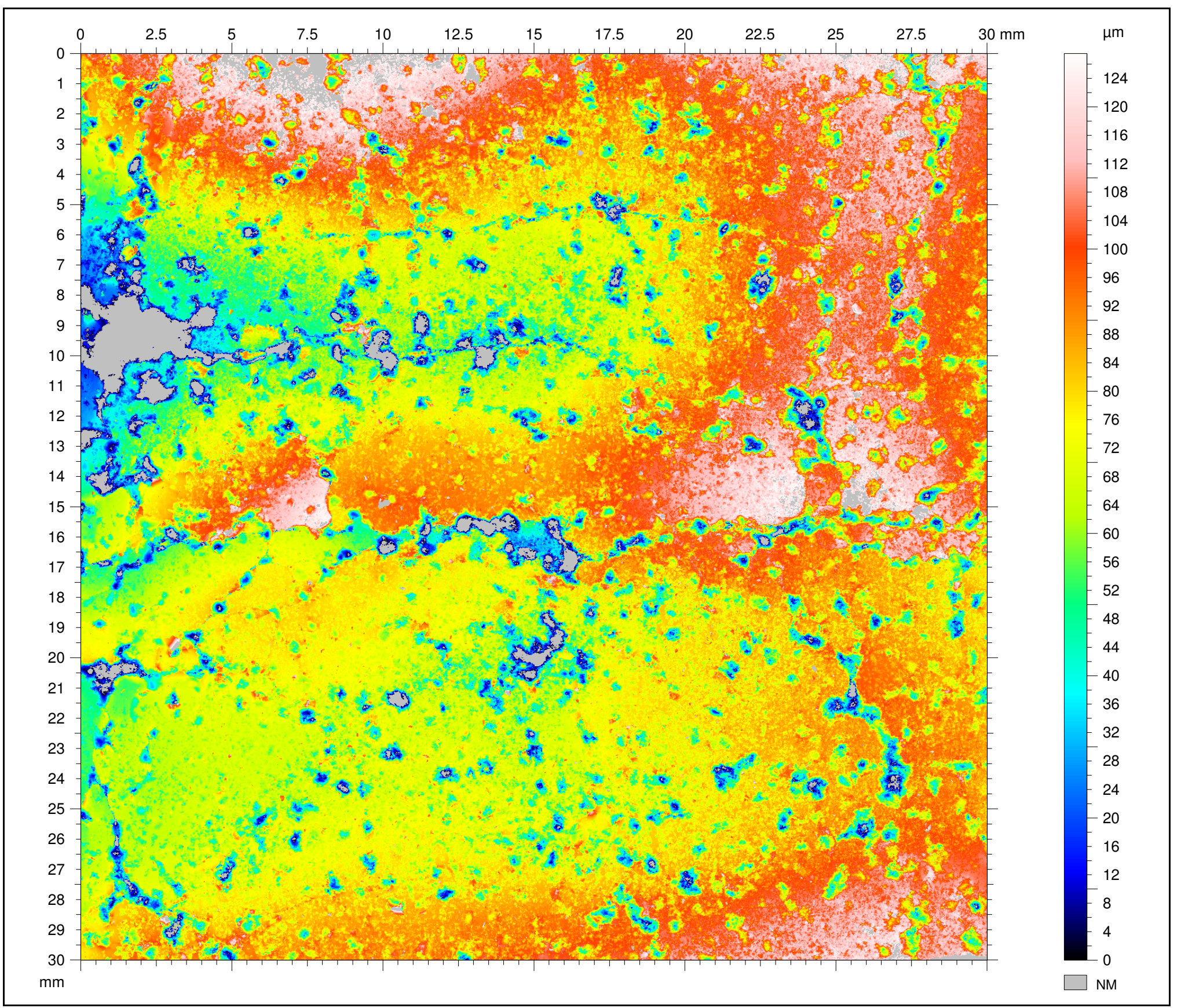

\section{Identity card}

Name: MiddleBakken_20-40_ResinCoatedSand_Top_Height

Measured by: Chris Beddoe

Created on: $\quad$ 7/3/2012 2:23:05 AM

Measure duration: 2 h $23 \mathrm{~m} 5.875000 \mathrm{~s}$

\section{Axis: $X$}

Length: $\quad 30.01 \mathrm{~mm}$

Size: $\quad 1668$ points

Spacing: $\quad 0.0180 \mathrm{~mm}$

Offset: $\quad 0.000 \mathrm{~mm}$

\section{Axis: Y}

Length: $\quad 30.01 \mathrm{~mm}$

Size: $\quad 1668$ lines

Spacing: $0.0180 \mathrm{~mm}$

Offset: $\quad-30.0 \mathrm{~mm}$

\section{Abbot- Firestone Curve}

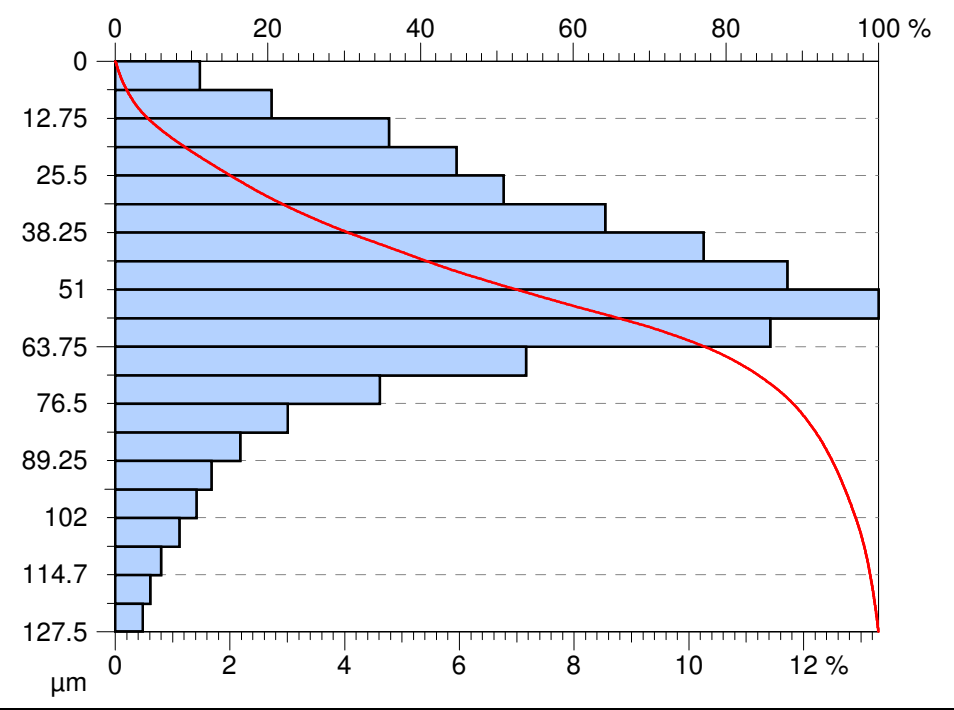



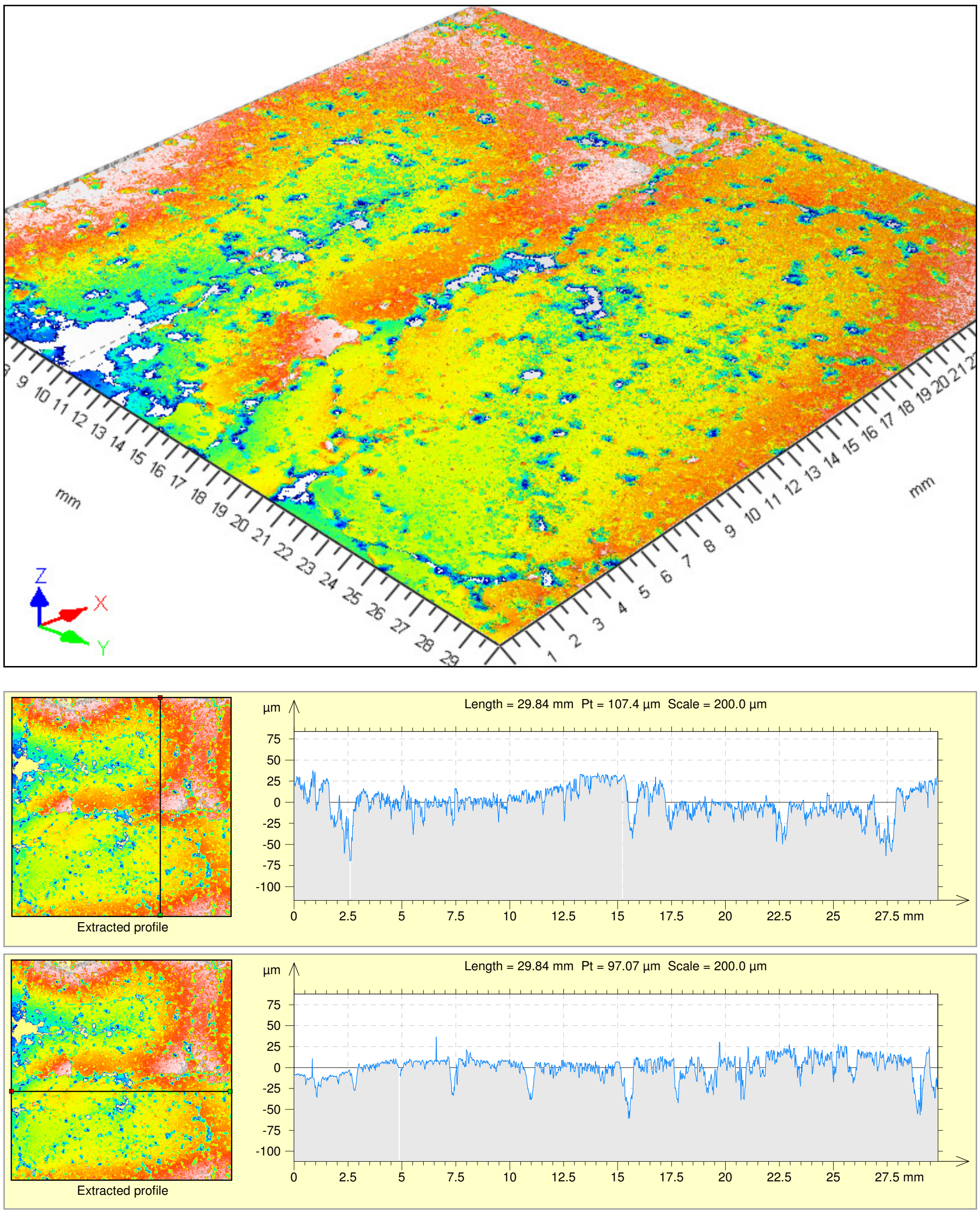
APPENDIX D10

\section{MIDDLE BAKKEN RESIN-COATED SAND BOTTOM SLAB}




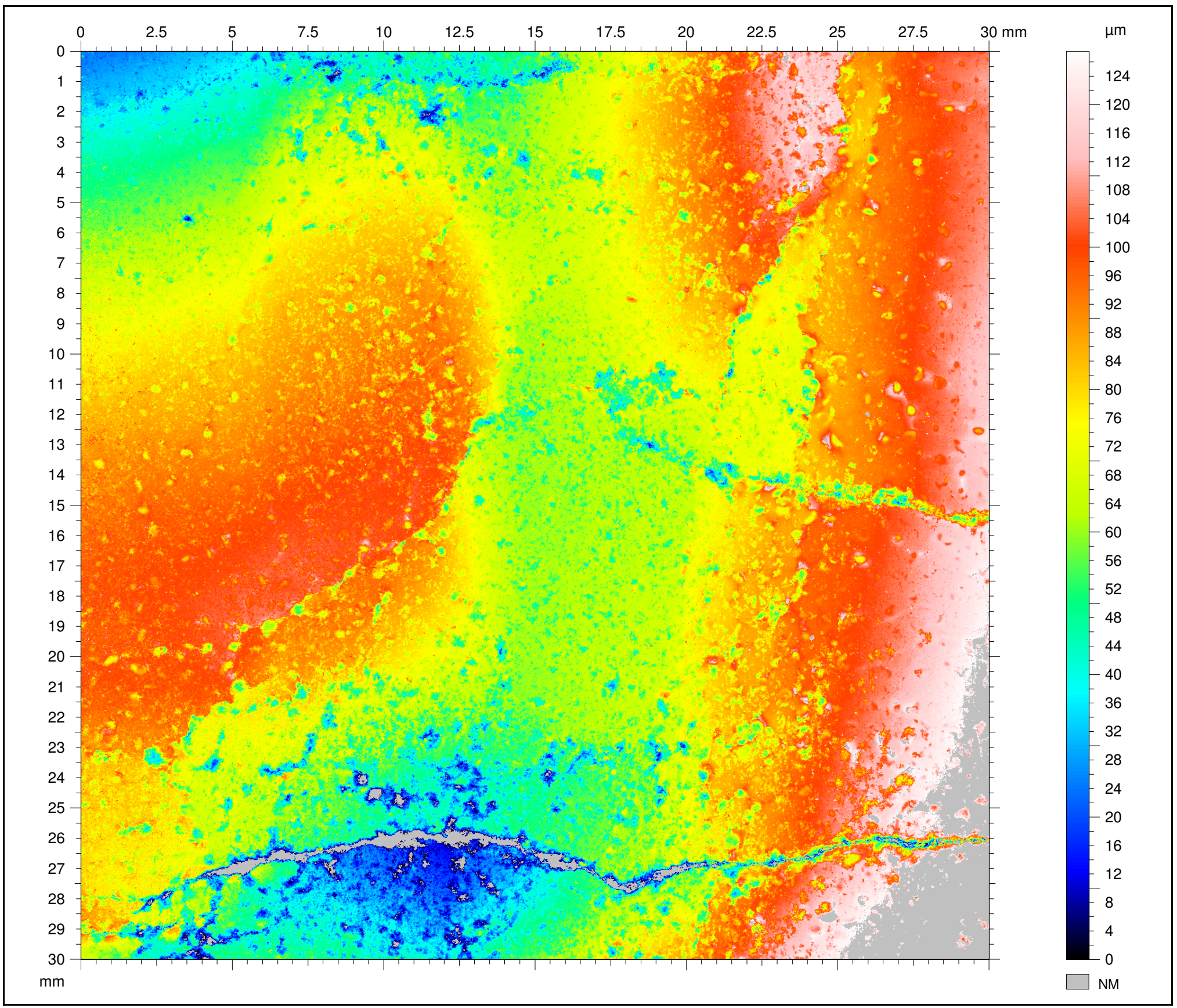

\section{Identity card}

Name: MiddleBakken_20-40_ResinCoatedSand_Bottom_Height Measured by: Chris Beddoe

Created on: $\quad$ 7/3/2012 2:22:51 AM

Measure duration: 2 h $22 \mathrm{~m} 51.328125 \mathrm{~s}$

\section{Axis: $X$}

$\begin{array}{ll}\text { Length: } & 30.01 \mathrm{~mm} \\ \text { Size: } & 1668 \text { points } \\ \text { Spacing: } & 0.0180 \mathrm{~mm}\end{array}$

Offset: $\quad 0.000 \mathrm{~mm}$

\section{Axis: $Y$}

Length: $\quad 30.01 \mathrm{~mm}$

Size: $\quad 1668$ lines

Spacing: $0.0180 \mathrm{~mm}$

Offset: $\quad-30.0 \mathrm{~mm}$

\section{Abbot- Firestone Curve}

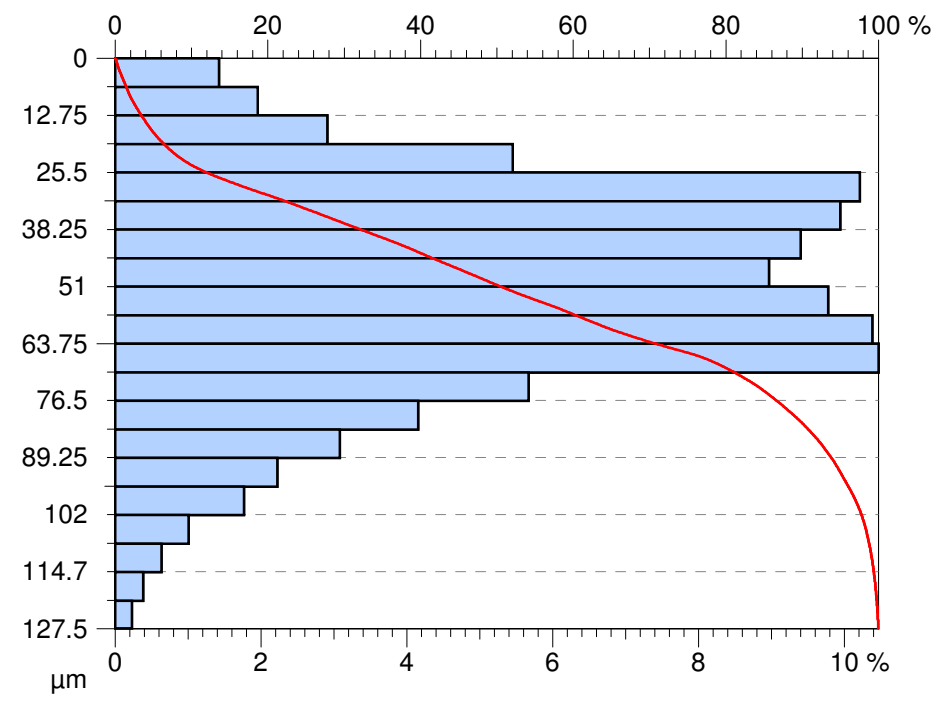



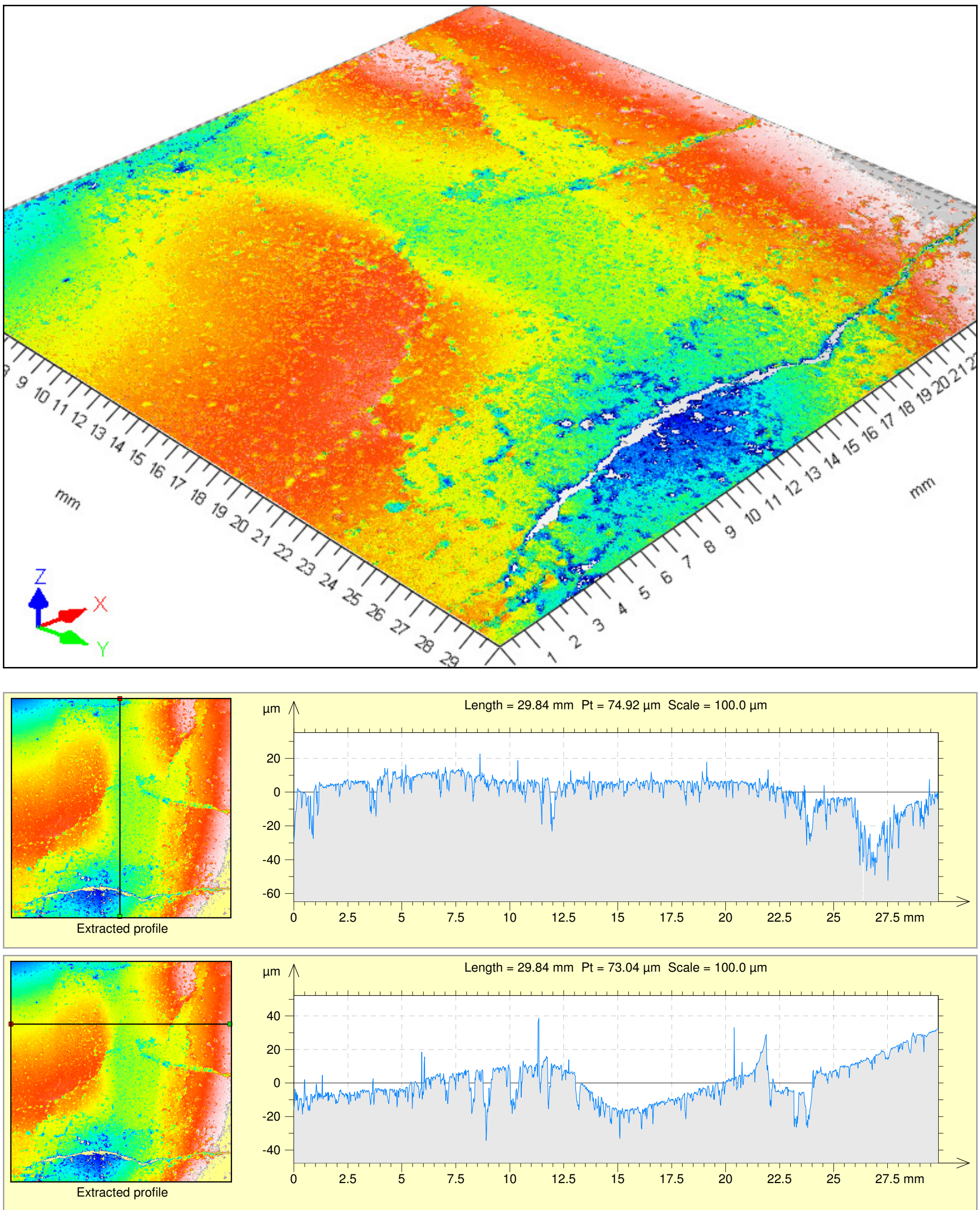
APPENDIX D11

\section{MIDDLE BAKKEN CERAMIC TOP SLAB}




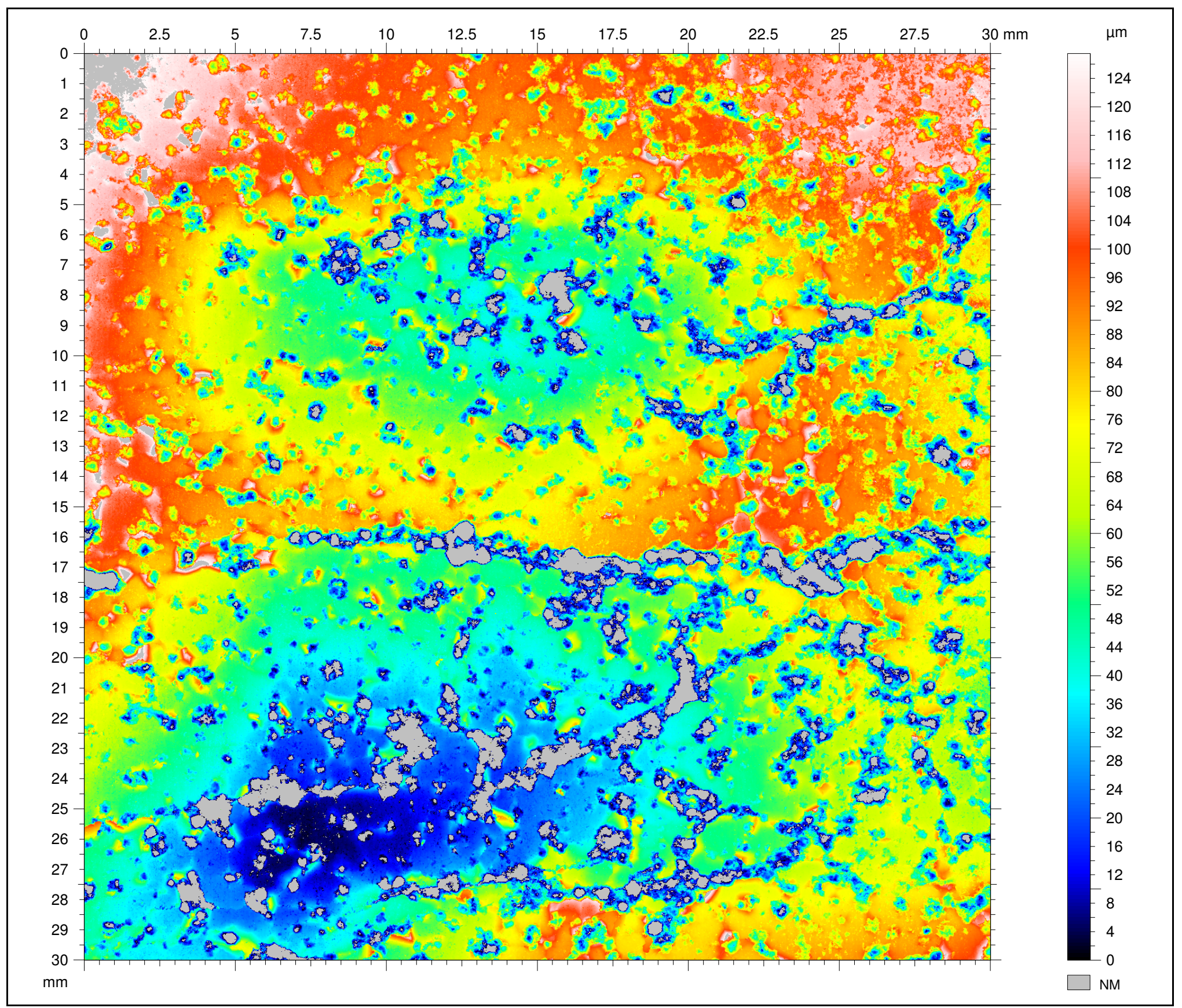

\section{Identity card}

Name: MiddleBakken_20-40_Ceramic_Top_Height

Measured by: Chris Beddoe

Created on: $\quad$ 7/3/2012 2:23:35 AM

Measure duration: 2 h $23 \mathrm{~m} 35.250000 \mathrm{~s}$

\section{Axis: $X$}

$\begin{array}{ll}\text { Length: } & 30.01 \mathrm{~mm} \\ \text { Size: } & 1668 \text { points }\end{array}$

Spacing: $0.0180 \mathrm{~mm}$

Offset: $\quad 0.000 \mathrm{~mm}$

\section{Axis: $Y$}

Length: $\quad 30.01 \mathrm{~mm}$

Size: $\quad 1668$ lines

Spacing: $0.0180 \mathrm{~mm}$

Offset: $\quad-30.0 \mathrm{~mm}$

\section{Abbot- Firestone Curve}

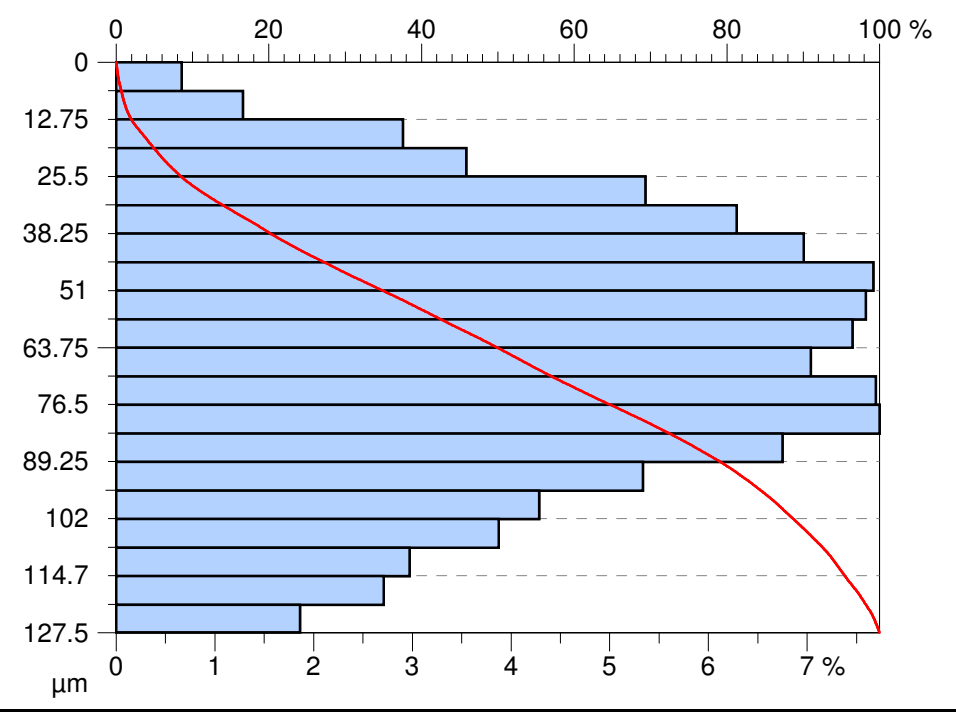



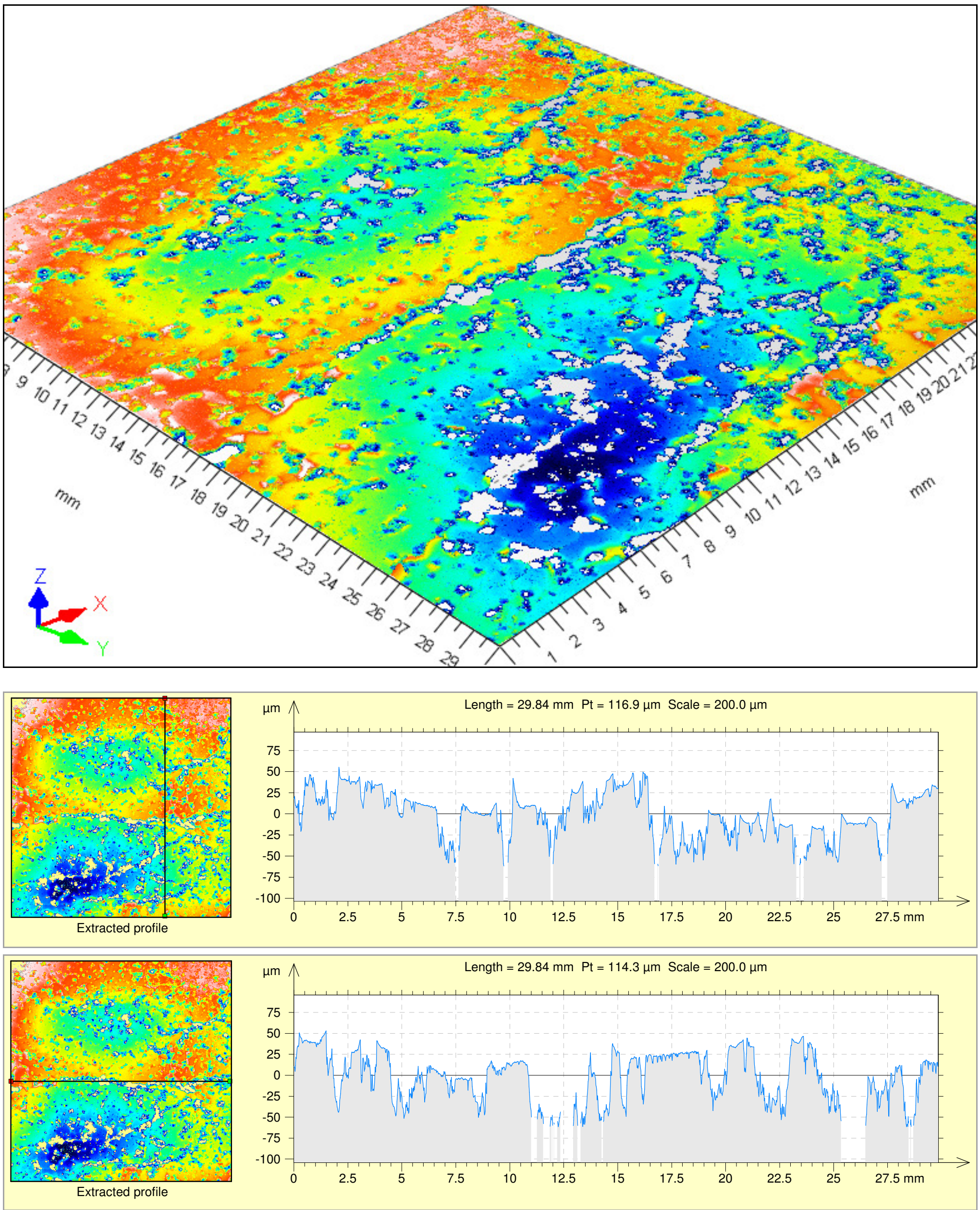
APPENDIX D12

MIDDLE BAKKEN CERAMIC BOTTOM SLAB 


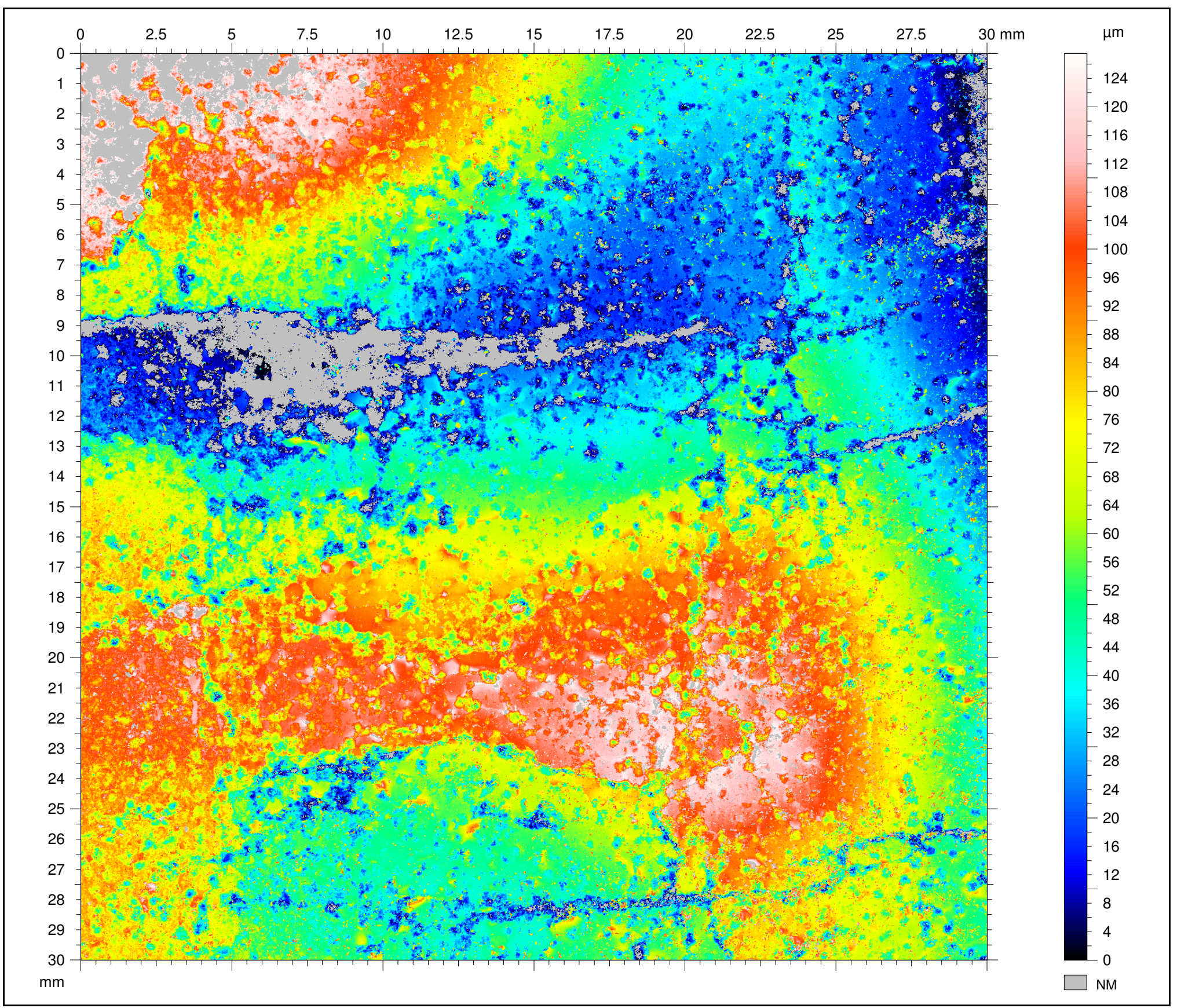

\section{Identity card}

Name: MiddleBakken_20-40_Ceramic_Bottom_Height

Measured by: Chris Beddoe

Created on: $\quad$ 7/2/2012 2:23:06 AM

Measure duration: 2 h 23 m 6.046875 s

\section{Axis: $X$}

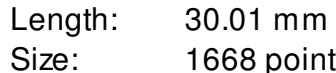

Spacing: $0.0180 \mathrm{~mm}$

Offset: $\quad 0.000 \mathrm{~mm}$

\section{Axis: $Y$}

Length: $\quad 30.01 \mathrm{~mm}$

Size: $\quad 1668$ lines

Spacing: $0.0180 \mathrm{~mm}$

Offset: $\quad-30.0 \mathrm{~mm}$

NMP ratio: $6.146 \%$ (170982 Pts)

\section{Abbot- Firestone Curve}

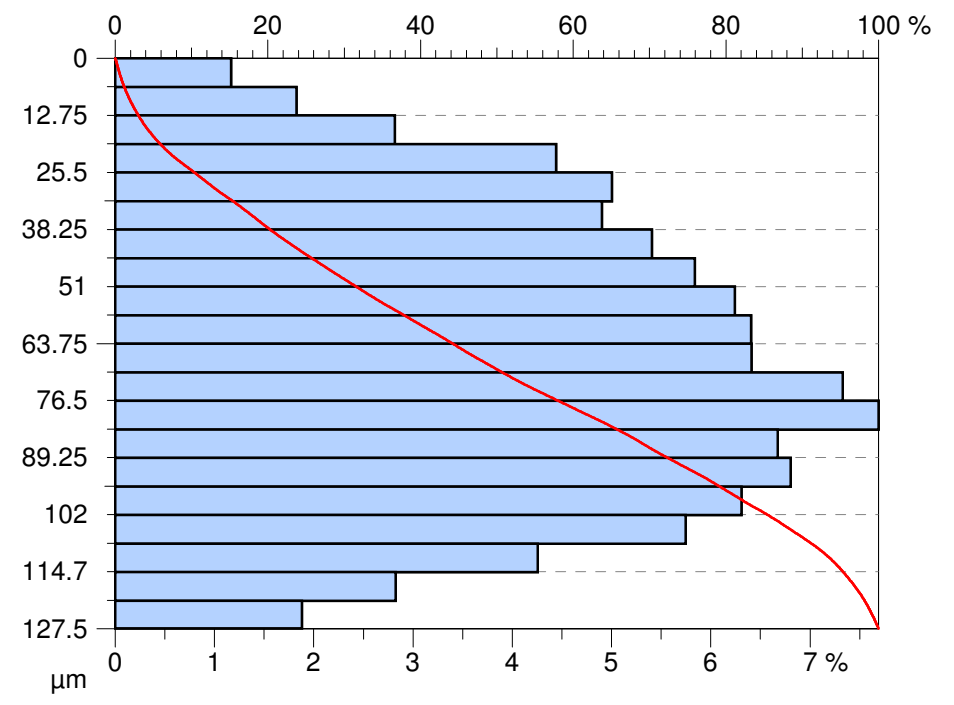



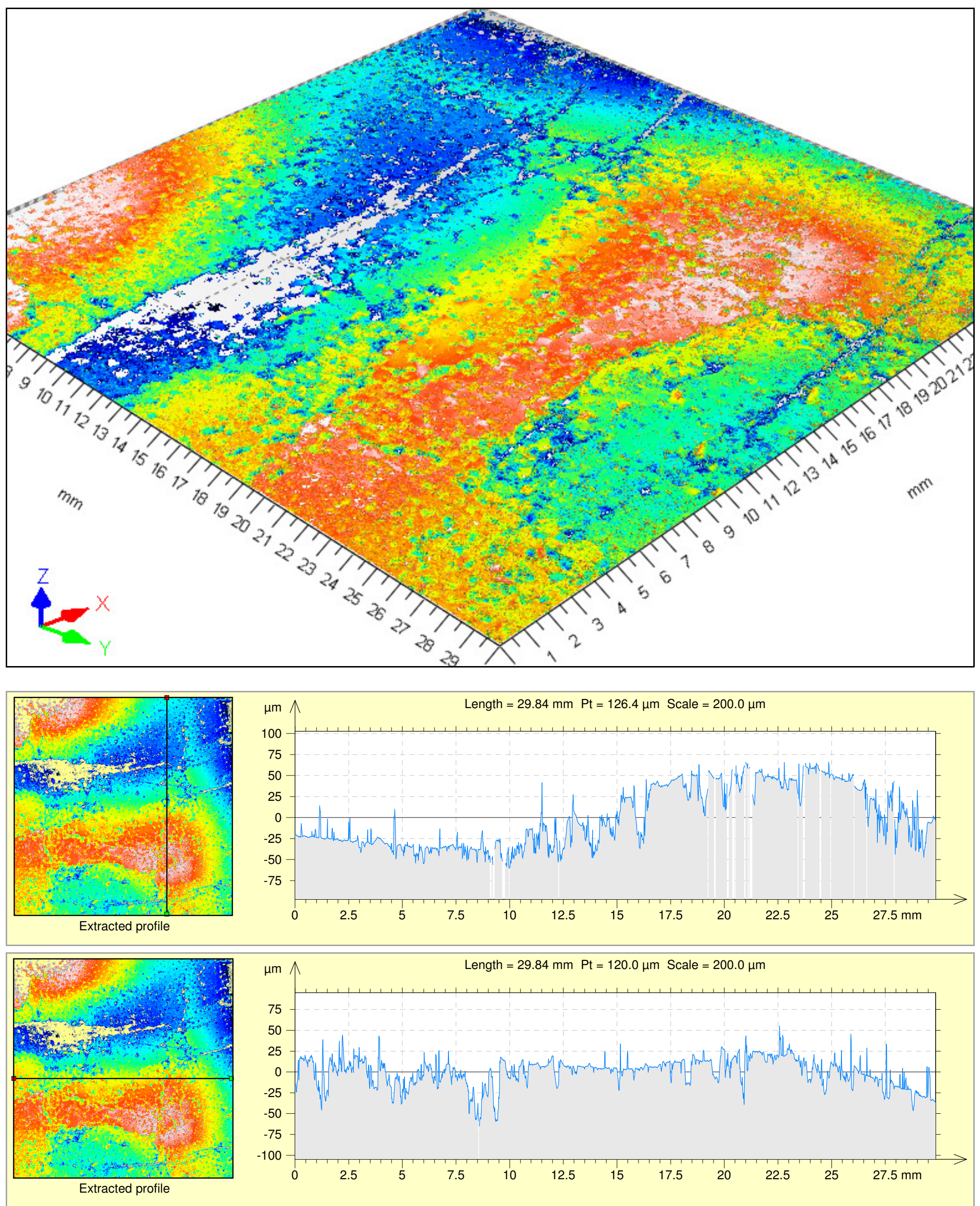


\section{APPENDIX D13}

\section{THREE FORKS OTTAWA SAND TOP SLAB}




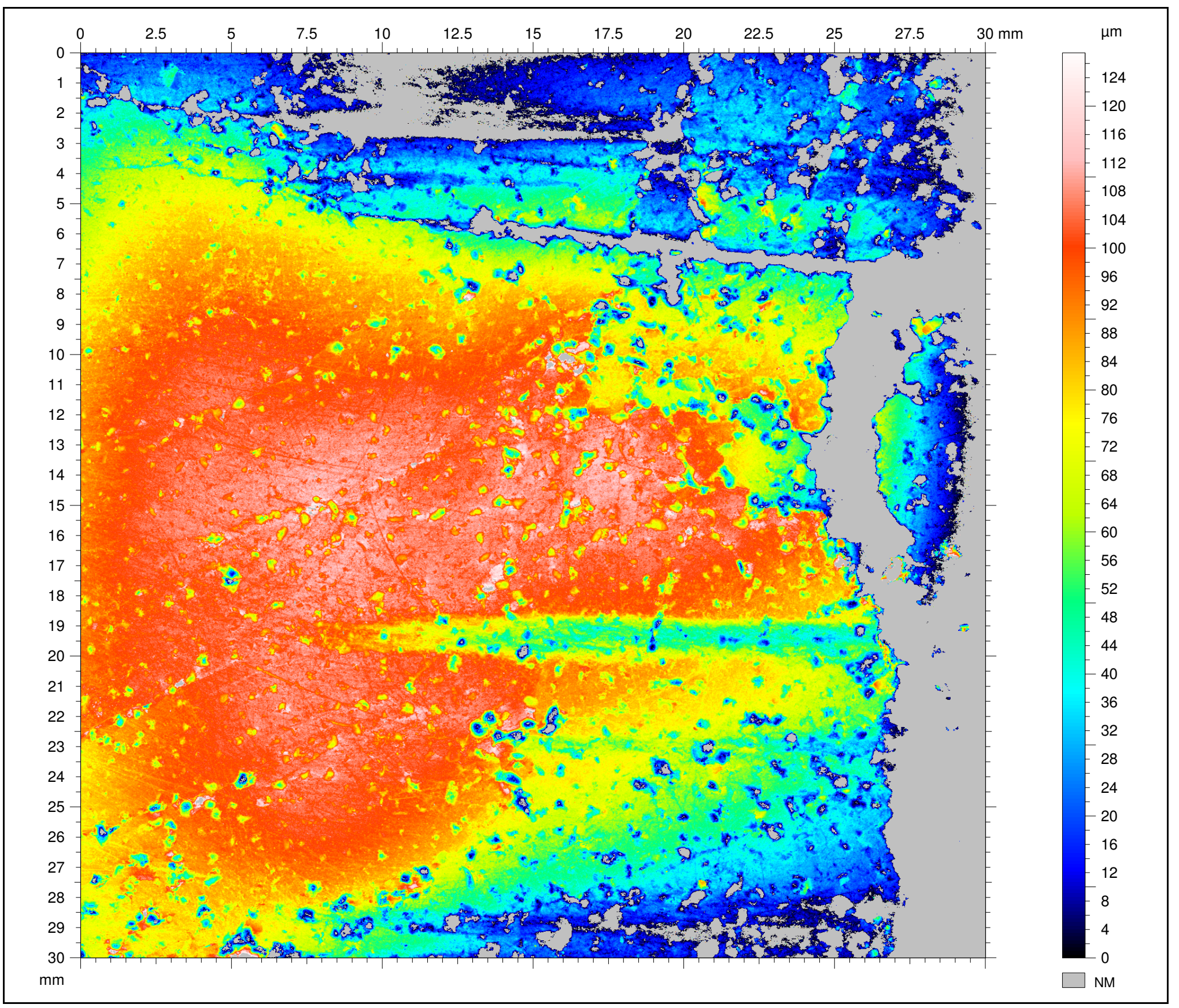

\section{Identity card}

Name: ThreeForks_20-40_Ottaw aSand_Top_Height

Measured by: Chris Beddoe

Created on: $\quad$ 7/4/2012 2:23:17 AM

Measure duration: 2 h $23 \mathrm{~m} 17.984375 \mathrm{~s}$

\section{Axis: $X$}

$\begin{array}{ll}\text { Length: } & 30.01 \mathrm{~mm} \\ \text { Size: } & 1668 \text { points }\end{array}$

Spacing: $\quad 0.0180 \mathrm{~mm}$

Offset: $\quad 0.000 \mathrm{~mm}$

Axis: $Y$

Length: $\quad 30.01 \mathrm{~mm}$

Size: $\quad 1668$ lines

Spacing: $0.0180 \mathrm{~mm}$

Offset: $\quad-30.0 \mathrm{~mm}$

\section{Abbot- Firestone Curve}

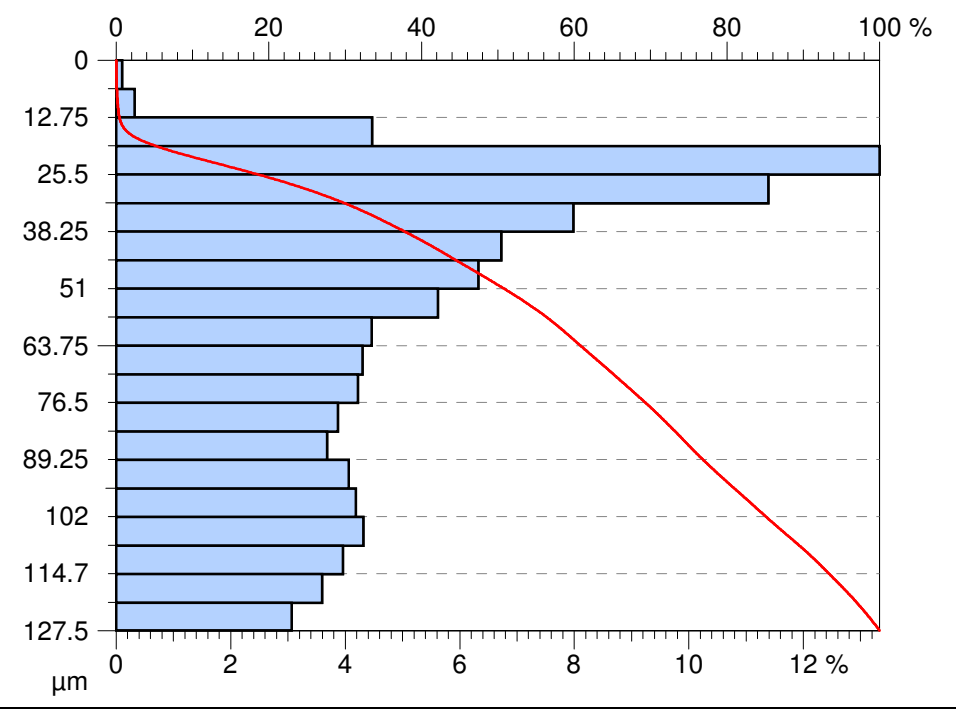



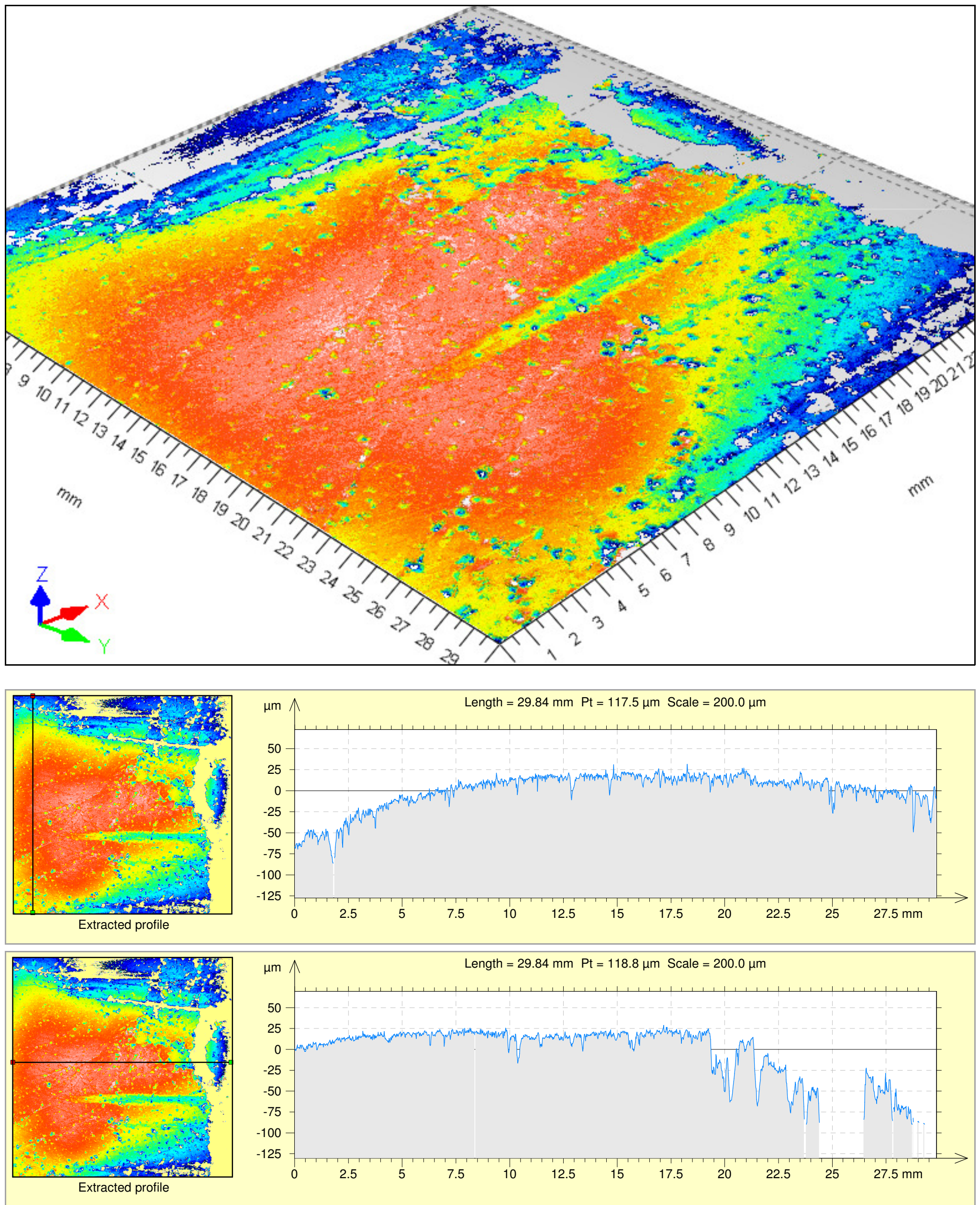
APPENDIX D14

THREE FORKS OTTAWA SAND BOTTOM SLAB 


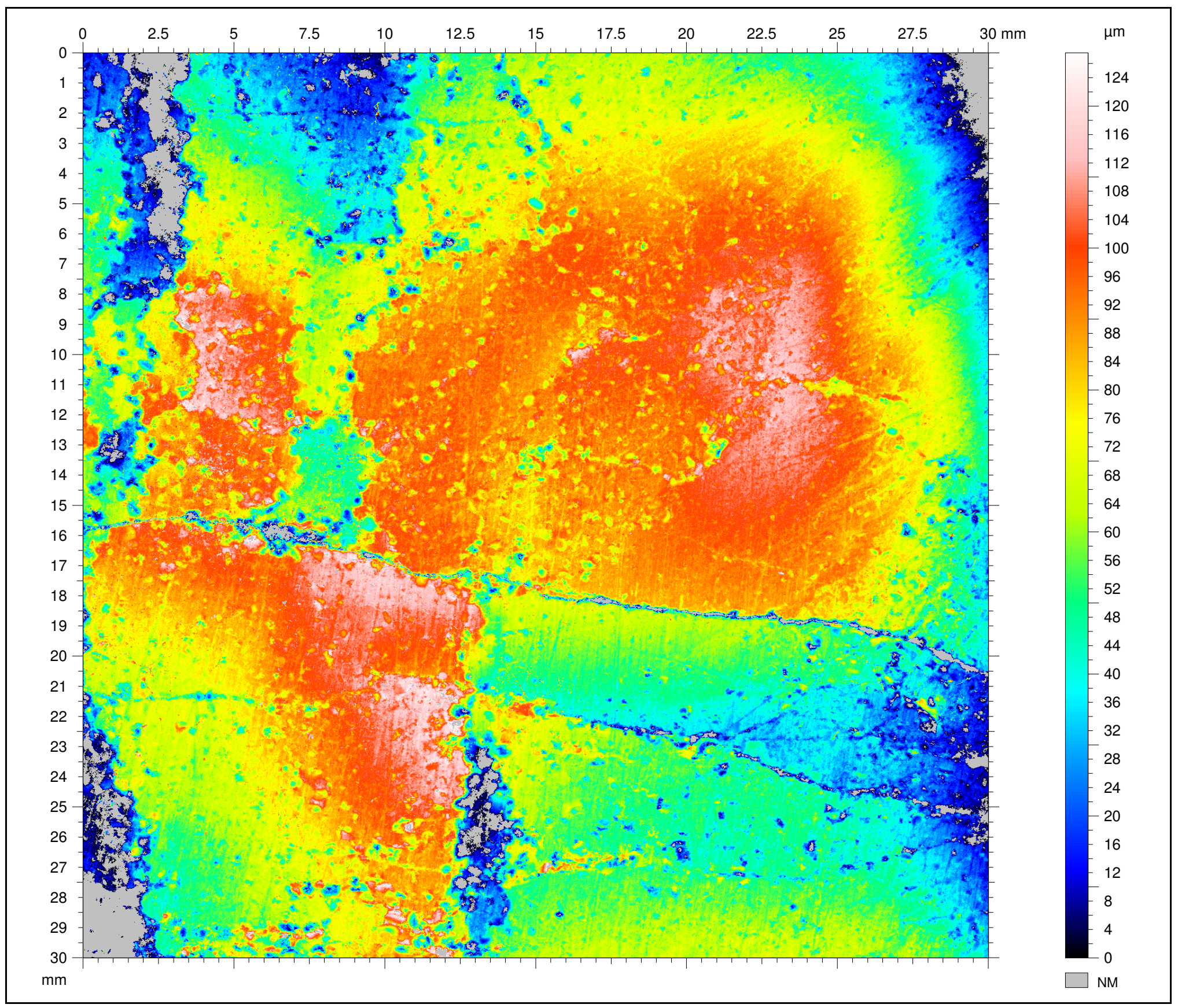

\section{Identity card}

Name: ThreeForks_20-40_Ottaw aSand_Bottom_Height

Measured by: Chris Beddoe

Created on: $\quad$ 7/4/2012 2:23:09 AM

Measure duration: 2 h $23 \mathrm{~m} 9.593750 \mathrm{~s}$

\section{Axis: $X$}

$\begin{array}{ll}\text { Length: } & 30.01 \mathrm{~mm} \\ \text { Size: } & 1668 \text { points } \\ \text { Spacing: } & 0.0180 \mathrm{~mm}\end{array}$

Offset: $\quad 0.000 \mathrm{~mm}$

\section{Axis: Y}

Length: $\quad 30.01 \mathrm{~mm}$

Size: $\quad 1668$ lines

Spacing: $0.0180 \mathrm{~mm}$

Offset: $\quad-30.0 \mathrm{~mm}$

\section{Abbot- Firestone Curve}

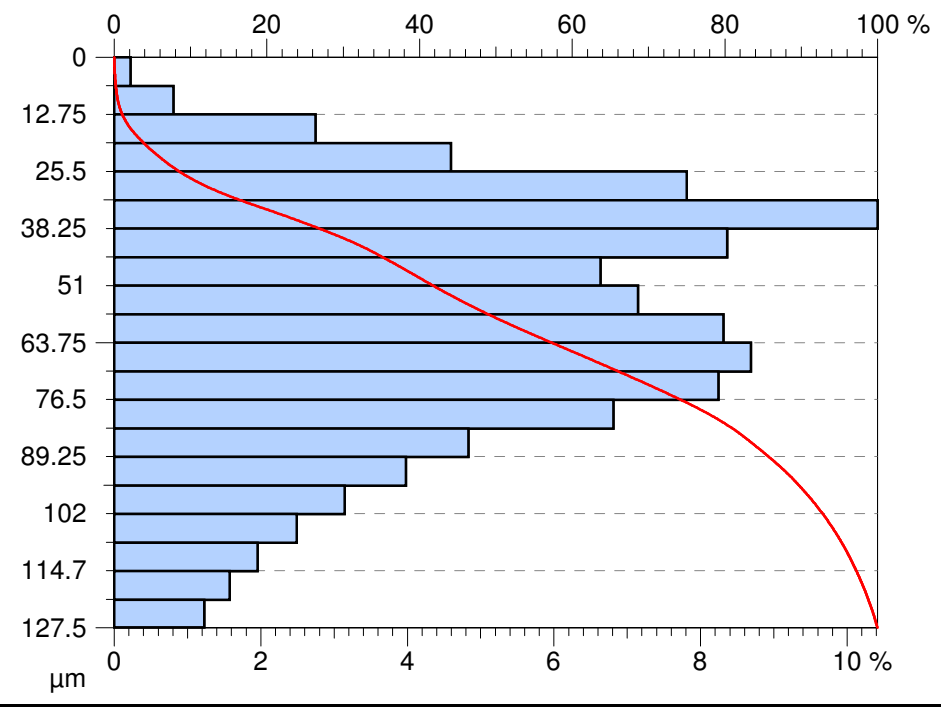



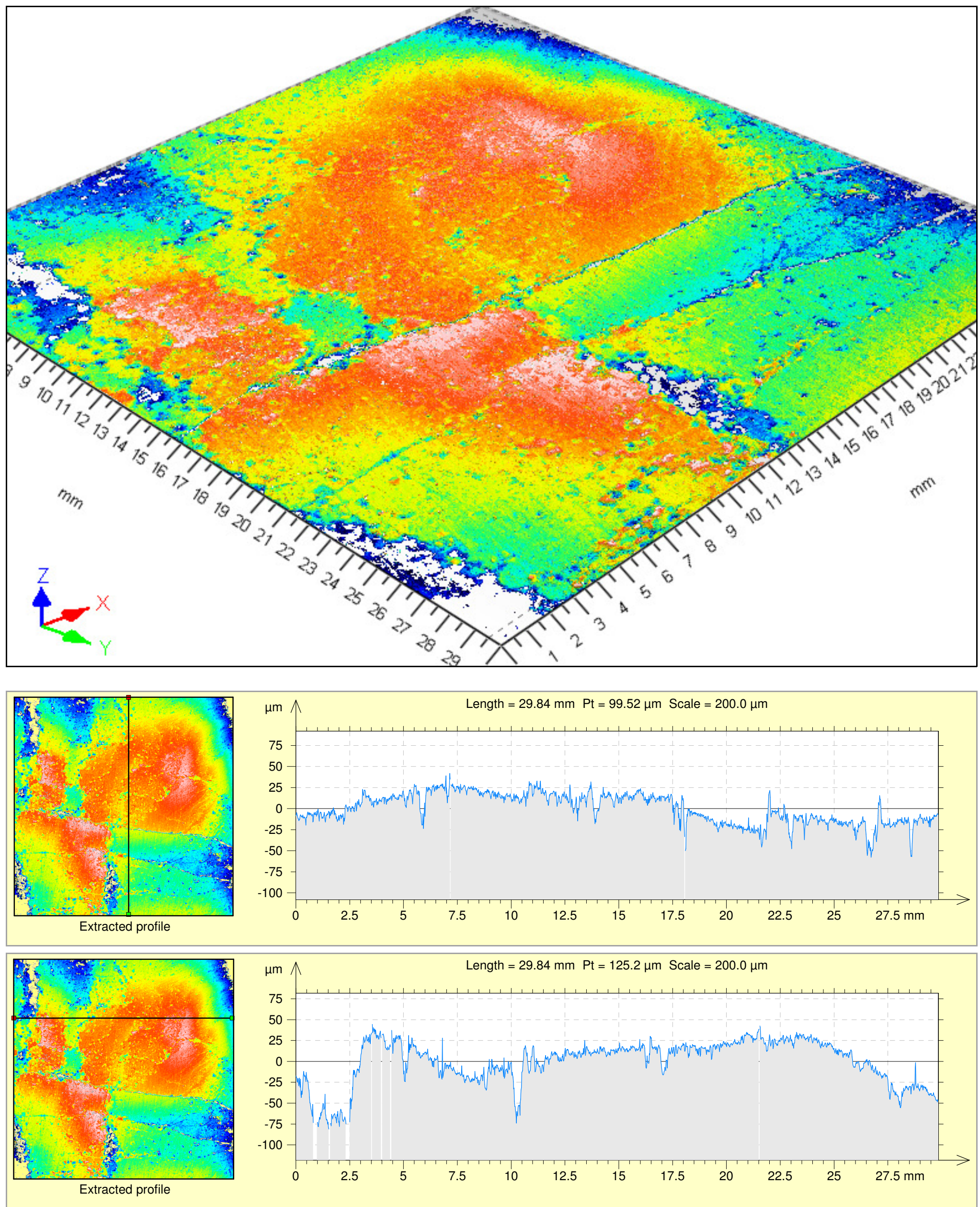


\section{APPENDIX D15}

\section{THREE FORKS RESIN-COATED SAND TOP SLAB}




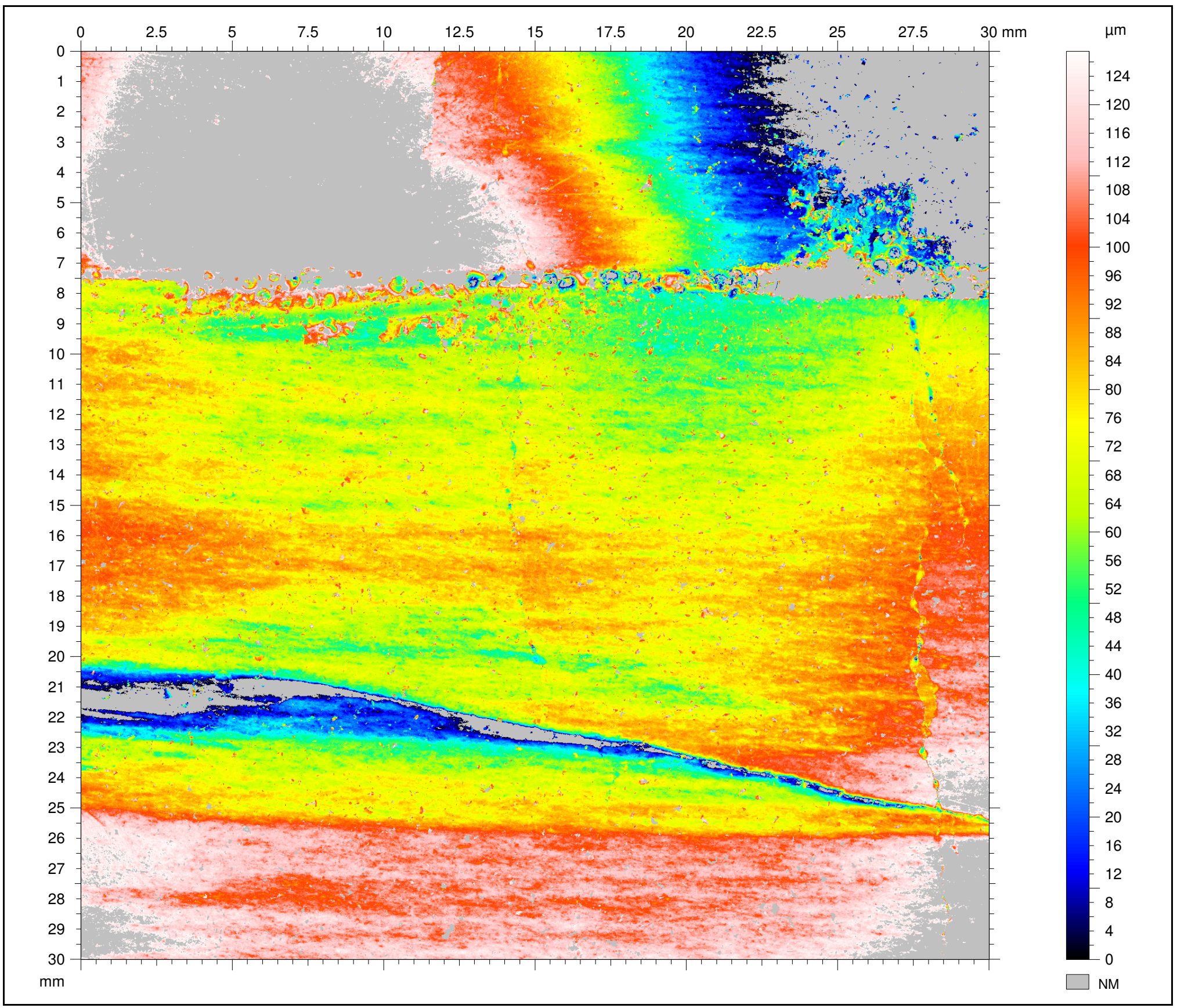

\section{Identity card}

Name: ThreeForks_20-40_ResinCoatedSand_Top_Height

Measured by: Chris Beddoe

Created on: $\quad$ 7/5/2012 2:23:21 AM

Measure duration: 2 h $23 \mathrm{~m} 21.406250 \mathrm{~s}$

\section{Axis: $X$}

$\begin{array}{ll}\text { Length: } & 30.01 \mathrm{~mm} \\ \text { Size: } & 1668 \text { points } \\ \text { Spacing: } & 0.0180 \mathrm{~mm}\end{array}$

Offset: $\quad 0.000 \mathrm{~mm}$

\section{Axis: Y}

Length: $\quad 30.01 \mathrm{~mm}$

Size: $\quad 1668$ lines

Spacing: $0.0180 \mathrm{~mm}$

Offset: $\quad-30.0 \mathrm{~mm}$

\section{Abbot- Firestone Curve}

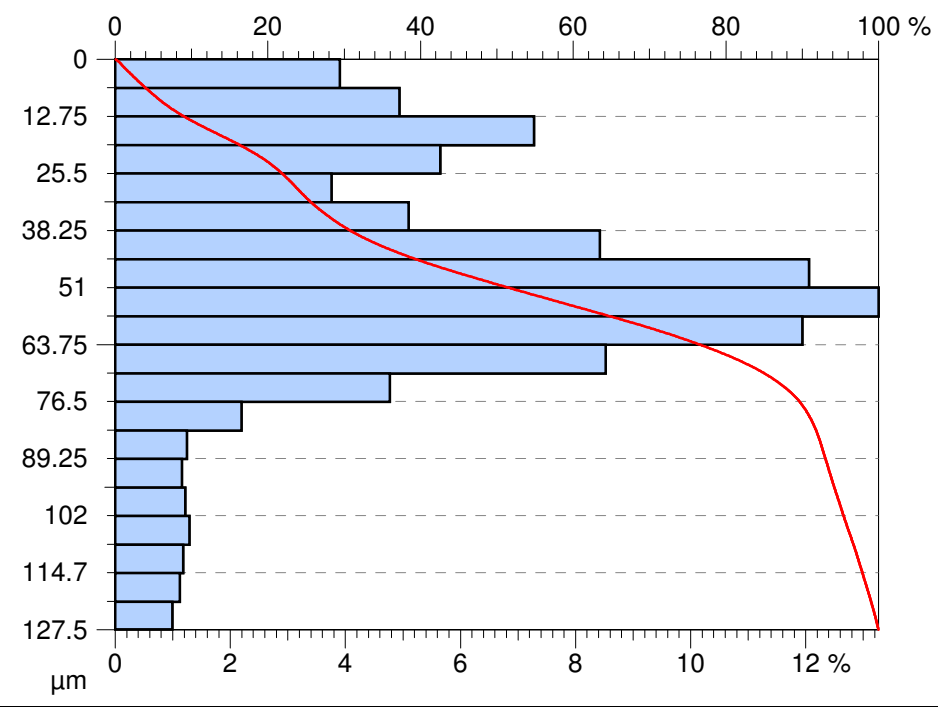



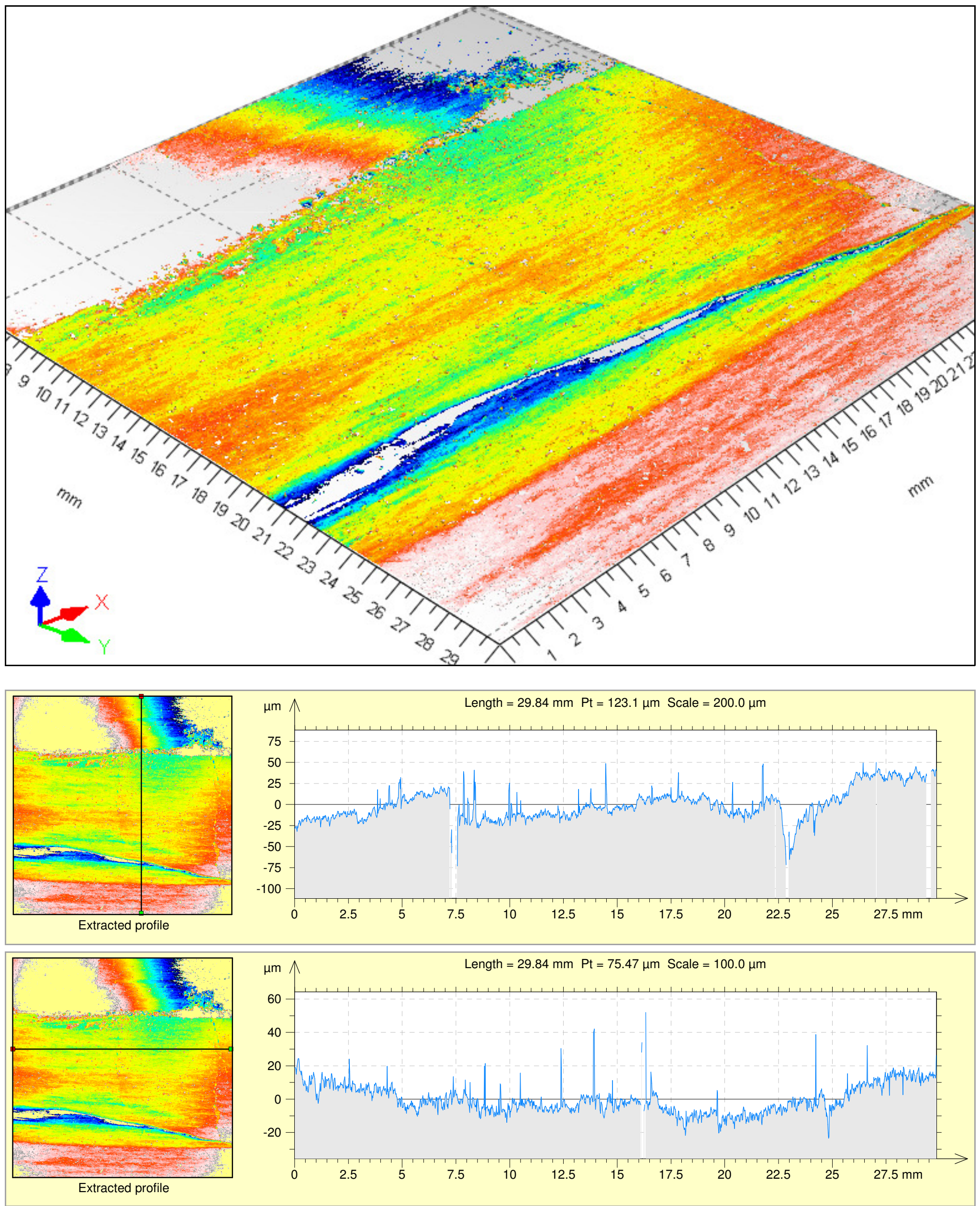
APPENDIX D16

\section{THREE FORKS RESIN-COATED SAND BOTTOM SLAB}




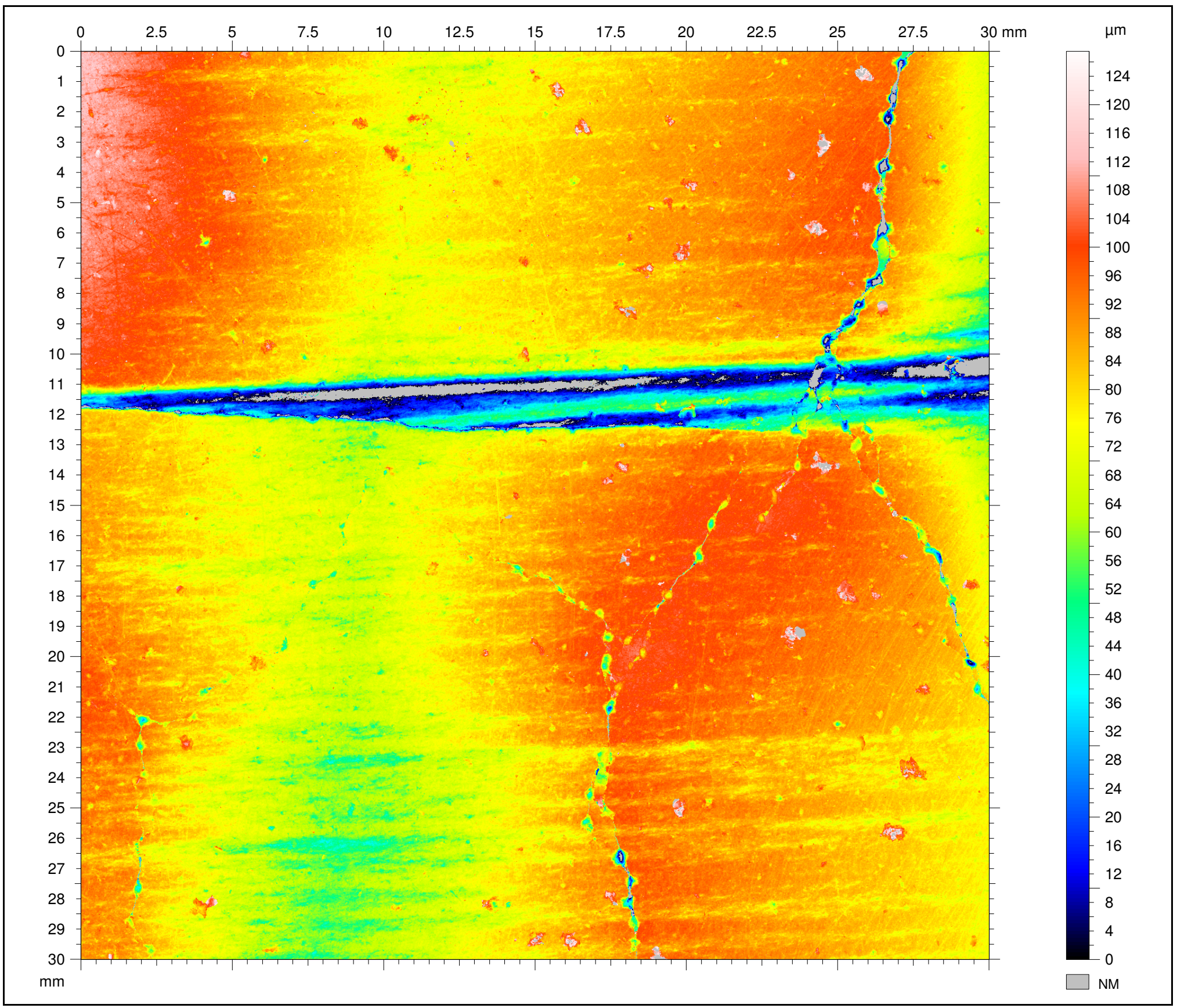

\section{Identity card}

Name: ThreeForks_20-40_ResinCoatedSand_Bottom_Height

Measured by: Chris Beddoe

Created on: $\quad 7 / 4 / 20122: 23: 49$ AM

Measure duration: 2 h 23 m 49.046875 s

\section{Axis: $\mathrm{X}$}

$\begin{array}{ll}\text { Length: } & 30.01 \mathrm{~mm} \\ \text { Size: } & 1668 \text { points } \\ \text { Spacing: } & 0.0180 \mathrm{~mm} \\ \text { Offset: } & 0.000 \mathrm{~mm}\end{array}$

Axis: $Y$

Length: $\quad 30.01 \mathrm{~mm}$

Size: $\quad 1668$ lines

Spacing: $\quad 0.0180 \mathrm{~mm}$

Offset: $\quad-30.0 \mathrm{~mm}$

\section{Abbot- Firestone Curve}

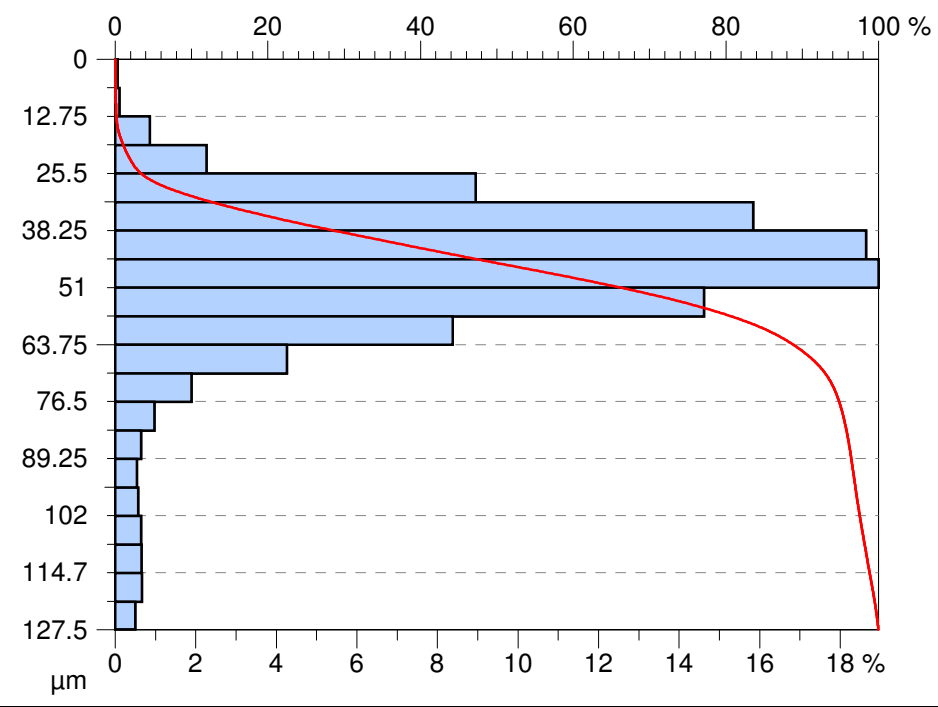



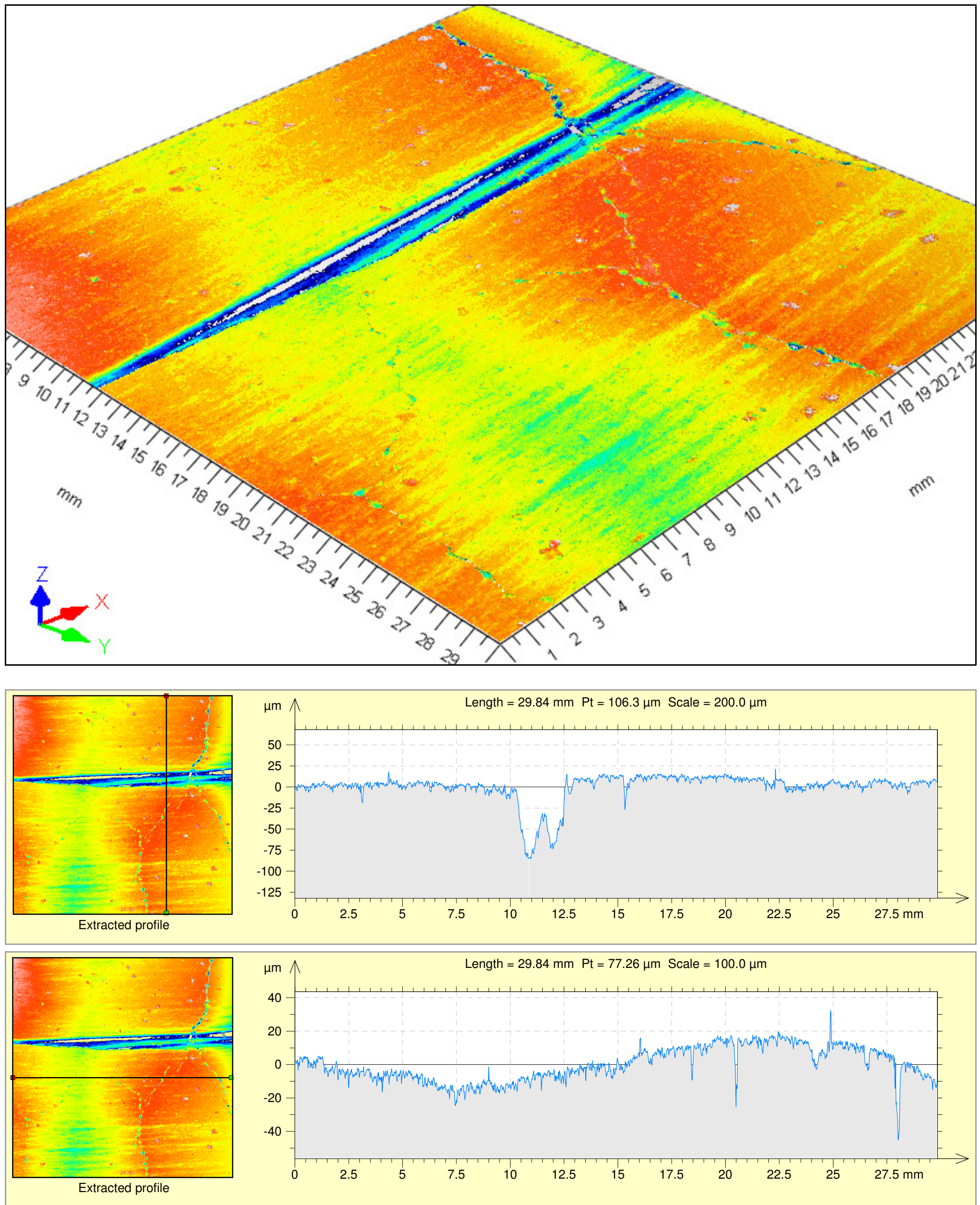
APPENDIX D17

\section{THREE FORKS CERAMIC TOP SLAB}




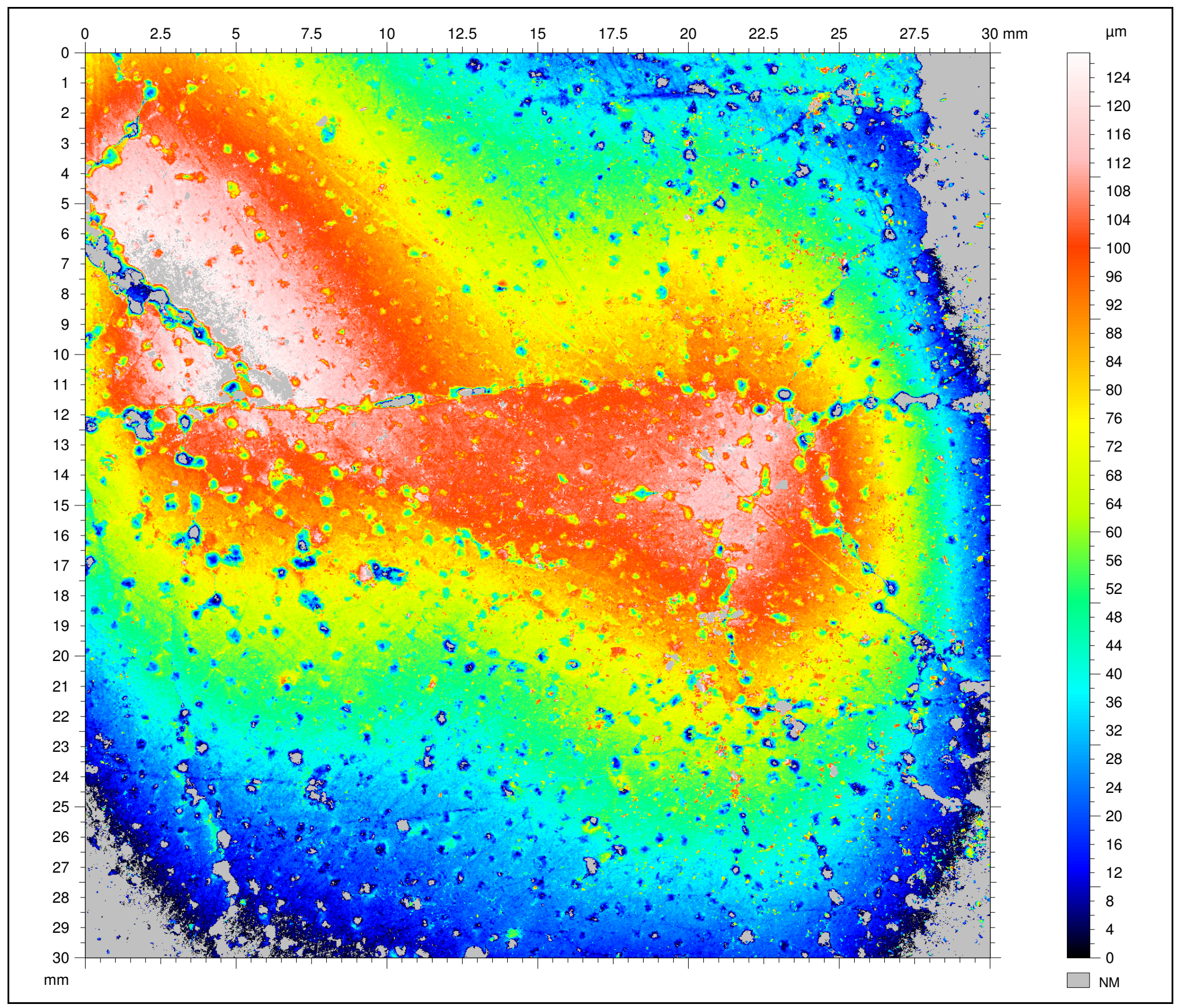

\section{Identity card}

Name: ThreeForks_20-40_Ceramic_Top_Height

Measured by: Chris Beddoe

Created on: $\quad$ 7/5/2012 2:23:12 AM

Measure duration: 2 h $23 \mathrm{~m} 12.171875 \mathrm{~s}$

\section{Axis: $X$}

$\begin{array}{ll}\text { Length: } & 30.01 \mathrm{~mm} \\ \text { Size: } & 1668 \text { points }\end{array}$

Spacing: $\quad 0.0180 \mathrm{~mm}$

Offset: $\quad 0.000 \mathrm{~mm}$

Axis: $Y$

Length: $\quad 30.01 \mathrm{~mm}$

Size: $\quad 1668$ lines

Spacing: $0.0180 \mathrm{~mm}$

Offset: $\quad-30.0 \mathrm{~mm}$

\section{Abbot- Firestone Curve}

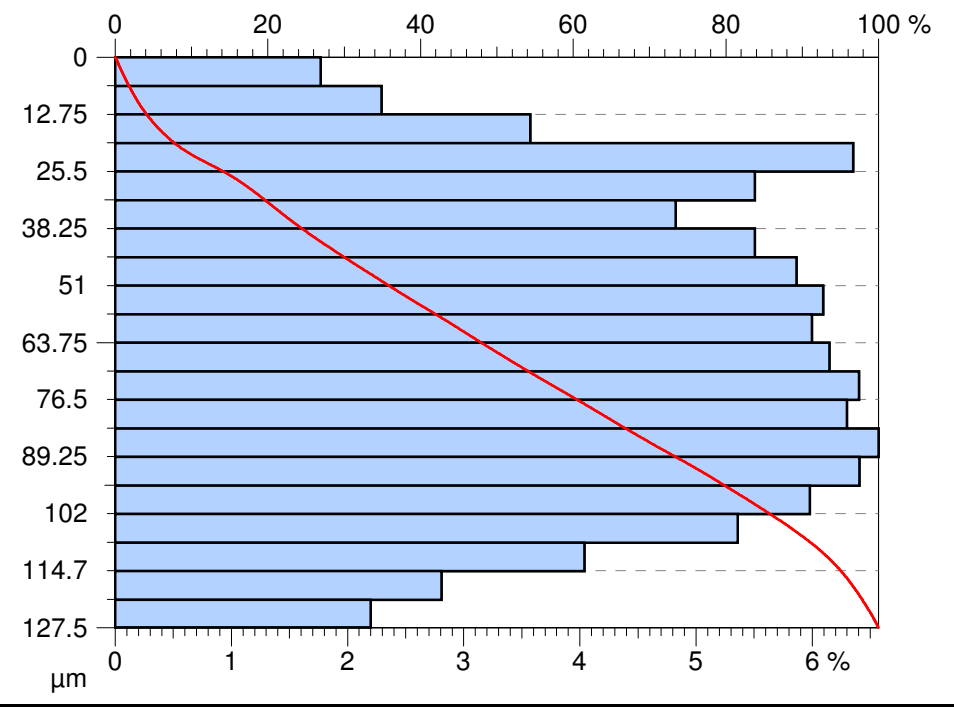



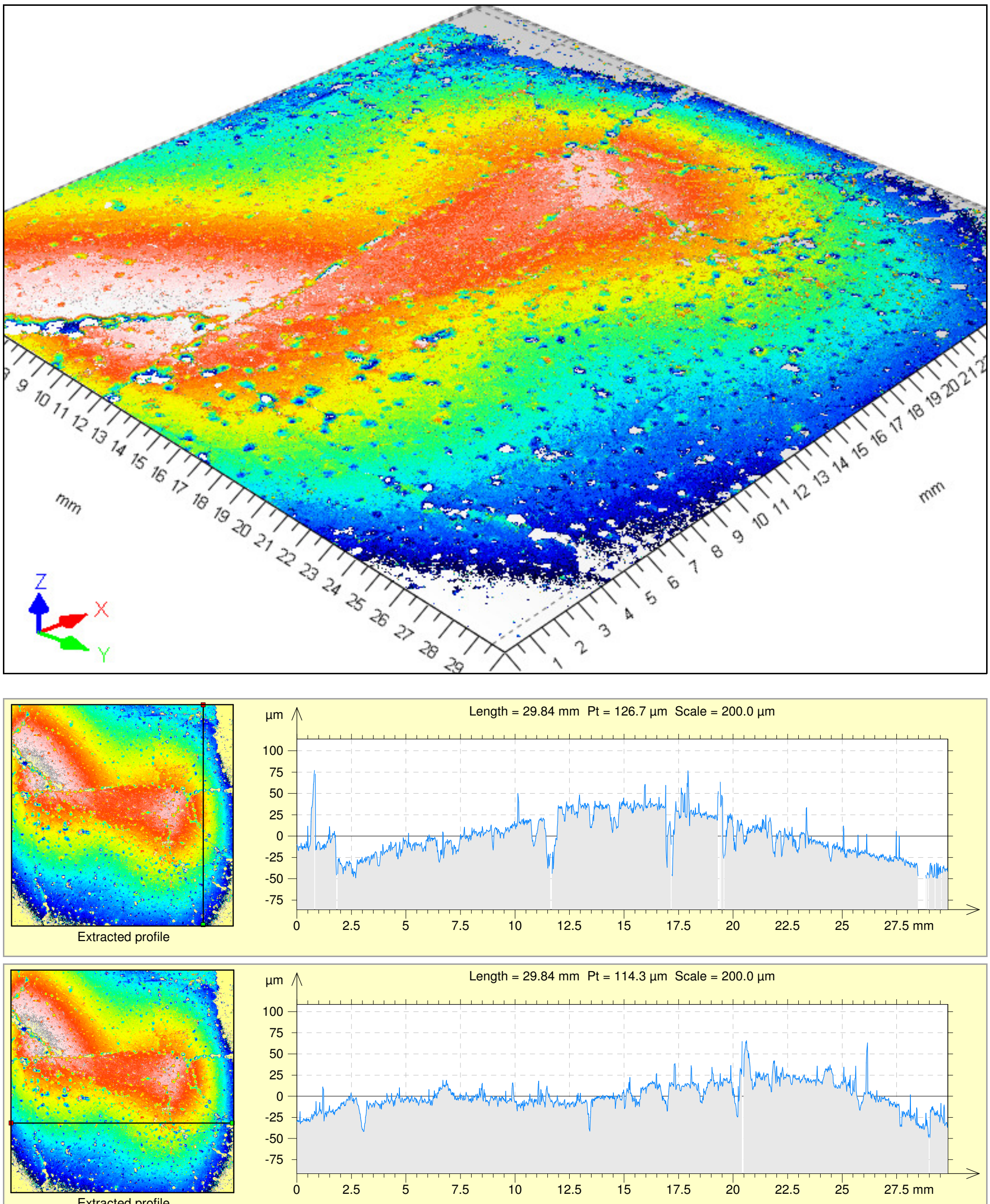
APPENDIX D18

\section{THREE FORKS CERAMIC BOTTOM SLAB}




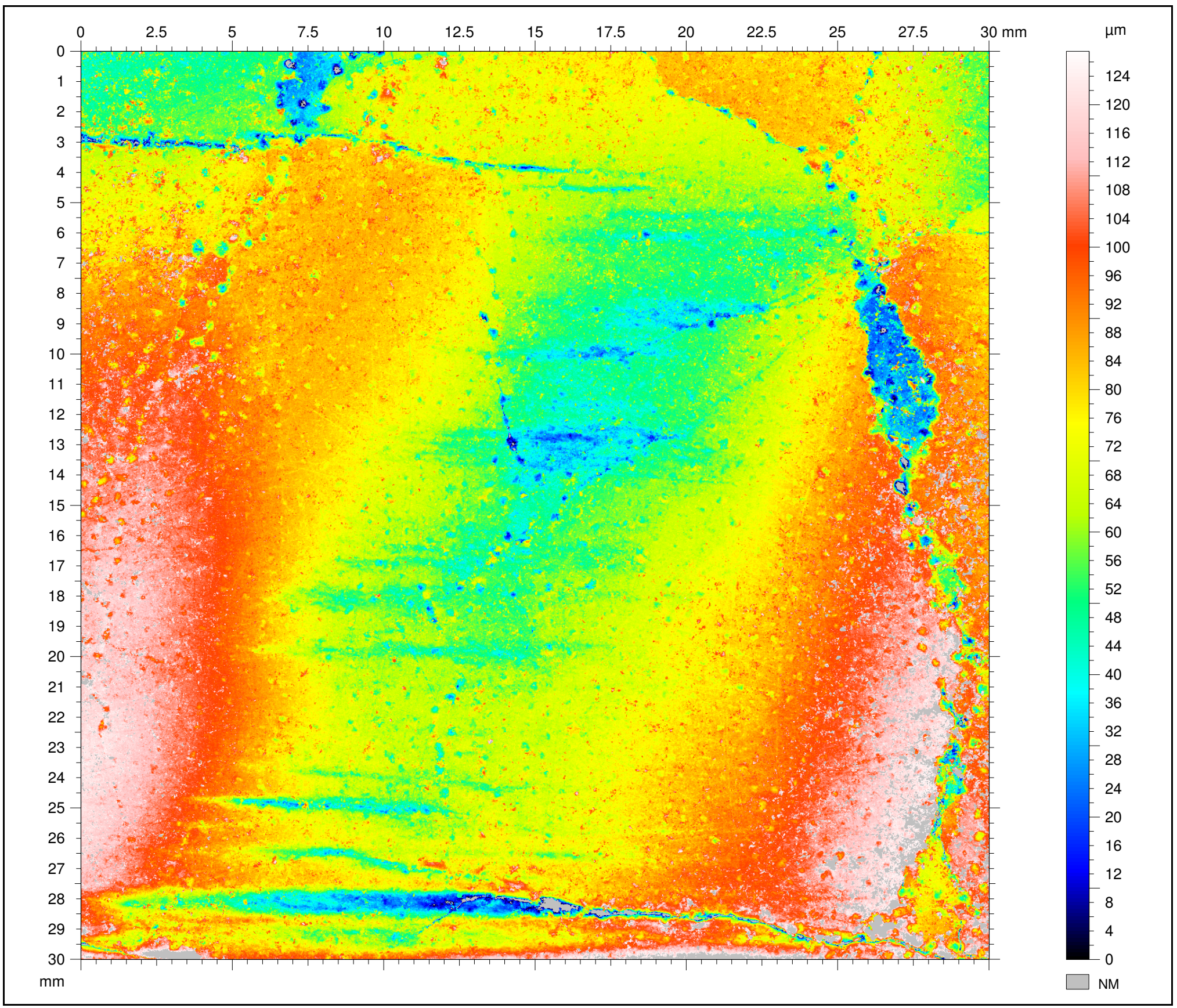

\section{Identity card}

Name: ThreeForks_20-40_Ceramic_Bottom_Height

Measured by: Chris Beddoe

Created on: $\quad$ 7/5/2012 2:23:34 AM

Measure duration: 2 h 23 m 34.453125 s

\section{Axis: $X$}

$\begin{array}{ll}\text { Length: } & 30.01 \mathrm{~mm} \\ \text { Size: } & 1668 \text { points } \\ \text { Spacing: } & 0.0180 \mathrm{~mm}\end{array}$

Offset: $\quad 0.000 \mathrm{~mm}$

\section{Axis: $Y$}

Length: $\quad 30.01 \mathrm{~mm}$

Size: $\quad 1668$ lines

Spacing: $0.0180 \mathrm{~mm}$

Offset: $\quad-30.0 \mathrm{~mm}$

\section{Abbot- Firestone Curve}

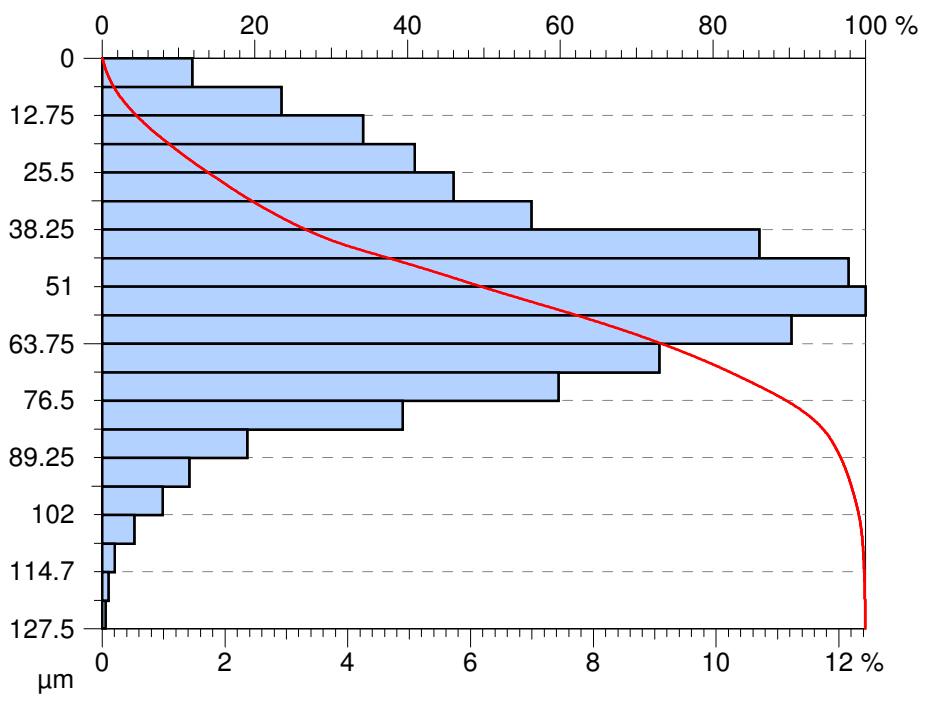



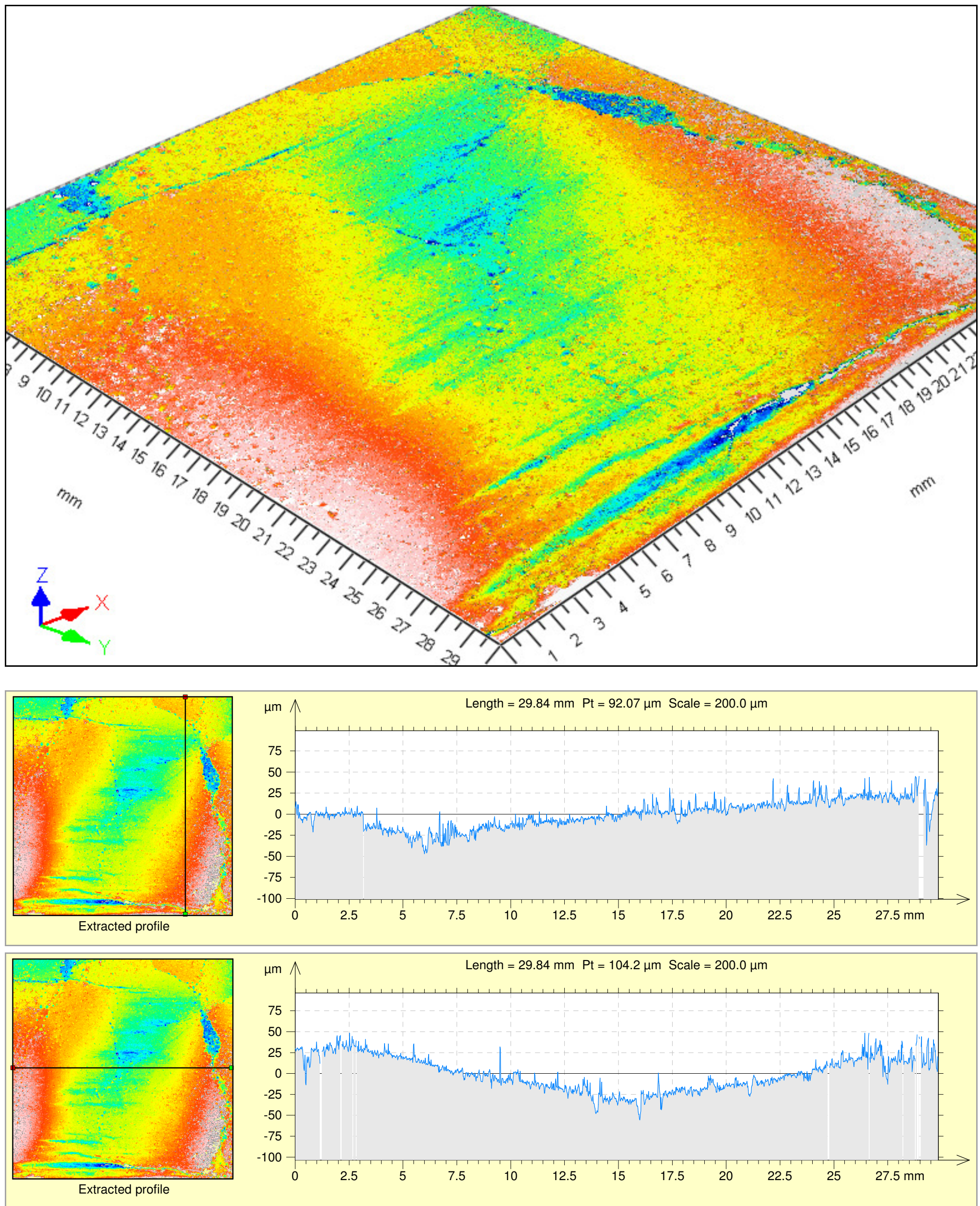